Chapman University

Chapman University Digital Commons

Summer 8-2021

\title{
Fighting An Uphill Battle: Black Undergraduate Women Navigating Higher Education While Acknowledging and Challenging Media Portrayals of Black Women
}

Kandace Branch

Chapman University, branc111@mail.chapman.edu

Follow this and additional works at: https://digitalcommons.chapman.edu/education_dissertations

Part of the Higher Education Commons

\section{Recommended Citation}

Branch, K. N. (2021). Fighting an uphill battle: Black undergraduate women navigating higher education while acknowledging and challenging media portrayals of Black women [Doctoral dissertation, Chapman University]. Chapman University Digital Commons. https://doi.org/10.36837/chapman.000315

This Dissertation is brought to you for free and open access by the Dissertations and Theses at Chapman University Digital Commons. It has been accepted for inclusion in Education (PhD) Dissertations by an authorized administrator of Chapman University Digital Commons. For more information, please contact laughtin@chapman.edu. 
Fighting an Uphill Battle: Black Undergraduate Women Navigating Higher Education While Acknowledging and Challenging Media Portrayals of Black Women

A Dissertation by

Kandace Nicole Branch

\author{
Chapman University \\ Orange, CA
}

Donna Ford Attallah College of Educational Studies

Submitted in partial fulfillment of the requirements for the degree of

Doctor of Philosophy in Education with an Emphasis in Cultural and Curricular Studies

August 2021

Committee in charge:

Lilia Monzo, Ph.D., Chair

Quaylan Allen, Ph.D.

Safiya Noble, Ph.D. 
The dissertation of Kandace Nicole Branch is approved.

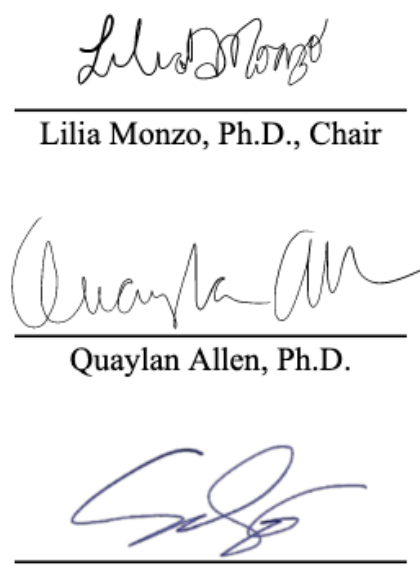

Safiya Noble, Ph.D.

June 2021 
Fighting an Uphill Battle: Black Undergraduate Women Navigating Higher Education While Acknowledging and Challenging Media Portrayals of Black Women

Copyright $@ 2021$

by Kandace Nicole Branch 


\section{DEDICATION}

I put in all this work just for you, Mary L. Lewis, also known as The Best Mother in The World! I hope you are proud of me. 


\section{ACKNOWLEDGEMENTS}

I have dreamed of this day since I made the declaration as a young child that I would have three degrees. As a first-generation student, I had no idea what that even really meant. I now know that the pursuit of this degree exemplified my resiliency, my ability to adapt and persist, and my determination to complete the things I begin. So, thank you to me.

Thank you to my dissertation committee. Dr. Lilia Monzo has been so gracious and kind from the moment I met her at my interview for the program. When I was questioning my capabilities, she always provided a positive push that ultimately led me to the finish line. Thank you Dr. Monzo for your time in talking through this research with me. Thank you to Dr. Quaylan Allen, who also was supportive in providing phenomenal feedback of my research but also a comforting face that was so encouraging. When I needed her most, Dr. Safiya Noble was able to step in and support me toward completion. Thank you all for graciously welcoming me into the academy.

A huge thank you to the thirty Black women that lent their time to help push this research study forward. So many women were willing to share their stories. Your experiences helped to create this dynamic research study that I cannot wait to share with the world. Without you, this would not be possible at all, so I thank you. A huge thank you to my accountability partners, Jackie and Kay Lynn, for being a constant push to the finish line.

Thank you to my friends for understanding the times when I could not go out because I was busy researching and writing. Thank you to my friends that also helped by being participants in this study. Thank you for going on this journey with me and encouraging me along the way.

I must acknowledge the women of The Real Housewives of Atlanta, especially Nene Leakes, for providing the entertainment during the nights that I spent writing into the wee hours 
of the morning. The joy I experience when watching episodes, many that I have seen numerous times, helped in getting the words on the paper that is presented here.

Lastly, thank you to Beyoncé Giselle Knowles-Carter. I internalized the words, "I'ma keep running 'cause a winner don't quit on themselves" and that is exactly what I did. Despite the numerous times that I did not think this document would ever be finished, I never quit on myself. The words of "Bigger" pushed me to finish this dissertation and complete this degree. I know that my work is a part of something way bigger!

If you feel insignificant, you better think again Better wake up because you're part of something way bigger

You're part of something way bigger

Not just a speck in the universe Not just some words in a bible verse

You are the living word Ahh, you're part of something way bigger

Bigger than you, bigger than we Bigger than the picture they framed us to see

But now we see it And it ain't no secret

- Beyonce "Bigger" (2019) 


\begin{abstract}
Fighting an Uphill Battle: Black Undergraduate Women Navigating Higher Education While Acknowledging and Challenging Media Portrayals of Black Women by Kandace Nicole Branch
\end{abstract}

The stereotypes present in popular television shows often become barriers that limit Black women in higher education, influencing the ways in which they experience college campuses, including how they are treated by faculty and peers and how they interact with others in these spaces. This study examined the perspectives of Black women regarding how media portrayals of Black women and specific popular characters influence their learning opportunities and sense of belonging as undergraduates in college campuses. Black Feminist Theory was employed to analyze the experiences of the participants, Black women, and Critical Race Theory aided in understanding how these women function within the system of higher education. These theories work in conjunction to address racist, sexist, and classist conditions to which Black women are subjected and their responses in specific contexts. Four major themes emerged, each having a set of subthemes. The four themes are: (1) Black womanhood is multi-layered and multi-faceted, (2) Black women in the media, (3) this is not my space, and (4) creating a sense of belonging. 


\section{TABLE OF CONTENTS}

\section{Page}

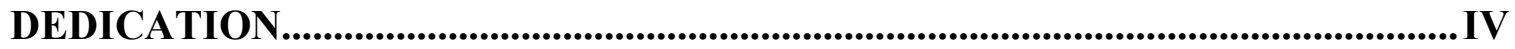

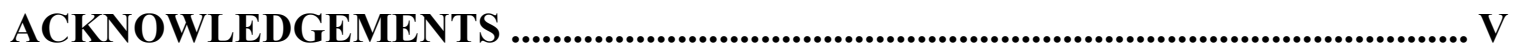

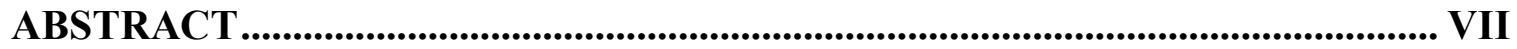

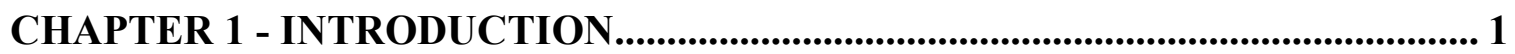

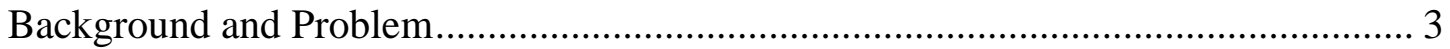

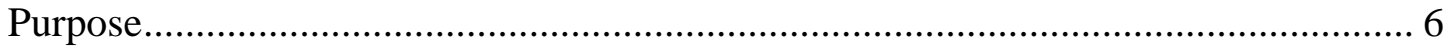

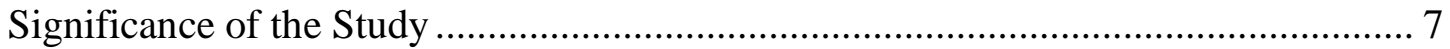

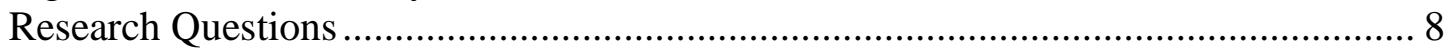

Overview of Research Design ........................................................................ 9

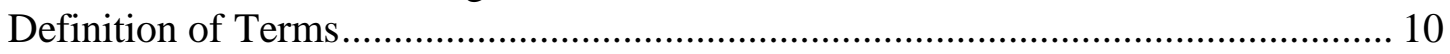

Contributions to the literature and Black women participants............................... 10

Summary and Organization of the Remainder of the Study .................................... 11

CHAPTER 2 - LITERATURE REVIEW.............................................................. 12

Collegiate Experiences of Black Undergraduate Women ...................................... 13

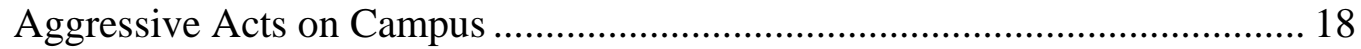

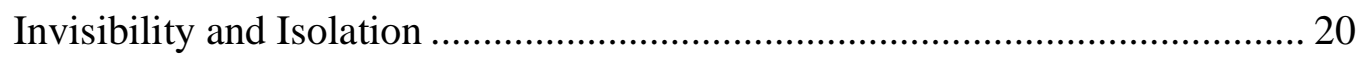

Resiliency and Coping ............................................................................ 23

Representations of Black Women and Black Womanhood ................................... 25

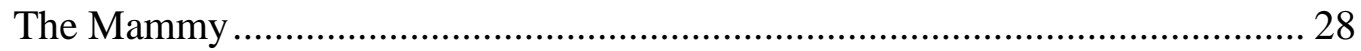

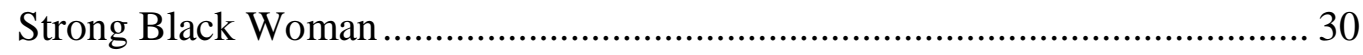

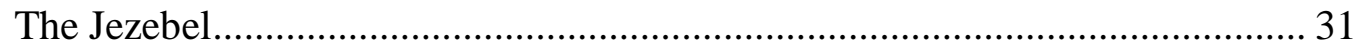

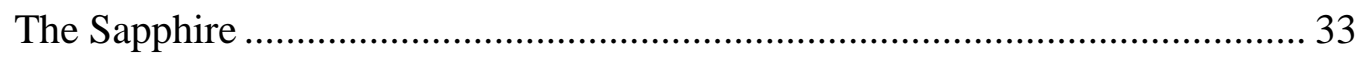

Impact of media portrayals on Black undergraduate women ................................. 35

Stereotype Threat ..................................................................................... 36

A Form of Dominance ................................................................................ 38

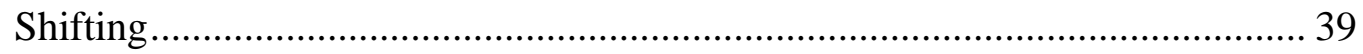

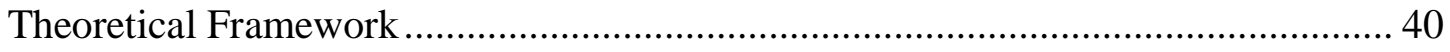

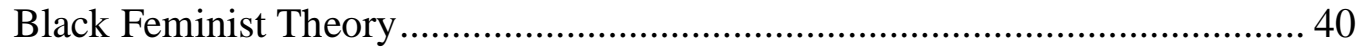

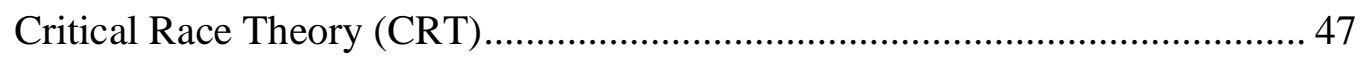

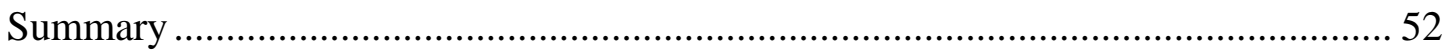

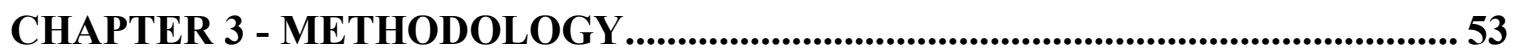

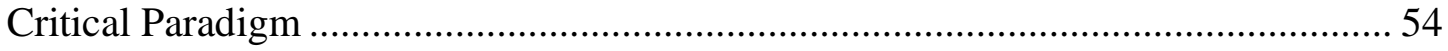




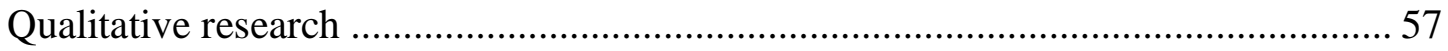

Culturally Responsive Narrative Inquiry ………………............................. 58

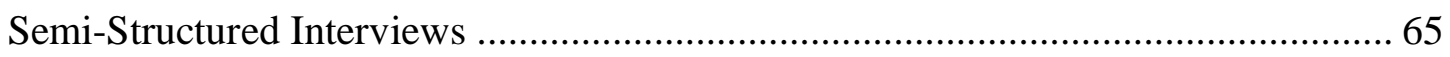

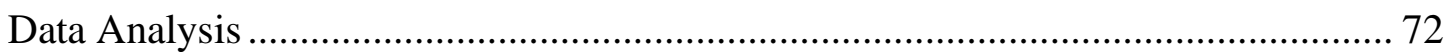

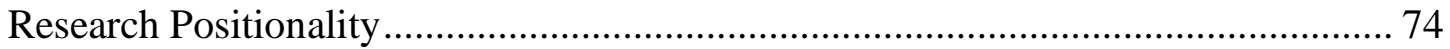

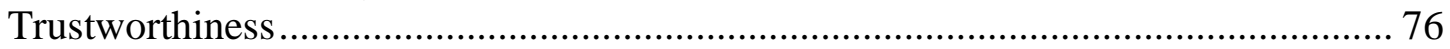

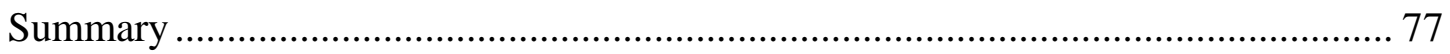

CHAPTER 4 - FINDINGS ................................................................................................ 78

Black Womanhood is Multilayered and Multifaceted …………………………...... 80

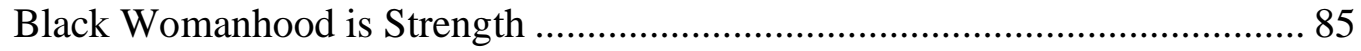

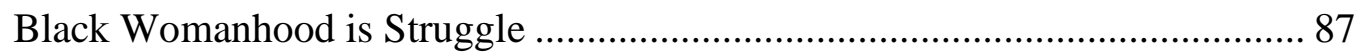

Black Womanhood is Nurturing ………………………............................... 90

Black Women in the Media ............................................................................... 92

Media Characters Who Represent Participant Ideals of Black Womanhood .... 94

The Influence of Media Portrayals on Black Women ......................................... 96

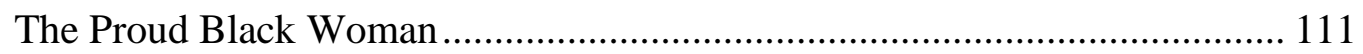

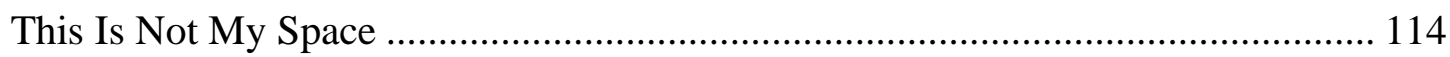

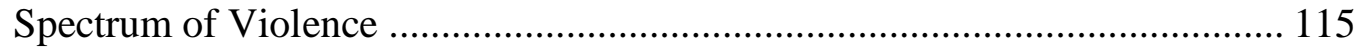

Feeling Alone on White College Campuses ……………………………...... 117

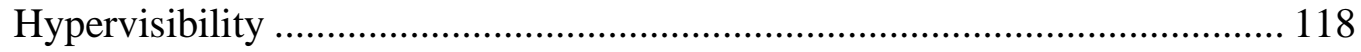

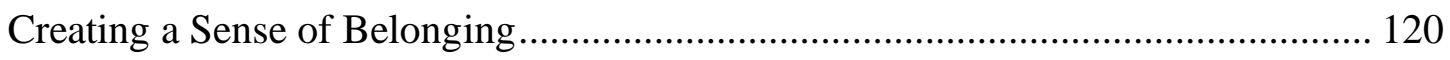

HBCUs Affirm Black Identity .................................................................... 120

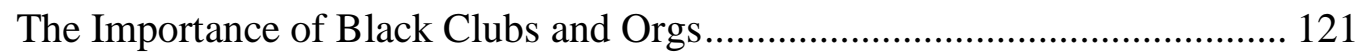

Seeking Supportive Faculty, Administration, and Spaces ............................... 124

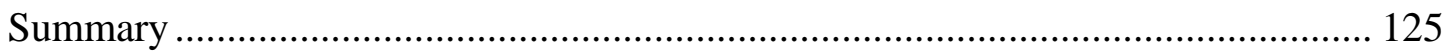

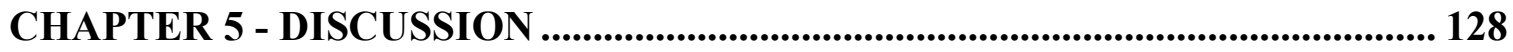

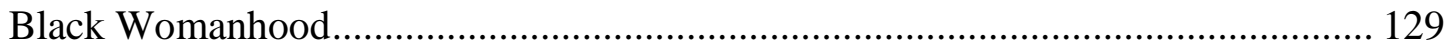

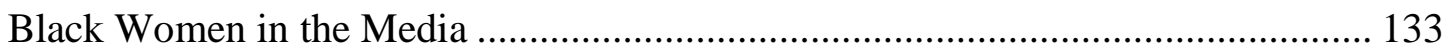

Black women being supported by their institutions ................................................ 141

CHAPTER 6 - IMPLICATIONS, FUTURE RESEARCH, AND CONCLUSION 146

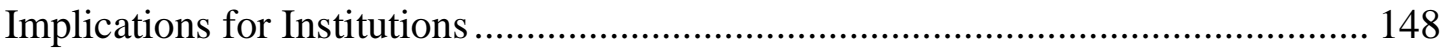

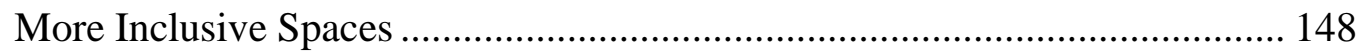

Creating More Nuanced Programs............................................................... 150

Increase in Black Faculty and Administrators ............................................... 150

HBCUs Acknowledge Gendered Oppressions ............................................... 151

Diversity Trainings and Anti-Racist Pedagogy ……………………............. 152

Implications for Media Makers.......................................................................... 153

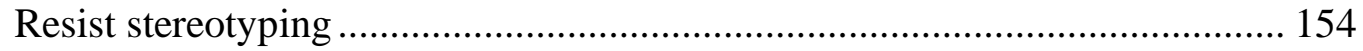

Increase in Black Women Media Makers ................................................... 154

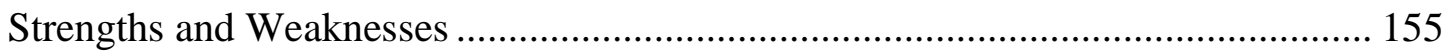




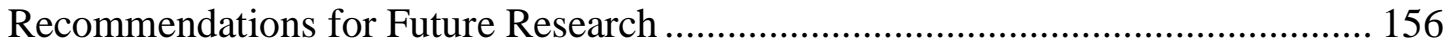

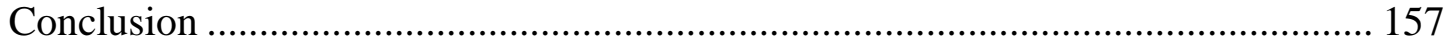

REFERENCES

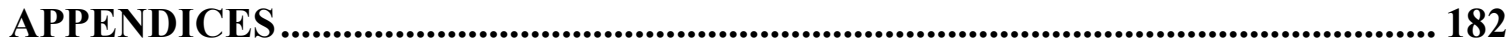




\section{LIST OF TABLES}

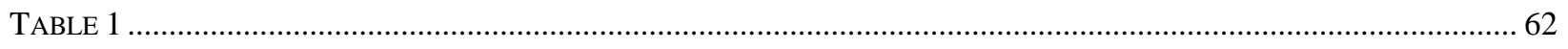

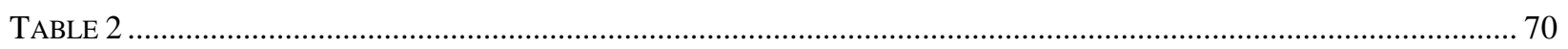




\section{Chapter 1 - Introduction}

In the early $20^{\text {th }}$ century, W.E.B. Du Bois introduced the term “double-consciousness". Du Bois (1903) sought to explain how Black Americans must manage not only being American but also being Black, thus the term double-consciousness. Du Bois (1903) wrote, "one ever feels his two-ness - an American, a Negro; two souls, two thoughts, two unreconciled strivings; two warring ideals in one dark body" (p. 2). Du Bois work on double consciousness fails to recognize the experiences of Black women who experience a triple consciousness, where they navigate and view the world through the lens of being, American, being Black, and being a woman (Welang, 2018). Even more so, Black undergraduate women face their own set of oppressive challenges stemming from societal definitions and depictions of, not only who they are as human beings, but also who they are as students (Banks, 2009).

In 2008, America was preparing for a historic presidential election. A Black senator from Chicago was inching closer and closer to becoming the first Black president of the United States of America. With his presidential campaign came this metanarrative of Americans living in a postracial society in that Black people have achieved racial equality (Dawson \& Bobo, 2009). However, we know that to be untrue and willfully ignorant because a post-racial narrative blatantly ignores the political and economic institutions that maintain racism (Giroux, 2009). I allowed the notion of a post-racial society to permeate my ideals about college and what I expected my college experience to be. In 2008, I was starting my post-secondary educational journey as a firstgeneration, Black woman, college student leaving South Central Los Angeles headed to Berkeley, California. As an only child, movies and television were a key player in my socialization process. With media being such a pivotal part of my life, I relied on media messages to guide many of my 
life experiences. I did not know how I was going to navigate undergraduate college life. Movies and television influenced my ideals and expectations of college and my collegiate experiences. Whether athlete or not, Love \& Basketball (2000) showed me that Black people from my very own community can get accepted to a prestigious school like University of Southern California (USC). Elle Woods from Legally Blonde (2001) symbolized resilience after many people doubted her abilities to succeed at Harvard and become a good lawyer. I was certain that when I got to college, I was going to find the love of my life like Whitley and Dwayne from A Different World (1987). However, my time as an undergraduate was absolutely nothing like what I was seeing in the media.

I had a very fictive, fairytale-like fantasy about college. I soon learned through various campus interactions that my peers had preconceived ideas about my character simply based on my physical appearance. When wearing athletic clothes on campus, I would get asked "What sport do you play?", as if I were only at this prestigious school because I was an athlete. A group of friends and I were once not admitted to a white fraternity party because "they didn't want any problems", as if Black women go around just starting arguments and fights. While eating in the university dining hall, I was even called "Sheneneh", the name popularized by the loud, in-your-face character on the television show Martin (1992). It was apparent that these perceptions of Black women were informed by the portrayals of Black women in the media. As a result of internalizing many of these tropes, I silenced myself during classroom discussions because I did not want to be perceived as "the ghetto Black girl". I had yet to learn the formalities of code-switching because it was not necessary during my upbringing. I was secure in my Blackness but felt as though my peers and my institution did not feel comfortable with my presence. I relied on my close network of friends, who were mostly Black women navigating similar experiences, to push me through once I realized my college experiences were not what I expected it to be. 
These experiences, along with many others, sparked an interest in hearing the first-person accounts of Black undergraduate women's experiences but specifically understanding how media portrayals of Black women impact the college experiences of Black women. Following my own personal encounters with racist and sexist acts on campus, I began to wonder how other Black women felt when having to navigate similar instances on campus. With the understanding that negative portrayals of Black women exist, I wondered in what ways Black undergraduate women were resisting these stereotypes. I was also curious about how my peers were confronting these portrayals in comparison to generations prior. These wonderings ultimately led to conducting this research study.

I sought to better understand the experiences of Black undergraduate women. More specifically, how Black women relate to the characterizations of Black women within popular media. Through semi-structured interviews, thirty Black women shared their opinions about Black womanhood, the representations of Black women in the media, and how each informed their college experience. In the subsequent sections of this chapter, I will explain the background and problem which led to the purpose of this study. In this chapter, I will also present the research questions that guided this study and why this research is significant.

\section{Background and Problem}

In February 2010, a group of White students attending University of California San Diego (UCSD) invited guests via FaceBook to a party titled "The Compton Cookout". The first line of the invitation states "February marks a very important month in American society", alluding to the celebration of Black History Month. To celebrate this cultural holiday, white UCSD students decided to host a racially charged "Compton Cookout" day party. With over 100 confirmed guests, the Facebook invite offered recommendations of what to wear by gender. The suggestions for men were very superficial and related solely to appearance. For instance, men were asked to wear 
jerseys, Black-owned fashion brands popularized by Black rappers such as, F.U.B.U. (For Us, By Us), Nike Jordan brand shoes and excessive tattoos. On the other hand, the recommendations for women were more specific and detailed, suggesting not only how a woman attending the party should look but also how she should act. The following was taken directly from the invitation:

For girls: For those of you who are unfamiliar with ghetto chicks-Ghetto chicks usually have gold teeth, start fights and drama, and wear cheap clothes - they consider Baby Phat to be high class and expensive couture. They also have short, nappy hair, and usually wear cheap weave, usually in bad colors, such as purple or bright red. They look and act similar to Shenaynay, and speak very loudly, while rolling their neck, and waving their finger in your face. Ghetto chicks have a very limited vocabulary, and attempt to make up for it, by forming new words, such as "constipulated", or simply cursing persistently, or using other types of vulgarities, and making noises, such as "hmmg!", or smacking their lips, and making other angry noises, grunts, and faces. The objective is for all you lovely ladies to look, act, and essentially take on these "respectable" qualities throughout the day. (retrieved from https://stopracismucsd.wordpress.com/2010/02/19/screengrab-of-originalcompton-cookout-event-another-similarly-themed-event/)

Racially themed parties are disproportionally hosted by white Greek organizations that target marginalized communities by perpetuating negative stereotypes through problematic and derogatory behaviors and actions (Garcia, Johnston, Garibay, Herrera \& Giraldo, 2011) "The Compton Cookout" illuminates how college campuses are racially hostile places for students of color across the United States (Ross, 2016). These hostile racial climates can impact achievement, integration, and retention for Black students (Fries-Britt \& Griffin, 2007).

Following her win as student government president, Black student, Taylor Dumpson, awoke to images of bananas hanging from noose-shaped strings marked with the letters AKA, the 
acronym for the first Black sorority of which Dumpson is a member (Sturdivant, 2017). Philosophers, scientists, and the media have created and maintained a narrative that draws connections between Black people and primates, with this racist ideology being pushed through the masses through literature and films such as the cinematic hit King Kong (Hund, Mills, \& Sebastiani, (2015). Dumpson, who was directly targeted because of her race and gender, suffered from post-traumatic stress disorder, and feared for her safety (Padilla, 2019). Her experience is not isolated. In this political climate, hate crimes, criminal offenses motivated, in whole or in part, by an offender's bias against race, religion, ethnicity, gender, sexual orientation or disability, on college campuses are on the rise (NCES, 2019), with college campuses being the third most common setting for racially bias hate crimes (Criminal Justice Information Service Division, 2009).

These are just two examples of how Black women are directly targeted and experience racist and sexist acts within collegiate spaces. More so, both instances demonstrate the ways in which stereotypes and myths related to gender, race, and class influence the ways Black women are treated within higher education (Banks, 2009). Despite gaining access to higher education, Black women's voices and experiences are often lost or diminished amongst narratives of higher education (Commodore, Baker, \& Arroyo, 2018).

The exaggeration of Black women in the media leaves real Black women unseen and unable to just be (Jones and Shorter-Gooden (2003). As a result, parties, like "The Compton Cookout" make a mockery of the experiences of Black people, more particularly Black women. With their increased media use (The Nielsen Company, 2017), Black women are more susceptible to internalize the messages and portrayals presented in the media. The stereotypes present in popular television shows aid in being barriers that limit Black women in higher education (Howard-Hamilton, 2003). While many Black women choose to actively fight against the racist 
agenda (hooks, 1981), the sexist agenda is just as important. It is also important to acknowledge how the media compounds this relationship for Black women. My own college experience, along with campus incidents similar to "The Compton Cookout" and Dumpson's experience with gendered racism, led to the construction of this research study.

\section{Purpose}

Rooted in the maintenance of hegemonic power and served to justify and legitimize keeping Black women at the margins of society, dominant narratives about Black women helped create universal truths, or stereotypes, about the lived experiences of Black women (Lundy, 2018). According to Jacobson (2005), stereotypes in the media tend to follow patterns of power, specifically by diminishing those that have little power or influence in society. Jacobson (2005) adds, gendered stereotypes inform our shared ideas about men and women based on characteristics of that group, such as appearance, behaviors, and occupation. Stereotypes are important because of what they do and what they mean (Gorham, 1999). Stereotypes can influence the behaviors and attitudes of the perceiver and stereotyped individual (West, 1995). Additionally, racial stereotypes can be determining factors when labeling someone (Love, 2014). Black girls and women are infantilized and hypersexualized (Dagbovie-Mullins, 2013), criticized for being loud (Morris, 2007), and ridiculed for their physical appearance, particularly their hair (Muhammad \& McArthur, 2015) as a result of their portrayals in the media. The over-exposure and oversaturation of negative images in the media, relevant to the lives of Black people, make it difficult for Black girls and women to form positive self-images (hooks, 1981, West, 2008). Reductive caricatures of Black women lead to the invisibility of Black women where they hide their true selves to appease their White counterparts, Black men, and other parts of their community (Jones \& Shorter-Gooden, 2003). 
The purpose of this research study was to examine how media portrayals of Black women in the media influence the collegiate experiences of Black undergraduate women. Even more so, how Black undergraduate cope with interactions with peers and faculty because of the perceived discrimination due to racial and gendered stereotypes of Black women. This study adds to existing literature by exploring how Black undergraduate women understand their racialized and gendered experiences on college campuses. Black college women often feel isolation, alienation, and culture shock as a result of their experiences on college campus (Winkle-Wagner, 2009). This is then compounded by the dominant portrayals of Black women in the media. These media portrayals of Black women narrowly define Black women as overbearing, loud, cantankerous, and hypersexual while also being asexual (Bogle, 2001). The static representations of Black women in the media reinforces the archetype of what it means to be a Black woman in America, while maintaining hegemonic forces that continue to marginalize Black women (Emerson, 2002).

\section{Significance of the Study}

Black undergraduate women are a growing population. In the fall of 2018, 16.6 million students enrolled as undergraduates in a degree-granting postsecondary institution, of which 2.1 million were Black (NCES, 2020). Amongst the total number of Black undergraduate students, Black women exceeded Black men by nearly twenty-five percent (Espinosa, Turk, Taylor, \& Chessman, 2019). Despite the national increase of Black undergraduate women enrollment, they remain a largely ignored population (Banks, 2009; Patton \& Croom, 2017). However, disparities exist between Black undergraduate women enrolling in post-secondary institutions and the conferral of degrees and graduation rates (Commodore, Baker \& Arroyo, 2018). This reveals that there is an existing disconnect between Black women's persistence in completing their postsecondary degrees. This research study is significant in that it explores how dominant representations of Black women in the media incite a perceived racial and gendered discrimination 
that women experience within higher education. Despite the racialized and gendered conditions for Black undergraduate women within higher education, this research study reveals the resiliency of Black women to thrive, not just survive, in often hostile environments.

The research study is also significant because it adds to the limited existing qualitative literature that offers insight into the firsthand experiences of Black undergraduate women. The dire need to help Black boys and men has led to the scholarly neglect of Black women and girls where little is known specifically about the experiences and challenges of Black women in college (Patton, Crenshaw, Haynes \& Watson, 2016). This research study adds to the growing field of studying media stereotyping effects (Dixon, 2019). More specifically, this research adds to the lack of qualitative research analyzing the ways in which the media impacts an already under researched population of Black undergraduate women. The lack of research specific to the racialized and gendered experiences of Black undergraduate women limits the resources and services provided to them (Banks, 2009; Winkle-Wagner, 2015). The findings of this research study can inform institutions on acknowledging the racial and gendered oppressions Black collegiate women experience all while providing more inclusive spaces on campus that reflect their various identities, increasing the number of Black women faculty and administrators on campus, and offering trainings that equip stakeholders with the knowledge to work with others from varying backgrounds. Additionally, the findings of this research study encourages a need for more Black women media makers to create positive characterizations of Black women.

\section{Research Questions}

The purpose of this research study is to examine popular media character influences on Black women. Specifically, the question guiding this research study is: How does media representations of Black women influence of Black undergraduate women? This research question can be operationalized by answering the following sub-questions: 
1. In what ways did Black undergraduate women define Black womanhood?

2. How did they feel about the representations of Black women in the media? In what ways did they respond to and/or resist specific tropes in educational spaces? What were some of the coping mechanisms used to deal with negative portrayals?

3. In what ways did they feel supported, as Black women, by their institution?

This study examines how the media is both influential and complicit in the racial and gender socialization process of young Black women. Additionally, this study questions on how Black women are expected to live up to the ideals of how Black women are portrayed in the media. Even more so, this study seeks to understand how Black women recognize, understand, and address the messages presented about Black womanhood in the media. Framed using Black feminist theory and critical race theory, a qualitative narrative study was used to explore these questions in gaining a better understanding of how media portrayals of Black women impact the collegiate experiences of Black undergraduate women.

\section{Overview of Research Design}

To best answer these research questions, qualitative methods are employed. This research study used a combination of single semi-structured interviews and focus groups. The use of Black feminist theory and critical race theory encouraged the use of culturally responsive narrative inquiry because it privileged the stories in the most authentic way (Etter-Lewis, 1993). Thirty Black undergraduate women participated in this study. Some of the women were current students, while others had graduate nearly twenty years ago. The women in this study also attended various types of institutions from predominately white institutions to historically Black institutions as well as community colleges. Participants participated in a single semi-structured interview where we discussed their collegiate experiences as well as watched clips from three popular television programs and drew comparison between their college experiences and the character scenarios. 
Additionally, participants were invited to participate in one of two focus groups. The use of semistructured interviews allowed an in-depth understanding of the experiences of Black undergraduate women, particularly in uncovering where their race, gender, sexuality, and other identities intersect (Few, Stephens \& Rouse-Arnett, 2003; Rosenthal, 2016; Stephens \& Few, 2007)

\section{Definition of Terms}

Media. According to Reeves (1998), "media is defined as all means of communication, whatever its formats, which includes symbol systems as diverse as print, graphics, animation, audio, and motion pictures" (p.1). This paper focuses on visual media, but more specifically television. Through this paper, media will be used broadly.

Black. Black is consciously used throughout this research study. The term is more inclusive being that there are Black people living in the United States that are not African-American (Tatum, 1997). I will use African American as it is referenced in the work of other authors.

PWI. This is an abbreviation for predominantly white institutions. A college or university in higher education that is historically founded for the education of White students, and most of its student population, faculty, and administrators are White (Rodgers \& Summers, 2008).

HBCU. This is an abbreviation for historically Black colleges and universities.

\section{Contributions to the literature and Black women participants}

Black women collegians are largely understudied in comparison to their Black male peers (Commodore, Baker \& Arroyo, 2018). As a result, there is a lack of research that qualitatively examines the collegiate experiences of Black women. Even more so, there is a dearth of research that specifically examines how Black undergraduate women are navigating higher education while acknowledging and challenging dominant portrayals of Black women in the media. This study extends this scholarship by using Black feminist theory and critical race theory to demonstrate the ways race and gender interplay to impact the collegiate experiences of Black women. As a Black 
woman researcher conducting research with Black women, this research affirms that Black women's knowledge and thought is important and powerful. Additionally, this research study offers insight into the experiences of Black undergraduate women to show current Black women collegians that they are not alone in their experiences. For future Black women undergraduates, the experiences of the women in this research study suggest ways to persist within higher education.

\section{Summary and Organization of the Remainder of the Study}

College campuses can be hostile environments for Black undergraduate women, in part because of internalized presumptions about Black women displayed through the media and projected from their peers. This study explored media representations of Black women and how it impacts Black undergraduate women's college experiences. Chapter two explores the existing literature that examines the origins and maintenance of the dominant representations of Black women in the media and how these portrayals impact Black undergraduate women. The second chapter also presents the theoretical frameworks used to explore Black undergraduate women's experiences. Chapter three goes more in-depth into the methodology, research design of this study, participants, procedures, and data analysis. Chapter three also explains my position as a researcher in this study. The emergent themes from the data are presented in Chapter four. In Chapter five, the themes of the data are explored by drawing connection to the existing literature. Lastly, chapter six culminates this research study by offering implications for institutions and media makers, as well as areas of future research that can continue to engage in this topic by expanding on what is presented here. 


\section{Chapter 2 - Literature Review}

More than two hundred years following the beginning of slavery, Alexander Lucius Twilight became the first known Black man to earn a bachelor's degree in 1832. Thirty years after Twilight, and twenty-two years after the first white woman, Mary Jane Patterson became the first Black woman to receive a bachelor's degree in 1862 from Oberlin College (Henle \& Merril, 1979). Following the ending of the American Civil War, educational opportunities for Black students increased due to the founding of many notable Black-serving institutions such as Fisk University (1866), Howard University (1867), and Clark University (1870). The number of conferred degrees during this time more than doubled (Haynes, 2006). By the 1900's, 2,000 Black students had earned higher education degrees with nearly twenty percent being from predominantly White colleges and universities. Between 2000 and 2016, enrollment of Black students increased from twelve to fourteen percent with Black undergraduate women enrollment nearly doubling that of Black undergraduate men (NCES, 2019). However, the retention and graduation rates of Black undergraduate women is significantly lower in comparison to their female peers revealing the existence of underlying issues for Black undergraduate women (Commodore, Baker \& Arroyo, 2018).

In the United States, Black people watch the most television of any other ethnic group watching nearly 200 hours per month (The Nielsen Company, 2015). Black women, specifically, spend more time weekly consuming different types of media across various devices than any other group of women in the United States (Grace, McCaskill \& Roussell, 2017). Additionally, based on the top shows watched by Black women, Grace, McCaskill and Roussell (2017) found Black women favor television programming that features a predominately Black cast or Black lead characters. Consumption of high levels of media and preference of programming with Black 
characters can also lead to internalization and endorsement of stereotypes about Black women. Littlefield (2008) argued mass media serves as a system of racialization in that it is a device "used to perpetuate the dominant culture's perspective and create a public forum that defines and shapes ideas concerning race and ethnicity" (p. 677). Ultimately, the over-exposure and oversaturation of negative images in the media, relevant to the lives of Black people, make it difficult for Black girls and women to form positive self-images (hooks, 1981, West, 2008).

This study examined visual media influence on Black undergraduate women and their collegiate experiences. Literature was gathered using Google Scholar and EBSCOhost using various keywords and phrases like "Black college women and media". This chapter begins by presenting the literature on the collegiate experiences of Black students, specifically Black women. The literature revealed the ways in which stereotypes impact Black undergraduate women's college experiences. Therefore, an exploration of the most recurring and dominant portrayals of Black women in the media will also be presented. This includes the Mammy, the Strong Black Woman, the Jezebel, and the Sapphire. Lastly, the chapter concludes with an exploration of Black feminist theory and critical race theory, which were used as the theoretical frameworks for this research study. The gap in the literature is revealed by the scarcity of literature that focuses solely on a qualitative examination of the impact media portrayals have on the experiences of Black undergraduate women.

\section{Collegiate Experiences of Black Undergraduate Women}

A narrative has been crafted that showcases Black women as succeeding within higher education in comparison to their Black male counterparts (Patton \& Croom, 2017). For example, in a comparative investigation of student outcomes at predominately white institutions and historically Black institutions, Allen (1992) found gender identity to be a predictor of student success where Black women reported higher confidence. Here, Allen (1992) makes the argument 
that predominately white institutions are more detrimental for Black men than Black women. Chavous, Harris, Rivas, Helaire, and Green (2004) make a similar argument where they contend Black men may be more vulnerable to stereotype expectations at predominately white universities due to the limited number of Black men at these schools. Additionally, in an examination of gender and racial gaps amongst freshman students attending twenty-four predominately white universities, Keels (2013) found Black women graduate at nearly a twenty percent higher rate than Black men in a four-year span and nearly ten percent hear within six years. As these studies illustrate, Black women's academic successes are often used in comparison to Black men or, even more broadly, used to show the success of all Black students (Patton \& Croom, 2017). Yet, there is a lack of research that examines the conditions Black women must combat against in order to persist within higher education.

Higher education is full of inequities that makes completion more difficult for some in comparison to others, but more importantly privileges the white dominant group and is constructed around whiteness (Banks, 2009). Whiteness is a system of ideologies and practices that serve to maintain racial hierarchies and white supremacy and that are deeply embedded within the language, knowledge, and traditions of higher education (Gusa, 2010). The exclusion of Blackness was standardized from the student body to the faculty, to the curriculum, where whiteness, European history, ideas, and people were made to appear normal (Kendi, 2012). This intentional exclusion within higher education has created conditions that illuminate the periphery positioning of marginalized communities, which impacts their collegiate experiences and more generally the campus climate.

Campus racial climate is broadly defined where the focus is exclusively on the students, the faculty, or both, as well as placing emphasis on the campus community members (Miller, 
2014). According to Rodgers and Summers (2008), campus climate is defined "by current perceptions, attitudes, and expectations that define the institution and its members" (p.176), which is often examined through differences between ethnic groups within higher education. To better understand and assess campus climate, Hurtado, Clayton-Pederson, Allen, and Milem (1998) developed a four-dimensional model to access campus racial climate. The four dimensions include an institutional history of inclusion and exclusion, structural diversity, psychological climate, and behavioral climate. The first dimension, institutional history of inclusion and exclusion, suggests that many universities, resisted desegregation and have maintained old campus policies that serve a particular population. The dimension of Structural diversity, according to these authors, is an important first step towards improving campus climate because it encourages universities to examine how the enrollment of diverse students has important educational benefits for all students. The psychological dimension of campus climate refers to the ways individuals view group relations, institutional response, racial conflict, and the attitudes of differing ethnic groups. Lastly, the dimension of behavioral climate focuses on the social interactions within and between racial and ethnic groups. These authors suggest improvement in campus racial climate is contingent on two questions, “(a) How diverse does the campus look in its representation of different cultural groups? and (b) To what extent do campus operations demonstrate that racial and ethnic diversity is an essential value?" (p. 297)

In her seminal work on campus racial climate, "The Campus Racial Climate: Contexts of Context", Hurtado (1992) argued large, predominately white, public institutions had a higher rate of perceived racial conflict where fostering diverse learning environments were not a priority. Hurtado (1992) conducted a study which examined racial climate issues amongst various ethnic groups at all types of four-year institutions. Findings in this study revealed that most undergraduate students agree that racial discrimination is a pertinent issue in society, with their perceptions of 
campus racial discrimination varying by their experiences. This research study also found Black students are more critical of their campus environments in comparison to other racial groups where they perceived higher levels of racial tension and lower levels of institutional efforts towards diversity. Additionally, this study revealed an increased enrollment of Black students is positively associated with white students' perceptions of racial tension insinuating white students may be threatened by the presence of Black students.

In a study of 578 African American, Asian American, Latino/a, and White undergraduates attending a large mid-Atlantic university, Ancis, Sedlacek and Mohr (2000) found significant differences in student perceptions of campus cultural climate. African American students reported greater experiences of racial-ethnic hostility, increased pressure to conform to stereotypes, faculty racism, and mistreatment from faculty, staff, and teaching assistants in comparison to other racial groups. These authors found Black students have a greater comfort with faculty and students of similar racial and ethnic background. In comparing campus racial climate and adjustment between Black and white students, Cabrera, Nora, Terenzini, Pascarella, and Hagedorn (1999) found perceptions of prejudice and discrimination had the greatest effect on Black student's academic experiences, academic ability, and social experiences. However, and importantly, the authors found that Black students' perceptions of discrimination and prejudice did not hinder their decisions to persist.

In a qualitative examination of Black college achievers and their response to racist stereotypes, Harper (2015) found student involvement or academic achievement did not protect them from being stereotyped by their white peers and professors. Additionally, through active campus involvement, the men in this study sought to dispel negative assumptions of Black men and other minority groups by promoting a more positive image. Additionally, the men in this study utilized their positioning as student leaders and achievers to speak up and out against injustices. 
Campus climate perceptions not only vary by race but also by gender. Hall and Sandler (1982) suggested women students do not experience educational equality on college campuses where women undergraduate and graduate students are often treated differently by peers and faculty. Even more so, these authors argued colleges and universities perpetuate environments in which differences are intensified, therefore women are often treated as second-class. Patton and Croom (2017) acknowledged that the existing literature on Black undergraduate does not offer enough nuance to the variance within Blackness by differentiating men from women. They write,

This well-intentioned and seemingly neutral narrative singlehandedly contributes to a divisive discourse that positions Black women and men against one another for no substantiated reason. This discourse also fails to account for an analysis (and definition) of success beyond numbers, one that considers a larger context in which intersections of identities and systems of oppression create uniquely raced, gendered, and classed experiences for Black women. The failure to account for racism/white supremacy and gender/patriarchy when considering Black collegiate women's experiences is nonsensical at least and absurd at best (p. 10)

As Patton and Croom (2017) have highlighted, there is an assumption in the literature that the college experience of Black students is homogenous. The overlapping racial and gender identities of Black undergraduate women presents its own set of challenges in their educational pursuits within higher education (Banks, 2009). Zamani (2003) argued the American educational system is a microcosm of the larger society where Black women are not given the same opportunities. Banks (2009) contend that the stories of being Black and a woman makes their educational journey unique in that "navigating both literal and figurative college and university spaces is an ongoing, dynamic, and complex process" (p. 9). Yet, the attention that has been placed on Black men, and broadly 
Black students, has led to an erasure of Black women within the literature (Commodore, Baker \& Arroyo, 2018). Synthesis of the existing literature on Black undergraduate women's collegiate experiences revealed Black women experience aggressive acts and are often diminished or invisibilized on campus, which leads to feelings of isolation. The literature also discusses the ways in which Black undergraduate women are coping within these hostile environments. Additionally, much of the empirical research focuses on the experiences of Black undergraduate women attending predominantly white institutions. Two-year institutions, or commonly referred to as community colleges, tend to be an initial entry point into post-secondary education for many Black students, but are not often discussed in empirical research (Patton \& Croom, 2017; Commodore, Baker \& Arroyo, 2018). Black women's college experiences are also often discussed by comparing predominately white institutions with historically Black colleges and universities. While Black women succeed academically at HBCUs, they still experience similar marginalization compared to their peers at PWIs and within greater American society (Commodore, Baker, Arroyo, 2018; Bond, 2011). This literature review will attempt to provide the most comprehensive review of Black women's collegiate experiences at all types of post-secondary institutions.

\section{Aggressive Acts on Campus}

Aggressive acts within education does not just begin at the collegiate level for Black women. In a two-year ethnographic study of a seventh and eighth grade middle school, Morris (2007) found dominant ideas of race, gender, and class influenced the ideals of femininity as it pertained to Black girls, in that their assertive behaviors made the girls in this study appear less feminine by their teachers, resulting in discipline practices intended to re-form their femininity into something more "acceptable". In a study of discipline experiences of elementary and secondary-aged Black girls, Blake, Butler, Lewis and Darensbourg (2010) found Black girls were twice as likely to get in-school and out-of-school suspensions, illustrating how discipline practices 
are more likely to remove Black girls from the classroom more than their white or Hispanic peers. In Pushout: The Criminalization of Black Girls in School, Morris (2016) affirmed the ways race, gender, and socio-economic inequities converge to marginalize Black girls within various learning environments. Morris (2016) argued,

The real and perceived experience of being a Black female student is informed not only by historical ideas about girls attempting to navigate spaces that have underserved their educational odds but also by how well Black girls have performed against the odds (p. 36) These negative experiences are carried throughout their schooling career and exacerbated at the collegiate level in a variety of ways.

In contrast to more blatant, "old-fashioned" racism, Dovidio, Gaertner, Kawakami, and Hodson (2002) argued contemporary racism, or aversive racism, is more subtle and unintentional where white Americans regularly engage in discriminatory practices while maintaining a nonprejudiced self-image. Sue (2010) argued that no one is free from inherit biases being that we are all exposed to a social conditioning process saturated with prejudices and stereotypes. As a result, marginalized groups experience racial microaggressions. Hamilton (2020) argued that microaggressions are a form of violence that refers to words and actions that demean one's race, gender, sexuality, or physical ability. Essed (1991), coined the term gendered racism, to name the ways in which Black women experience oppression on the basis of race and gender. In her qualitative study with Black women in the United States and Netherlands, Essed (1991) argued racism is an everyday part of Black women's lives that is maintained through marginalization, containment, and problematization. Essed (1991) wrote,

For the Black women who speak in this study, everyday life in a White-dominated society involves a continual battle against the denial of racism, against White centrism, against automatic in-group preference among Whites, against constant impediments to their 
aspirations, against humiliations, against petty harassment, and against denigration of their cultures. (p.10)

As Essed (1991) explained, there is an ever-present conflict for Black women to navigate the aspects of racism that appear normal. Using focus groups of Black undergraduate and graduate students to understand their racial and gendered experiences, Lewis, Mendenhall, Harwood, and Huntt (2016) found the women in their study experienced gendered racial microaggressions through projected stereotypes, silencing and marginalization, and assumptions about their style and beauty. More specifically, it was expected of the Black women to be sexualized beings because of the Jezebel stereotype where participants reported feelings of being sexualized and assuming they were promiscuous. Additionally, it was assumed Black women students would embody the Angry Black Woman, where participants felt pressure to alter their behaviors, so they did not perpetuate the stereotype. Participant's feelings of being silenced and marginalized were a result of their contributions being minimized where they struggled for respect and felt invisible on campus. Lastly, the participants in this study felt inferior and pathologized due to the assumption that Black women are loud and expected to have particular body types and physical features. This study illuminates how gendered racial microaggressions impact the experiences of Black women students within higher education. The findings of this study also suggest the ways stereotypes are used to invalidate the daily experiences of Black women. The historical underpinnings of these stereotypes will be discussed in greater detail in the next section.

\section{Invisibility and Isolation}

As a result of these violent acts from peers and faculty, Black undergraduate women experience isolation and have difficulty creating a sense of belonging, which makes them feel like an outsider-within (Howard-Hamilton, 2003; Bartman, 2015; Commodore, Baker Arroyo, 2018). Black undergraduate women "have been invited into places where the dominant group has 
assembled, but they remain outsiders because they are still invisible and have no voice when dialogue commences. A sense of belonging can never exist because there is no personal or cultural fit between the experiences of African American women and the dominant group" (HowardHamilton, 2003, p. 21). Additionally, Black undergraduate women do not fit into a one-size-fitsall approach for all Black students because it ignores the in-group differences, which heightens the problems that Black women face on college campuses (Hughes \& Howard-Hamilton, 2003). According to Commodore, Baker, and Arroyo (2018), socially constructed homogeneity exists where expectations are placed on Black women in college to act and dress in a certain way, which leaves little room for the amount of support provided to meet the variety of the student's needs.

In a phenomenological study of seven Black college women, Hannon, Woodside, Pollard, and Roman (2016) found Black college women live in two worlds, one that is Black and one that is white, where Black women students get involved and connect to their white community out of necessity. Yet, the women in this study believed these experiences helped prepare them for the world beyond their college experiences. These authors also found that Black women are also negotiating between the academic and career expectations they place on themselves and exceeding self-imposed expectations based on their perceptions of how they are viewed by their white peers. The women in this study also were constantly aware of their racial identity because they are often the only Black student in their classes. However, they see this as an advantage in being easily recognized by professors and peers.

In their qualitative examination of how Black undergraduate women made meaning of Black womanhood and being a Black woman on campus, Robinson, Esquibel, and Rich (2013) found Black undergraduate women experiences of being one of the few on campus led to a tokenism, which influenced how they utilized their voice. As a result, these authors also found that 
Black undergraduate women use strength in their self-definition, which is the internalization of the Strong Black Woman trope as an amour to protect them from gendered and racial oppressions.

Patton and Croom (2017) argued, "Black women have been navigating higher education, while postsecondary institutions have been overwhelmingly irresponsible in addressing racism, sexism, classism, and other forms of oppression that affect Black women” (p.3). Unfortunately, many higher education institutions do not do enough to make campuses more inclusive for Black students, and for Black women in particular. Strayhorn and Johnson (2014) found cross-racial interactions and acquaintances creates a sense of belonging on college campuses, but because they are a minority population on many campuses Black students are unable to escape these interactions unlike their White peers. As a result of racialized and gender tensions, Black women choose to self-segregate within social spaces, like residence halls, to avoid racial hostility and microaggressions because of feelings of only being provisionally accepted in white spaces (Haynes, 2019).

Class differences also altered Black women's sense of belonging and connecting with other Black women. Wilkins (2012) found middle-class Black women adopt race-neutral identities, which are expected to ease their transitions into higher education. However, hostile encounters with white students, such as overt racism and exclusion from white networks, pushed Black students to seek other Black students. Yet, prior to college, the women in this study did not consider themselves like other Black people because of class differences. Therefore, they were forced to bridge other differences that left them feeling uncomfortable participating in Black organizations. In his work with Black men, Allen (2010) affirms Black students are still susceptible to racial microaggressions despite class.

While the status of Black women has improved in college, in a review of the literature, Henry, Butler, \& West (2011) found the underrepresentation of Black women is related to various 
psychosocial factors that directly hinders their psychological and physical health. More specifically, these authors found that it is difficult to foster academic and social relationships due to the incessant racism and sexism experience on campus. The three most common psychosocial issues experienced by Black undergraduate women were anger, depression, and anxiety, which are similar to their White counterparts. These psychosocial issues then effect their health where Black undergraduates are experiencing a gradual increase in obesity, eating disorders, and sexually transmitted diseases.

\section{Resiliency and Coping}

Wang, Haertel, and Walberg (1994) suggest academic resilience is the "heightened likelihood of success in school and in other aspects of life, despite environmental adversities, brought about by early traits, conditions, and experiences" (p. 46). For Black undergraduate women, resilience is a necessary part of their schooling labor as they are challenging the historical exclusion of Black women being educated (Banks, 2009). The institutional response to Black collegians' needs is important to their achievement (Rosales \& Person, 2003). Despite a lack of attention and resources, Black women have found ways to sustain within higher education.

Through twenty-three life-story interviews, McGee and Martin (2011) contend academically successful and resilient Black college students in mathematics and engineering utilize stereotype management strategies to persist in their programs. In other words, the exposure of stereotypes were utilized to maintain high academic achievement, where students' success was centered on trying to prove others wrong. In a quantitative study of fifteen Black doctoral students attending predominately white institutions, Shavers and Moore (2014) sought to examine the strategies Black women utilized to persist and cope academically in their programs. Through semistructured interviews and analysis, an overarching theme emerged which the authors call "the 
double-edged sword" (p. 23), referencing the metaphor of a sword with two sharp edges. Within this theme, two subthemes emerged. One edge of the sword being the prove-them-wrong syndrome, where Black women internalized a belief of working hard to overcome stereotypes and adversity. The other edge of the sword was part-of-a-bigger-whole syndrome which alluded to the women understanding their academic pursuits were greater than themselves and a way to give back to their community. Both strategies helped Black women persist academically, but both also put the well-being of these women at risks. The findings of this study suggested Black women must choose between their academic pursuits and their well-being.

According to Howard-Hamilton (2003), the success of Black undergraduate women is reliant on their ability to find safe spaces with individuals like themselves, such as Black student unions and sororities, but key institutional figures must aid in establishing these spaces. Patton (2006) examined how Black undergraduate students experienced and made meaning of the Black cultural centers on their campus. Black cultural centers were found to be beneficial for helping students get adjusted to the campus environment, offered resources to Black students, and acted as a "home" for Black students to feel at ease (Patton, 2006).

Black Greek-lettered organizations have also been studied to explore their impact on college experience. There are nine Black Greek-lettered organizations known as the "Divine Nine", which include five fraternities and four sororities. These organizations include Alpha Phi Alpha Fraternity, Inc., Alpha Kappa Alpha Sorority, Inc., Kappa Alpha Psi Fraternity, Inc., Omega Psi Phi Fraternity, Inc., Delta Sigma Theta Sorority, Inc., Phi Beta Sigma Fraternity, Inc., Zeta Phi Beta Sorority, Inc., Sigma Gamma Rho Sorority, Inc., and Iota Phi Theta Fraternity, Inc. Using focus groups and semi-structured interviews, Mitchell (2014) examined the social experiences of Black Greek-lettered organization members to explore the ways gender impacted the social capital 
gained through participation in these organizations. While men did not think gender was a salient part of their fraternal membership and participation, this study revealed same-gender relationships within their sorority were important. More specifically, their sororities served as safe spaces with women from similar experiences. Being that all the women in the sorority identify as Black, the women in this study shared that they were able to create deeper bonds which helped them navigate through campus. Additionally, being amongst like-minded women pushed them towards their educational and professional goals. Black sororities plays a major role in the narrative of Black college women by addressing the neglect and erasure of Black women in everyday life (Commodore, Baker \& Arroyo, 2018).

As the literature has shown, Black women have a unique collegiate experience that is often dictated and influenced by the public images of Black women. Various studies in the literature acknowledge the ways that stereotypes in the media influence the perception of Black undergraduate women, however there is an absence in the literature that offers a qualitative examination of how these portrayals influence the undergraduate experiences of Black women, which this study addresses. The next section will explore the formation of the most dominant portrayals of Black women.

\section{Representations of Black Women and Black Womanhood}

Black women in America have differing experiences from other men and women altering their views on womanhood, Blackness, and personhood (Settles, Pratt-Hyatt, \& Buchanan, 2008; Thomas, 2004). The genesis of the attitudes, particularly devaluation, towards Black women comes from American slavery (Awad, Norwood, Taylor, Martinez, McClain, Jones, Holman \& Chapman-Hilliard, 2015). These attitudes and beliefs have aided in the construction of Blackness in the media (hooks, 1992; Burrell, 2010). The ideologies of the slave era fostered several socially constructed images of Black womanhood as a means of maintaining Black women's subordination 
(Collins, 2000). Black women experience multiple oppressions, such as racism, sexism, and classism, that work together by acting upon one another in a multiplicative relationship (King, 1988). As Crenshaw (1989) argued single-axis analysis of Black women's experiences contributes to the marginalization of Black women. The subordinate status of Black women, being Black and a woman, has been maintained and enforced by white and Black men, as well as white women (Howard-Hamilton, 2003). Therefore, analysis that does not consider the intersectional experiences of racism and sexism cannot sufficiently address the ways in which Black women are subordinate.

While Black women and Black men struggle together against racism, Black women are also struggling with Black men against sexism (Combahee River Collective, 1977). Even more so, Black women cannot seek protection from white or Black men nor White women (hooks, 1992). Therefore, the gendered and racial experiences of Black women and girls differ from that of other racial groups. Epstein, Blake, and González (2017) found, in comparison to white girls, Black girls are perceived to need less support, less protection, need to be less comforted, are more independent, and as a result, Black girls receive harsher punishments within the educational system. Thiem, Neel, Simpson, and Todd (2019) found Black women and girls are more closely associated with danger in comparison to white women and girls. In a comparison of the beliefs of womanhood between Black and white women, Settles, Pratt-Hyatt and Buchanan (2008) found that both groups believe womanhood consists of gender-based mistreatment, perceived advantages, community and friendships, and caretaking. Where the two groups differ is that Black women attributed personal and emotional strength to being a Black woman, which was learned from their mothers and other women figures in their lives, which also supports the endorsement of the strong Black woman trope, which will be further explained later in this chapter. 
Black women often hide their true selves to placate and appease white people, Black men, and other members of the community (Jones \& Shorter-Gooden, 2009). Harris-Perry (2011) argued that, for Black women, the social world is not a positive mirror but more so like a carnival mirror that distorts the image of Black women and Black womanhood, making it more difficult to display an accurate image due to the constant stretching and shrinking on the surface. One way in which general notions of Black women and Black womanhood are distorted are through media portrayals and popular culture (Emerson, 2002). Many Black women and girls have to navigate the tension of media portrayals not being representative of their opinions of Black womanhood and girlhood. In their qualitative study with eight adolescent girls, Muhammad and McArthur (2015) found the ways in which they wished Black girls were portrayed in the media is in direct opposition to the ways in which Black girls are actually represented, where they are either completely absent or their characterizations are exaggerated. In their examination of Essence, a magazine targeted to Black women, Woodward and Mastin (2005) found the magazine tends to endorse middle-class ideals of Black womanhood, however the magazine neglects to address the societal and structural issues affecting poor Black women. Additionally, in an analysis of fifty-six music videos featuring Black women performers, Emerson (2002) found Black womanhood was presented as one-dimensional, where Black women were only seen as young eye candy, pregnant women, mothers, and anyone over thirty being seen as less desirable. These studies illuminate the ways Black women and girls are engaging with media that is not representative of their realities.

According to Cosby (1994), there has been a systemic exclusion of positive images of Black women throughout various forms of media, such as television, art, movies, textbooks, and magazines. Mckoy (2012) argued stereotyping is used to make distinction between the socially acceptable and unacceptable where stereotypes "grasp hold of those few vivid, simple, memorable and widely recognized characteristics about an individual, reduce the entire person down to those 
few traits, exaggerate them to simplify them, and then fix them without a chance for change or development" (p. 128). Harris (2015a) argued there is a quadrant of existing dominant stereotypes about Black women, the Mammy, the Jezebel, the Sapphire, and the Matriarch. The next few subsections will explore each trope.

\section{The Mammy}

The residual effects from slavery have had an impact on the formation of media representations of Black women, specifically the Mammy. The Mammy image was birthed in the slave era, where Black women were nurturing caretakers and domestic servants (West, 1995; McKoy, 2012). The Mammy caricature debuted in 1914 to "soothe the fears of a changing White America and nostalgically remember the antebellum South" (Slatton, 2014, p.17). The Mammy is depicted as an overweight, large breasted, asexual, cantankerous, but motherly woman (Bogle, 2001; Chen, Williams, Hendrickson, \& Chen, 2012; Love, 2014). Mammies were portrayed as jolly, good-tempered and willingly subservient to the white family she worked for (hooks, 1981; Bogle, 2001). The Mammy's appearance is in direct opposition to that of white beauty standards; fat, unattractive and dark skin (Sewell, 2013). The Mammy image gained popularity following Hattie McDaniel's portrayal of the character in Gone with the Wind.

In 1939, Gone with The Wind was released nationwide. The novel turned film presented the story of love and antebellum South. Gone With The Wind received critical acclaim garnering thirteen Academy Award nominations. The film went on to win ten of those thirteen nominations. One of those wins included "Best Supporting Actress" which was awarded to Hattie McDaniel for her role as "Mammy", which made McDaniel the first Black person to ever receive an Academy Award. While Daniel's win is a gain for all Black actors, her win was met with criticism from the Black community as they felt her role perpetuated the image of the Black woman as the domestic servant of white people (Sturtevant,1999). Economic realities restricted Black women from being 
free from their roles in the kitchen (Taylor, 1998). White people liked and supported the image of the Mammy because it portrayed Black womanhood through a sexist and racist lens (hooks, 1981). Scholars (hooks, 1981; Slatton, 2014) believe the Mammy is a figment of the white imagination and is the ideal construction of the Black woman according to white people. The Mammy portrayal does not threaten the existing white patriarchal social order (hooks, 1981). hooks (1981) adds that the Mammy is believed to dispel white women fears of interracial relationships between white men and Black women due to her asexual presentation. Slatton (2014) adds that the Mammy represents a woman who will pass on the same ideals of subordination to her children, which would maintain white patriarchal superiority.

The Mammy trope was created and has been maintained to rationalize the dislike for Black women's physical appearance, particularly for darker-skinned women (Balkum, 2021). While the Mammy is still very present in the media today, it has taken a more masculine shift (Love, 2014). Tyler Perry’s "Madea” stage plays and films and Martin Lawrence's "Big Momma's House" both exemplified the masculinization of the Mammy image. These portrayals of Black men in women's costumes reinforce and perpetuate the Mammy stereotype of being unwanted and asexual (Love, 2014). Chen, Williams, Hendrickson \& Chen (2012) found male Mammy characters can be more damaging for Black women because it robbed Black women of their own identity and could be detrimental towards one's body image, particularly for Black women who do not meet female beauty ideals. Portrayals of the Mammy are still very present today. Aunt Jemima, the known face on the pancake mix box, is the most visible representation of the Mammy stereotype. In 2020, public disapproval led to the removal of the pancake mascot.

\section{The Matriarch}

In 1965, Daniel Patrick Moynihan wrote The Negro Family: The Case for National Action. Moynihan (1965) challenges the Black familial structure. In this report, Moynihan highlighted the 
increase in women-led families within the Black community, attributing this phenomenon to a rise in unemployment, poverty, and welfare dependency. Moynihan's report aided in sparking media portrayals of Black women as the Matriarch. Moynihan used the Black matriarch image to criticize and pathologize Black women for being an economic provider in the Black family (Slatton, 2014). White people ignored the systemic racist societal structures that forced Black women to enter the labor force and assume nontraditional roles for the sake of family survival. However, white women in the same predicament were not subjected to such ridicule. Hooks (1981) wrote, "when White women enter the workforce today it is seen as a positive step, a move toward gaining independence, while more than ever before in our history Black women who enter the workforce are encouraged to feel that they are taking jobs from Black men or de-masculinizing them" (p. 83). Through these acts of survival, Black women came to realize their strength, hence the "strong Black woman". According to Slatton (2014), the construction of the matriarch image allowed blame to be placed only on Black women for their economic and familial problems.

\section{Strong Black Woman}

The strong Black woman stereotype is unique because it is viewed as positive trope amongst many Black women but is also an added stressor for others (Harris-Perry, 2011). This stereotype originated as justification for the physical and psychological strength of Black women during slavery in comparison to white women (Harrington, Crowther \& Shipherd, 2010). Black women have reclaimed their strength under the guise of positivity (Harrington, Crowther, \& Shipherd, 2010). The strong Black woman stereotype intersects the identities of being a woman and being a Black person, which results in a unique collection of experiences and expectations that are different from Black men and white women (Baker, Buchanan, Mingo, Roker \& Brown, 2014). Melissa Harris-Perry (2011) argued that the strong Black woman stereotype shares characteristics

of the three dominant stereotypes, Mammy, Jezebel and Sapphire. Harris (2015) supports this by 
stating Black women are work-houses, that are over-educated, tired mothers without assistance, undesirable, something to fear, and unable to show emotional or physical weakness.

Strong has become the default category when describing Black women because it acknowledges Black women as tough, independent, and invulnerable (Harris-Perry, 2011). In a conceptualization of a Strong Black Woman Collective theory, Davis (2015) argued Black women's strength happens individually through communication practices through the utilization of distinct communication strategies, such as code-switching. As a collective, Black women utilized these strategies to adapt and empower themselves against oppressive forces and to conceal their emotional lives. Corbin, Smith, and Garcia (2018) argued that the "Strong Black Woman" trope is a coping mechanism for being considered angry, which then blurs the lines of oppression and self-definition. Internalization of this stereotype has emotional and psychological consequences, which leaves Black women sicker, less satisfied, and more burdened than any other group (Harris-Perry, 2011; Settles, Pratt-Hyatt, \& Buchanan, 2008). Additionally, out of fear of not appearing strong, Black women often silence themselves (Woods, 2013). West, Donovan, and Daniel (2016) framed their work using an intersectional lens to analyze the internalization of the Strong Black Woman stereotype amongst Black college-aged women. Participants in their study aspired to become the strong Black woman but were also aware of the negative health effects associated with the image, acknowledging the juxtaposition of strength and weakness. The strong Black woman stereotype makes it difficult for others to see Black women and, most importantly, makes it difficult for Black women to see themselves (Harris, 2015).

\section{The Jezebel}

The Jezebel is the antithesis of the Mammy representation (Sewell, 2013). The Jezebel image also began during slavery. bell hooks (1981) argued the Black enslaved women experience is entangled with racist and sexist oppression. Enslaved women were constantly aware of their 
sexual vulnerability and lived in fear that any male, Black or white, could victimize her (hooks, 1981). This sexual vulnerability led to the rape of Black women, which became an institutionalized method of terrorism that demoralized and dehumanized Black women (hooks, 1981). The sexual exploitation of Black women persisted long after slavery and was later institutionalized as a means of social control (hooks, 1981).

The Jezebel was believed to be a seductress who would seduce her slave master. However, Black women were being raped by their slave master and were, then. being blamed for their own rape (Muhammad \& McArthur, 2015). The Jezebel stereotype was used to excuse and justify the rape of enslaved women by the slave master (Burrell, 2010). Contemporary portrayals of the Jezebel uses her sexuality to exploit men's weakness for personal gains (McKoy, 2012). The Jezebel is often portrayed as a "light-skinned woman who has an amazing body, long hair, and is beautiful however, she is promiscuous and often uses sex as a tool to manipulate men and putting her in advantageous positions" (Tindall, 2012). Contemporary portrayals of the Jezebel include a young, promiscuous, over-sexed woman who uses sexuality for personal gain (Collins, 2000; Stephens \& Phillips, 2003). Burrell (2010) argued that female rappers today like Nicki Minaj, perpetuate the Jezebel stereotype by presenting sexually explicit music.

This stereotype purports the message that Black women are not suitable for relationships but can only be sexually desired (Tindall, 2012). For Black undergraduate women, this trope can impede their romantic relationships and attitudes toward dating (Henry, 2008). Additionally, this trope assumes that all Black women are promiscuous, which leaves Black women feeling exoticized, sexualized and objectified by men (Lewis, Mendenhall, Harwood, Huntt, 2016). 


\section{Hair and Body Image.}

The dominant portrayals of Black women in the media, but particularly the Jezebel trope, places great attention on Black women's bodies and physical appearance. he public image of Black hair and physical appearance

In her book, Hair Matters: Beauty, Power, and Black Women's Consciousness, Banks (2000) argued hair is how Black women make sense of larger cultural issues which aids in shaping our ideas about race, gender, class, sexuality, images of beauty, and power. Mercer (2000) argued that hair, just as skin color, is "the most tangible sign of difference" (p. 35) that is intertwined in privileging Eurocentric standards of beauty and creating a polarization between aesthetics in determining what is beautiful and ugly. Muhammad \& McArthur (2015) found Black girls, between the ages of thirteen and seventeen, felt they were negatively judged by their hair. More specifically, participants felt their natural hair was labeled as "bad hair".

\section{The Sapphire}

The Sapphire is the counterpart of the Mammy image, where Black women are evil, bitchy, stubborn and hateful (hooks, 1981). The name Sapphire comes from the 1950s television show Amos ' $N$ ' Andy, which began as a radio broadcast and later transitioned to television. Sapphire is depicted as "angry, emasculating, and loud" (Thompson, 2016, p. E6). The Sapphire image is sassy displaying the stereotypical body language of neck-rolling, eye-rolling and the hands on her hip (McKoy, 2012). The Sapphire representation is seen to be the most problematic because of the long history with anger and aggression amongst Black women. This stereotype is seen as a desire to control Black men, families, and communities but fails to acknowledge Black women's anger as a valid reaction and emotion which is used to shame and silence them (Harris-Perry, 2011). bell hooks (1992) argued the everyday, average Black woman rejected the image of Sapphire claiming "she was not us" understanding her frustrations but being displeased with the way she was mocked. 
For Black undergraduate women, feelings of invisibility from white peers and Black men, feelings of rejection, and stress lead Black undergraduate women to employ an intimidating persona which is displayed through anger and thus the maintenance of the "angry Black woman" (Henry, Butler, \& West, 2011).

Today, Sapphire is the "bitch" in misogynistic rap, who is money-hungry, and manipulative (Adams and Fuller, 2006). Even more so, the Sapphire is seen as uneducated, unpleasant, and the enemy of the Black man (Tindall, 2012). As a result of the Sapphire representation, many Black women censor themselves to avoid the depiction of the "angry Black woman" stereotype (hooks, 1981; West, 2008). The various reality television stars, such as Joseline Hernandez on Love and Hip Hop Atlanta and Tami Roman on Basketball Wives, are contemporary depictions of the Sapphire image.

The Sapphire, or "Angry Black Woman" trope is the most salient for Black women (Cox \& Ward, 2019). In analyzing the portrayals of Black women characters in 12 scripted programs, such as Insecure, Black-ish and This Is Us, Cox and Ward (2019) found, when on screen, Black women are often shown giving orders or commands, particularly when engaging in work-related actions. According to Cox and Ward (2019), these portrayals add to the narrative that Black women are bossy, sassy and embody being "The Sapphire".

Entertainment media is the most common source for information, misinformation, distortion, and stereotypes (Holtzman, 2004). The media images that are always on display are often created by individuals that are not representative of the characters. Even more so, the accessibility of various forms of media via the internet has led to an increase in data discrimination that maintains the status quo and privileges whiteness (Noble, 2018). The persistence of the static representations of Black women has been attributed to the lack of Black media makers. An examination of 234 original, scripted comedy and drama series across eighteen networks revealed 
$91 \%$ of showrunners are white and $80 \%$ were men with less than $5 \%$ of writers being Black (Hunt, 2017). The overexposure of the portrayals created by these media makers has a resounding impact on Black women, and Black undergraduate women specifically. However, research has found that Black-oriented media has a positive impact on Black women in regard to body image (Schooler, Ward, Merriwether \& Caruthers, 2004). Additionally, ethnic specific media is associated with an increase in ethnic pride and performance (Ramasubramanian, Doshi \& Saleem 2017).

It can be argued that representations of Black women are changing due to an increase in the number of Black women in leading roles, such as Kerry Washington as "Olivia Pope" of Scandal and Issa Rae as "Issa Dee" of Insecure. Wooten (2019) analyzed two popular sitcoms, Insecure and Scandal, to determine if current programming was deviating from historical stereotypes. While both shows do display characteristics of dominant tropes, they also differ in that they do not display Black women as one-dimensional.

\section{Impact of media portrayals on Black undergraduate women}

The perceptions of Black women seep into the public conscious making all Black women susceptible to the images even if they go to college (Morris, 2016). Given the prevalence of the tropes in the media, this research study questions how these portrayals can influence the experiences of Black undergraduate women. The previous section showcases how Black undergraduate women have a unique college experience. With the understanding of the tropes in the media and the unique experience of Black undergraduate women, this section explores the impact that media portrayals have on the collegiate experiences of Black undergraduate women based on the literature.

It is important to note that environmental factors can alter one's acceptance and internalization of the stereotypes in the media. One's sense of belonging to their ethnic group 
(Jerald, Ward, Moss, Thomas, and Fletcher, 2016), and knowledge of Black history (Adams-Bass, Stevenson \& Kotzin, 2014) have been linked to one's acceptance or dismissal of stereotypes about Black women. For example, in their quantitative study of Black college students, Jerald et. al (2016) found students with a greater sense of belonging to their ethnic group had weaker endorsement of the Jezebel and Sapphire stereotypes. Sullivan and Platenburg (2017) found consumption of Black media has both positive and negative effects where an increase in Black media can positively affect racial identity development but also decrease public regard where Black people believe other groups have negative attitudes towards them. As a minority group on college campuses, Black undergraduate women are navigating this tension. The literature reveals that media portrayals of Black women have the ability to impact Black undergraduate women in the following ways: activating stereotype threat, acting as a form of dominance, and causing Black women to dissemble where they shift between identities.

\section{Stereotype Threat}

One way in which Black undergraduate women are impacted by stereotypes is through stereotype threat. Stereotype threat describes the way widely known stereotypes about one's particular social group alter self-characterization when the individual is at risk of confirming to the stereotype (Steele \& Aronson, 1995). Steele \& Aronson (1995) argued the mere existence of a stereotype, particularly negative stereotypes, can cause targets of the stereotype to feel it is true of them and conform, influencing how they view themselves and how they are viewed by others. The concept of stereotype threat acknowledges that the target is not a passive victim and actively fights to resist stigmatization which, in some instances, can lead to the confirmation of the stereotype (Bonnot \& Croizet, 2011). Additionally, negative stereotypes are more salient and have the possibility of inhibiting performance (Sackett, Hardison, \& Cullen, 2004). Steele and Aronson (1995) found, while taking a standardized test, Black students experienced stereotype vulnerability 
causing them to underperform in comparison to their White counterparts. Much of the empirical research examining stereotype threat is connected to academic or intellectual performance (Steele \& Aronson, 1995; Steele, 2003; Bonnot \& Croizet, 2011) and reveals that women underperform, not only academically but professionally, in comparison to men (Shantz \& Latham, 2012).

The understanding that stereotypes can have detrimental outcomes on highly stereotyped groups draws comparison to the same effects that stereotypes portrayed through the media can have on groups of people, specifically Black women (Davies, Spencer, Quinn and Gerhardstein, 2002; Brown Givens \& Monahan, 2005). Davies, Spencer, Quinn and Gerhardstein (2002) showed stereotypical television commercials prior to taking a math test to both men and women, however the threat of the stereotype led the women to underperform. After participants watched video of stereotypical and non-stereotypical images of Black women, observed a mock interview of a Black and white women, and completed measures of implicit and explicit racial prejudice, Brown Givens \& Monahan (2005) found participants more quickly associated the Black interviewee with negative terms like aggressive.

In a qualitative study of 30 undergraduate Black woman, Neal-Jackson (2020) found that Black college women navigated stereotype threat in three ways, to dispel stereotypical behavior by offering a counterexample, to speak directly to peers about problematic assumptions, or to request faculty or administrative leadership address existing stereotypes. The women in this study used the strategy of dispelling stereotypes the most and utilizing institutional support the least. For the Black college women in this study, the utilization of these strategies was motivating and empowering but also illuminated the ways in which Black women are expected " to engage in burdensome peer education processes in order to survive these spaces" (Neal-Jackson, 2020, p. 330). For Black college women, the prevalence of these stereotypes can restrain them from 
engaging in conversations or debates and joining campus organizations, so they are not viewed as angry (Commodore, Baker, \& Arroyo, 2018).

\section{A Form of Dominance}

Another way in which media stereotypes impact Black women is by acting as a form of dominance that maintains their subordination. Representations of race are created within highly structured systems of power, which diminishes individuals with little power and influence (Jacobson, 2005). Patricia Hill Collins (2000) uses the term controlling images to discuss the representations of Black women. These images are used to justify the oppression of Black women by making social injustices, such as racism, sexism, and classism, appear normal and a part of everyday life (Collins, 2000). bell hooks (1992) affirmed this point by arguing Black women representations within the media influence how Black people are seen and interact with others. These representations work together to push forward a racialized misogynistic agenda that keeps women, specifically Black women in subordinate positions (hooks, 1992). Racialized hatred and sexism lie at the root of many myths that were used to and continue to stereotype Black women (Adams and Fuller, 2006).

Cultural images of African American women based on stereotypes are at the very foundation of Black people's limited access to societal resources and institutions (Collins, 2000). bell hooks (1992) argued a direct connection exists between the maintenance of White supremacist patriarchy and mass media images of Blackness that "support and maintain the oppression, exploitation, and overall domination of all Black people" (2). In turn, many Black people subscribe to the politics of respectability, a set of rules and beliefs that if they correct the traits (i.e., behaviors, speech, appearance) that are deemed bad they can "uplift the race" (Harris, 2014). Njoku and Patton (2017) found HBCUs promote politics of respectability in their support of heteronormative expressions of femininity, yet HBCUs also supported subcultures where students 
were able to construct and resist institutional policing of their own versions of Black womanhood. Adhering to these social policies often causes psychological stress, such as depression and anxiety, coupled with psychosocial experiences, like marginalization and negative stereotypes, can act as barriers in Black college women persisting in postsecondary institutions (Henry, Butler, \& West, 2011).

\section{Shifting}

Black women also shift between public and private identities to shield from affirming negative portrayals of Black women in the media. According to Jones and Shorter-Gooden (2003), Black women are constantly shifting between public and private identities. The caricatures of Black women in the media render Black women invisible because they are unable to show their authentic selves (Jones and Shorter-Gooden, 2003). The bombardment of negative stereotypes makes it difficult for Black women to develop a positive self-image (hooks, 1981).

Shorter-Gooden (2004) found that Black women employ internal and external strategies to cope with the stress of racism and sexism. For example, Shorter-Gooden (2004) found Black women sustained a positive self-image, relied on social support and spirituality, role flexed, diminished contact with certain people and situations, and stood up and fought back. Lewis, Mendenhall, Harwood and Huntt (2013) also found Black college women utilized resistance coping strategies, like using their voice and resisting Eurocentric standards, self-protecting coping strategies, like being a superwoman and escaping, as well as a collective coping strategy of relying on one's support network when handling gendered racial micro-aggressions.

Black women dissemble to protect themselves from existing myths about the Black women experience (Harris-Perry, 2011). According to Darlene Clark Hine (1989), Black women were forced into developing a cult of secrecy to protect themselves from racist, sexist, and classist discrimination. Black audiences have developed their own defense mechanisms to curb the effects 
of less favorable images within the media, which includes disassociating from negative characters, using in-group opposed to out-group comparisons, and understanding the prejudice attitudes of the media (Conrad, Dixon, \& Zhang, 2009).

\section{Theoretical Framework}

Black feminist theory and critical race theory are utilized to frame this research study with Black undergraduate women. Black feminist theory acknowledges the intersections of race, gender, sexuality, and class amongst Black women (Collins, 2000) while critical race theory challenges dominant discourse on race and racism (Calmore, 1992). These theoretical frameworks rightfully understand the lived experiences of being Black, being a woman, and the oppressive forces that act as barriers for the advancement of Black women. When paired together, Black feminist theory and critical race theory help our understanding of the experiences of being a Black woman in the United States.

\section{Black Feminist Theory}

Feminism is a particular view of traditional social and political thought which includes a critique of male superiority and centrality (Beasley, 1999). Feminist thought in the United States occurred in three waves, each having a different agenda (Scholz, 2012). The term wave is used to show that feminism is an ongoing project (Scholz, 2012). While feminism had an agenda to empower all women, the term itself implies that there is a single feminism although there are multiple feminisms (Campbell \& Wasco, 2000). More specifically, feminism failed to acknowledge women of color and poor women (Collins, 2000, Mowatt, French \& Malebranche, 2013). Women who most greatly experience sexist oppression were left powerless to conduct change within the movement (hooks, 2000) and the contributions of Black women, specifically, are often excluded from the history of feminism (Johnson, 2015). Black feminists and activists understood then, and understand now, that the combination of their racial and sexual identities 
make their life and political struggles unique (Combahee River Collective, 1977). Within each wave of feminism, Black women developed their own distinct consciousness as a means of empowerment (Taylor, 1998).

The first wave took place following the abolitionist and anti-slavery movements in the early to mid 1800s and focused on women being viewed as human beings, gaining civic, social, economic, and intellectual equality (Scholz, 2012). Although slavery was legally abolished in 1809, southern states depended on slave labor, maintaining racial inequality (Freedman, 2002). Black women were excluded from anti-slavery societies (Johnson, 2015) and as a result Black women, particularly in the North, created their own groups that, not only fought against slavery, but also racism and sexism (Freedman, 2002). Sojourner Truth was a prominent figure for Black women during this first wave of feminism. Truth delivered her historic speech titled “Ain't I A Woman?", comparing her experiences as a slave-born Black woman to the experiences of White women and interactions with White men. Truth addressed the marginality of Black women foreshadowing the Black feminist movement (Brah \& Phoenix, 2013). She argued that while she is a woman and mother, she is also working in the fields just as men and not receiving the same courtesies that are given to other women justifying the need for equal rights for men and women, as well as the abolition of slavery (Taylor, 1998). Truth's speech empowered Black women because it illustrated the ways in which race, gender, sexuality, and social class interplay (Taylor, 1998; Brah \& Phoenix, 2013). Her speech resonates because it reminds feminists that middle-class White women do not experience the full extent of subordination (Freedman, 2002).

Women's suffrage increased the tensions between abolitionists and feminists after the thirteenth and fifteenth amendments were passed (Taylor, 1998a). The thirteenth amendment legally abolished slavery and the fifteenth amendment gave voting rights to Black men. Utilizing scientific evidence to support their racial superiority (Freedman, 2002), White suffragists 
abandoned Black activists and the fight for womanhood (Taylor, 1998a). White abolitionists argued against slavery, not because it was inhumane or racist but for moral reform and White suffragists maintained similar sentiments (hooks, 1981). White women were unwilling to reject white supremacy for the greater good of all women (hooks, 1981). Suffrage groups began purposefully excluding Black activists from leadership positions (Freedman, 2002). Black leaders, like Ida B. Wells-Barnett and Mary Church Terrell, relied on the women in northern states for support and began establishing organizations for Black women (Freedman, 2002). Black women soon realized that women's suffrage was used as "a weapon to strengthen white oppression of Black people" (hooks, 1981, p. 172). Black women were now fighting to, not only, improve conditions for all Black people, but also for equality with white women, and the right to vote (Freedman, 2002).

The civil rights and student movements influenced the second wave of feminism, believed to have begun around 1948 and reached its peak in the late 1960s, shifting the focus away from basic human and civil rights to sexist and physical oppressions (Scholz, 2012). Women's bodies are sites of "domination, stereotyping, violence, and oppression" which helped to shift the scope of the movement to include women's physical experience (Scholz, 2012, p. 6). During second wave feminism, feminist scholars began to question exactly whose experiences were being placed at the forefront within the movement and came to the realization that feminism did not acknowledge the intersections of gender with other social identities (Shields, 2008). The women's liberation movement was met with criticism by Black women (Giddings, 1984). Economic conflicts between Black and White women arose (Giddings, 1984) due to Black women still being underpaid and exploited in domesticated work (Taylor, 1998). As the women's movement was on the rise, the deterioration of the Black civil rights movement was taking place as assassinations and internal conflicts were leaving many groups in disarray (Giddings, 1984). Black women were 
experiencing isolation from men, Black and White, and White women (Taylor, 1998). The National Black Feminist Organization (NBFO) was created after Black women were experiencing sexism within the Black Power movement and racism within the women's liberation movement (Taylor, 1998). However, NBFO did not have longevity because feminism became synonymous with White women and proved to be advantageous only for White women (Taylor, 1998).

Third wave feminism, starting in the mid 1990s, embraced multiplicity and diversity through identity, subjectivity, and thought (Scholz, 2013). Four trends were present during third wave feminism which are multiplicity and the rejection of norms, critique of the structures of thinking, use of popular culture, and political coalition building (Scholz, 2013). The exclusion of women of color led to the decentering of second wave feminism (Mann \& Huffman, 2005). More narrowly, Black women were still experiencing the same multiplicity of oppressions from White women and Black men that was experience during first and second wave feminism (Marbley, 2005). During third wave feminism, Black feminist were able to increase their reach into the legal realm helping to advocate on issues that directly impacted Black women (Taylor, 1998). Black feminists also prioritized women's health as well as challenging Black women's portrayal and treatment in popular culture (Taylor, 1998). In large part because of the racist and elitist historical weight that was attached to the word "feminist (Taylor, 1998), Black women were beginning to abandon the feminist movement (Springer, 2002). Black women were "coming to voice" and breaking their silence by confronting racism, sexism, and elitism in public (Collins, 1998).

Throughout the different waves of feminism, Black women were positioned as an outsiderwithin (Collins, 1986). The term outsider-within refers to individuals who are caught between groups of unequal power whether it be race, gender, class or a combination of various other social locations where they are at the margins (Collins, 1999). For Black women, this outsider-within positionality became most visible when they were employed to cook, clean, and care for the 
children of White families but realized they would never fully belong to, or be accepted by, the White families they worked for because of their race, gender, and class. This positionality offers a unique and marginal perspective, or standpoint, about self and society for Black women (Collins, 1986; Zinn \& Dill, 1996).

Black women developed a distinct standpoint to produce and validate their knowledge and experience (Collins, 2000). Standpoint theory argues that knowledge is constructed from a combination of physical location, history, culture, and interest and it is from this matrix that inquiry begins (Harding, 1998; Sprague, 2005). Nancy Hartsock and Donna Haraway are two of the major contributors to the development of standpoint theory, however these authors did not acknowledge the difference in the experiences of women (Hekman, 1997). A core theme within Black women's standpoint is the legacy of struggle (Collins, 1997). Despite differences in age, location, class, sexual orientation or historical era, Black women are bound together in their struggle against racism and sexism (Collins, 1997). A single woman's perspective ignores the important differences amongst women which perpetuates inequality (Catherine, 2010; Heckman, 1997).

Black women are unable to analyze their own lives and thus unable to define politics to help end their own oppression without race and gender (Combahee River Collective, 1977). Furthermore, elitism and racism created obstacles that marginalized the participation of women of color within the feminist movements and their journey to liberation (Combahee River Collective, 1977). Therefore, experiences of racism, sexism, and classism encouraged Black women to develop an intellectual framework that addressed how systems of power, such as race, gender, sexuality, and class intersect to produce inequality (Chepp, 2015). This framework came to be known as Black feminism.

Black feminist theory was developed out of the need for a framework to accurately describe the experiences of Black women (Few, Stephens, \& Rouse-Arnett, 2003). Black women's 
experience and involvement in other liberation movements revealed a need for antiracist and antisexist politics that was not comparable to White women, White men or Black men (Combahee River Collective, 1977). Venus Evans-Winters (2019) defines Black feminism as "a theoretical, methodological, and political discourse steeped in a tradition that centers the voices of Black women's socio-political struggles in a White supremacist, capitalist, patriarchial imperialist society that privileges Whiteness, maleness, and wealth" (p. 18). Black feminism critically challenges institutional, structural, cultural, and ideological systems of oppression to intersectionally analyze the experiences of Black women (Gist, 2016; Mowatt, French and Malebranche, 2013). Black feminists are actively and simultaneously fighting against racism, sexism, and poverty (Taylor, 1998). Black feminism is centered around the belief that the lives of Black women cannot be understood without examining how race, gender, and class are concurrently impactful, that the experiences of Black women are often marginally defined and discussed in relation to maleness and White femininity, and that Black women's lived experiences are a site of legitimate knowledge (Edwards, Esposito, \& Evans-Winters, 2017). Black feminism acknowledges the direct correlation between experience and consciousness (Woodard \& Mastin, 2005). Black feminist theory helps to contextualize Black girlhood and womanhood by examining the mind and social experiences of Black women (Lindsay-Dennis, 2015). The goal of Black feminism is to form a political movement that challenges exploitative capitalism and develops institutions to protect Black bodies and minds (Taylor, 1998). In doing so, Black women create oppositional forms of knowledge through their lived experiences and their own voices and stories.

The seminal work of Patricia Hill Collins helped develop a framework for examining the experiences of Black women. Patricia Hill Collins' (2000) notion of Black feminist thought is a central part of Black feminism and Black feminist theory. According to Collins (2000), Black feminist thought essentially acknowledges the standpoint of being both Black and being a woman 
in tandem with other intersecting oppressions. Black feminist thought produces ideas which seek to clarify the standpoint of and for Black women and, in doing so, acknowledges the work of Black female intellectuals who seek to share the unique, and often common, experiences that Black women have to endure (Collins, 1986). The purpose of Black feminist thought is to resist oppressive practices as well as the ideas that are used to justify oppression (Collins, 2000). Black feminist thought seeks to empower Black women to resist intersecting oppressions that impact their experiences racial and gender identities (Collins, 2000). For most Black women, understanding one's self also includes an understanding of how intersecting oppressions of race, gender, sexuality and class shape lived outcomes (Collins, 2000). Black feminist thought rearticulates an awareness of Black women's culture and traditions that already exists by infusing new meaning and encouraging Black women to value their knowledge and experiences (Collins, 2001). Black feminist thought also helps Black women "survive in, cope with, and resist" (Collins, 2000, p. 31) injustices that result in differential treatment with the aim of finding a collective, selfdefined voice of and for Black women.

One tension of Black feminist thought is the notion that the experience of Black women is static. While Black women share commonalities in their experiences of being Black and being a woman, variations within these experiences exist. Collins (2000) affirms this tension by acknowledging all Black women will not develop this "group consciousness" (p. 25). While all Black women experience forms of institutionalized racism, the ways in which Black women acknowledge and respond to challenges facing Black women as a group differ greatly (Collins, 2000). With this understanding, I feel it is important to excavate and illuminate the individualized voices and experiences of Black women, particularly young Black women, as a means of not being grouped collectively. 


\section{Critical Race Theory (CRT)}

Conversations in America rarely acknowledged how race and racism are deeply intertwined in American culture, making it difficult to acknowledge racism as a system of oppression (Parker \& Lynn, 2002). Critical race theory was developed as a response to the failures of critical legal studies to address race, racism and the systems, particularly the judicial system, that maintained White supremacy (Tate, 1997; DeCuir \& Dixson, 2004; Delgado \& Stefancic, 2017). Within a critical legal studies framework, critical race theorists felt restricted in their abilities to analyze racial injustices and wanted to disassociate from the Black/White binary that silenced other People of Color (Yosso, 2005). Critical race theory also built upon insights present within the radical feminist movement by analyzing the relationship between power, social roles, patriarchy, and other forms of domination (Delgado \& Stefancic, 2017). CRT is as a theoretical framework used to identify, analyze and change structural and cultural parts of society that marginalize people of color (Solórzano, 1997), which places race at the center of analysis (Roithmayr, 1999). Critical race theory highlights the ways race and racism perpetuate social disparities by specifically focusing on the effects of race and racism (DeCuir \& Dixson, 2004;Hiraldo, 2010). Additionally, critical race theory seeks to expose historical, ideological, psychological, and social contexts where it is believed that racism is no longer present (Parker \& Lynn, 2002). According to Parker and Lynn (2002), critical race theory has three goals: presenting storytelling and narratives as valid ways to examine race and racism, acknowledging race as a social construct and remove racial subjugation, and making connections between race and other forms of domination.

In Critical Race Theory: An Introduction, Delgado and Stefancic (2017) outline the basic principles of critical race theory. First, racism is an ordinary, common occurrence experienced by people of color and should not be thought of as an anomaly (Delgado and Stefancic, 2017). The permanence of racism suggests racism is a part of American culture and privileges White people 
over People of Color in almost all aspects of life (Hiraldo, 2010). White people in America tend to not see their political, economic, and educational advantages while People of Color have a clear view of the world that White supremacy has created (Taylor, Gillborn, Ladson-Billings, 2009).

Second, critique of liberalism derives from notions of colorblindness, neutrality of the law, and equal opportunity for all which fails to address the permanence of racism (DeCuir \& Dixson, 2004; Hiraldo, 2010). At the onset of critical race theory's inception, race and racism was closely connected to a conventional liberal model of law and society, which highlighted race-neutral concepts like "equal opportunity" and "merit" (Roithmayr, 1999). Myths, such as America being a melting pot, perpetuated color-blind ideology equipping those with political, social, and economic power with the language to argue for color neutrality (Steele, 1993). However, American history and politics has not been colorblind. As a result, race and racism is believed to be a permanent fixture in America's genetic makeup, governing all political, economic, and social domains (Decuir \& Dixson, 2004). Critical race theorists work to undress and uncover color-blind interpretations of the law which maintained White, European American hegemonic control (Parker \& Lynn, 2002).

Third, interest convergence suggests because racism often benefits White elites and exploits working-class people, society at large has very little motivation to get rid of the institutions, structures and systems that maintain it (Delgado \& Stefancic, 2017). Interest convergence is rooted in Marxist theory where the bourgeoisie would only listen to the proletariat, or the working class, if it were of greater benefit to the bourgeoisie (Taylor, Gillborn, LadsonBillings, 2009). The landmark case Brown vs. Board of Education of Topeka, Kansas (1954), which overturned the "separate but equal clause" in Plessy vs. Ferguson (1896), is believed to have occurred because it served the self-interests of Whites (Delgado \& Stefancic, 2017). The desegregation ruling took place at the height of the Cold War, with images of racial abuse 
spreading across the world via television and photography threatening the country's image as the model of democracy (Taylor, Gillborn, \& Ladson-Billings, 2009). The Brown vs. Board of Education of Topeka, Kansas ruling succeeded because the interests of Whites and Blacks converged at the time (Bell, 1995). However, the converged interests wanes when policy no longer meets the interests of Whites (Zamudio, Russell, Rios \& Bridgeman, 2011).

Fourth, critical race theory seeks to deconstruct the power of race being a social construct (Delgado \& Stefancic, 2017). Whiteness is considered a property interest because of the historical relationship the United States has had with race and racism had the role the legal system has played in the actualization of race (Capper, 2015). Additionally, it grants White people access to ownership which reinforces and perpetuates White supremacy (Hiraldo, 2010). Zamudio, Russell, Rios \& Bridgeman (2011) argue the value in being White is in the exclusion of non-whites from privileges only afforded to White people. The preservation of whiteness as property is maintained by ideologies of liberalism and colorblind racism (Zamudio, 2011).

Critical race theory also aims to give voice to the voiceless encouraging minorities to share their different histories and experiences with oppression from a perspective that is different from the dominant discourse (Delgado \& Stefancic, 2017). Counternarratives did not emerge as a result of CRT but rather CRT reached back to long-standing traditions of storytelling amongst oppressed groups (Zamudio et al., 2011). Capper (2015) defines counter storytelling as "a method of telling a story that aims to cast doubt on the validity of accepted premises or myths, especially ones held by the majority" (p. 795). Counternarratives are purposeful in redirecting the dominant gaze and placing emphasis on the positionality of oppressed groups within various structures in society (Taylor, Gillborn, \& Ladson-Billings, 2009). Additionally, Counternarratives dispel negative stereotypes by legitimizing the experiences of People of Color aiding in moving minorities from 
marginalized outsiders to active participants in America's history and their own histories (DeCuir \& Dixson, 2004; Hiraldo, 2010; Zamudio et al., 2011).

Lastly, intersectionality, coined by Black feminist legal scholar, Kimberle Crenshaw, is used as a critical lens to analyze discriminatory experiences on two or more markers of identity, such as race, gender or class (Garcia \& Ortiz, 2013). Crenshaw (1991) argued women of color have experienced patterns of racist and sexist acts as a result of the intersectional identity of being both a person of color and a woman, which leaves women of color marginalized within both. Collins (1998) defined intersectionality as "an analysis claiming that systems of race, economic class, gender, sexuality, ethnicity, nation, and age form mutually constructing features of social organization” (p. 278). According to Golpadas (2013), intersectionality has micro and macro definitions. Intersectionality on the macro level encompasses the multiplicity and interactivity of social identities such as race, gender, and class. At the micro level, it is implied, every person experiences social advantages and disadvantages due to their positionality at the intersection of multiple identities. Intersectionality highlights the various forms of oppression and the systems that reinforce them (Anderson \& McCormack, 2010). This particular research study will examine the experiences that lie at the intersections of race and gender but is also cognizant of the varying social factors that potentially meet at the same intersection, such as class and sexuality. Black women experience their social identities simultaneously

Critical race theory was largely utilized in legal studies research but has since transcended to other disciplines including education (DeCuir \& Dixson, 2004). Within education, CRT can be used as a tool to define, expose and address educational problems (Parker \& Lynn, 2002). Critical race theory is key to this particular research study because it analyzes the ways that race and racism directly impacts the lives of marginalized groups, particularly the structures, practices, and discourses (Yosso, 2005). The use of critical race theory as a framework for this research helps to 
understand the ways in which white privilege and white supremacy work in conjunction with media conglomerates to produce images of Black women, which can influence how Black women position themselves within higher education.

According to Solórzano and Yosso (2002) critical race theory helps to name and challenge normative forms of scholarship allowing those injured by racism to become empowered and provide a counter-story to the existing master narrative. Additionally Solórzano and Yosso (2002) argue, critical race theory critiques the status quo which often reduces the experiences of others to cultural foods, songs and dances. These authors criticize the ways in which the experiences of others are placed under the umbrella of multiculturalism not accounting for the differing perspectives that exist. A challenge to this tension is to address these differing perspectives head on.

Feminist theory accounts for the varying experiences of women. Even more so, Black feminist theory provides a collective voice of and for Black women (Collins, 2000). The pairing of Black feminist theory and critical race theory reveals when and where the racial and gendered identities of Black women intersect. Scholars (Wing \& Willis, 1999;Few, 2007; Evans-Winter \& Esposito, 2010) have used Black feminist theory and critical race theory together which is called critical race feminism. While critical race feminism expands upon critical race theory by adding an intersectional and gendered perspective (Childers-McKee \& Hytten, 2015), I have made the conscious decision to use Black feminist theory and critical race theory as two separate theories to frame my work. This decision is influenced by the need to examine the experiences specific to being both Black and being a woman. Black feminist theory is employed to analyze the experiences and voices of the participants, Black women, while critical race theory will aid in understanding how these women function within the system of education, and greater society, where whiteness has historically excluded Blackness (Ladson-Billings \& Tate, 1995). These theories work in 
conjunction to address racist, sexist, and classist conditions by which Black women are subjected to.

\section{Summary}

In this chapter, I shared the relevant literature in examining the media portrayal of Black women as well as the experiences of Black undergraduate women. The influence and impact of these media portrayals was also explored in this chapter. Additionally, I discussed the theoretical frameworks that will be used in this study, Black feminist theory and critical race theory. These theories are utilized because they acknowledge the standpoint of Black women while also acknowledging the structures of power which maintain oppression. The next chapter will explain how this research study was conducted including the research design, participants, data collection and analysis. 


\section{Chapter 3 - Methodology}

The portrayals of Black women in the media create a negative perception of all Black women. As explored in the previous chapter, media representations have the ability to influence Black undergraduate women's collegiate experiences. To understand the social construction of media images of Black women and their impact on Black undergraduate women, methods that will privilege the voices and lived experiences of Black women while naming the oppressive forces that maintain their persistence are necessary. The purpose of this research study was to examine how Black undergraduate women made meaning of Black women portrayals and scenarios and how these may have influenced their experiences in and how they navigated collegiate spaces. The research question that guided this study was: How do media representations of Black women influence the behaviors of Black undergraduate women? In engaging the questions and design of the study I was guided by Black feminist theory and critical race theory. An existing gap in the literature are the number of qualitative studies conducted to explore media effects on Black undergraduate women. A qualitative study was deemed most appropriate to answer the research question and to uphold the values and epistemological foundations embedded in these theories.

Black Americans have rightfully distrusted research in their communities due to racial discrimination and exploitation and, as a result, are not as receptive to being participants in research (Gamble, 1993; Freimuth, Quinn, Thomas, Cole, Zook, \& Duncan, 2001; Corbie-Smith, Thomas \& George, 2002). The Tuskegee Syphilis study exemplified this distrust in which nearly 400 African American men in the study were not informed that they were infected with syphilis (Freimuth et al., 2001). Black Americans have also been apprehensive about participating in research because of the uncertainty of how the results will directly impact their communities (Corbie-Smith, Moody-Ayers \& Thrasher, 2004). Few, Stephens, and Rouse-Arnett (2003) 
identified five ways in which Black women's experiences are "misrepresented, misappropriated and/or misconstrued" (Few, Stephens, \& Rouse-Arnett, 2003, p. 205) in research, including research is often from a deficit lens, Blackness is often compared to whiteness, lack of withingroup differences, quantitative findings about the effects of race typically control for race, and researchers using theories that do not account for Black women's experiences. Few, Stephens and Rouse-Arnett (2003) argued that when Black women researchers conduct research with Black women they must contextualize research, contextualize self in the research process, monitor symbolic power, triangulate sources, and care for the participants. As a Black woman researcher conducting research with Black women, I considered these recommendations to avoid misrepresenting, exploiting and endangering participants (Vanner, 2015). In this chapter, I outline how Black feminist theory and critical race theory are utilized to frame the research design. This chapter also outlines the procedures and data analysis used in this study. I also offer my positionality in explaining how I situate myself within this research.

\section{Critical Paradigm}

According to Merriam (2002), the goal of critical inquiry is to "critique and challenge, to transform and empower" (p. 327). According to Fossey, Harvey, McDermott, and Davidson (2002), the critical paradigm stems from socio-political and emancipatory traditions which prioritizes the social and historical origins and contexts of meanings. Critical research acknowledges that knowledge does not derive from objective inquiry but rather critical discourse. Additionally, critical inquiry illuminates the beliefs and actions that are oppressive with the intent to change and "confront those in power and expose the oppressive structures that subjugate people and create inequality" (Rehman \& Alharthi, 2016, p. 57). Critical race theory and Black feminist theory are two frameworks within the broader critical inquiry paradigm. 
Critical race theory and Black feminist theory affirm the experiences of Black women while acknowledging the historical structures that persist in society (Howard-Hamilton, 2003). Black feminist theory demands the centering of Black women's voices in order to challenge systems of oppression (Evans-Winter, 2019; Gist, 2016). More specifically, research with Black women must privilege the participants' voice by facilitating dialogue that allows them to name their own experiences. The use of dialogue and sharing of stories, particularly in the research setting, provide opportunities for healing but also communicates that Black women are capable of being generators and validators of knowledge (Lindsey-Dennis, 2015; Phillips \& McCaskill, 2006). Black feminist theory acknowledges that the intersections of race, gender, and class must be examined to understand the lived experiences of Black women, while also acknowledging lived experiences as legitimate sites of knowledge (Edwards, Esposito \& Evans-Winter, 2017). Thus, Black feminist theory recognizes that in order to truly understand Black women's experiences we must seek to understanding the multiple minority positions they occupy within society. Yet we must also recognize the diversity among Black women who shares gendered and racialized experiences but may differ in terms of class, religion, sexual orientation, education, as well as individual experiences. While applauding the gains that many Black women have accomplished despite the racism and sexism of our society, we must be steadfast in critiquing the systemic barriers that keep many Black women from achieving their goals (Mowatt, French \& Malebranche, 2013). Collins' (2000) outlined four Black feminist epistemological principles: (1) lived experience as a criterion of meaning, (2) use of dialogue in assessing knowledge claims, (3) ethics of caring, (4) ethic of personal accountability. The four principles informed much of this research design and process. The use of interviews in this study were to privilege the experiences of Black undergraduate women. 
For critical race theorists, racism is not something we need to study to see if people experience it. Rather, racism is a constant aspect of the lives of Communities of Color. How they experience racism and how they respond to it, though can be very different and must be studied. Critical race theory recognizes race as a social construct, that nonetheless functions as a real category in that people live their lives as racialized beings. Critical race theory, like Black feminist theory, also highlights intersectionality and seeks to reveal the connections between race and other forms of domination. Critical race theory grew from critical legal studies and radical feminism to address race, racism and the systems, particularly the judicial system, that maintain White supremacy (Tate, 1997, DeCuir \& Sixson, 2004, Delgado \& Stefancic, 2017). Additionally, critical race theory challenges dominant discourses on race and racism (Calmore, 1992). These theories work in conjunction to expose the ways in which oppressive forces, such as racism, sexism, and classism, act as barriers for the advancement of Black women.

Critical race theory notes that the histories of communities of color have been either excluded from history or told by the dominant group. This is an aspect of white supremacy - that the voice of white (mostly) men are those that become "naturalized" and made "superior", while counterstories are made invisible or delegitimized. For Black women this is especially troublesome given the significant social distance and power relations between white men and Black women. To speak for another and determine the ways in which they are defined has been a powerful way in which to distort Black history and herstory.

Dominant perspectives have dictated what is truth and knowledge, where there is difficulty for intellectuals and outsider to study and understand Black women's knowledge (Collins, 2000). Collins (2000) charged researchers that center Black women with using creative methods to understand, disseminate, and uphold Black women's knowledge. Thus, this study employed 
qualitative methods of interviews and focus groups but offered a different dimension in which we collectively watched clips from contemporary television shows. Qualitative methods produce data with a deeper meaning revealing an individual's views, experiences or beliefs (Gill, Stewart, Treasure \& Chadwick, 2008).

Unfortunately, what has often been used to study the media's effect on Black women have been quantitative studies where quantitative methods reduce the experience of African Americans to scales, or other measures, that are, generally, culturally incongruent (Few, Stephens \& RouseArnett, 2003; Lindsey-Dennis, 2015). Therefore, this study honored the perspectives and beliefs of Black undergraduate women by offering a space to have dialogue centered around their shared realities which may offer opportunities for participants to become empowered (Auerbach \& Silverstein, 2003; Russell, 2013).

\section{Qualitative research}

Qualitative researchers examine a variety of topics in natural settings in an attempt to understand how people make meaning of particular phenomena (Denzin \& Lincoln, 2011). Additionally, qualitative research exceeds quantitative research by providing an extended meaning to the data. Few, Stephens, and Rouse-Arnett (2003) explained, qualitative methods enrich empirical data by revealing the meaning behind the numbers. Qualitative research aids in our understanding of our lives, as well as the sociohistorical context within which our lives are situated (Merriam, 2002). Even more so, qualitative research offers academic inclusion to those deemed invisible in social research, such as women and People of Color (Leavy, 2015).

Qualitative research methods are used to gain an in-depth understanding of human behavior (Rosenthal, 2016). Interviews are the most common method for gathering qualitative data (King, 2004). Interviews (individual and group), provide a more holistic account of the social, political, 
economic and educational factors (Tillman, 2002), offering insight into the perspectives of others, which can reveal shared values in a particular community (Ochieng, 2010). Additionally, interviews are an effective way of soliciting and capturing an individual's or group's feelings, attitudes, and beliefs about their own lived experiences (Saldaña, 2011). By using qualitative methods, particularly in-depth conversations, participants informed me, as the researcher, of the experiences where race, gender, class, and sexuality intersect (Few, Stephens \& Rouse-Arnett, 2003; Stephens \& Few, 2007).

\section{Culturally Responsive Narrative Inquiry}

According to Berryman, SooHoo and Nevin (2013), culturally responsive research is the collaboration between researcher and participant in "carving out a liberatory research pathway toward mutual respect and freedom from domination" (p.4). Extending the work of decolonizing methodologies, culturally responsive research values the lived experiences of both the participant and the researcher in the co-construction of knowledge (Berryman, SooHoo \& Nevin, 2013). Additionally, in culturally responsive methodology, individuals engage in a relational and dialogical relationship that honors and supports one another (Berryman, SooHoo, Nevin, Ford, Nodelman, Valenzuela \& Wilson, 2013). Culturally responsive approaches place Black people at the center of the research rather than at the margins by acknowledging intersecting oppressions, understanding, and responding to unequal power relations, and validating their experiential knowledge (Tillman, 2002). To resist the margins in research, Black women reclaim their knowledge by using different ways of producing and constructing knowing, which, in turn, validates and affirms the authentic experiences of Black women (Collins, 1990; Few, Stephens, \& Rouse-Arnett, 2003). 
This research study sought to challenge the traditional colonizing approach to research that has often characterized research on Black communities. The goal was to engage in research with Black women by recognizing the important experiential knowledge Black women possess and the importance of their interpretations of their own lived realities. The theoretical frameworks in which this study is situated centers providing space for the oppressed to express their experiences and realities (Ladson-Billings \& Tate, 1997). Narrative inquiry analyzes the stories people tell to better understand the meaning of their experiences (Merriam, 2002). With storytelling being an integral part of Black culture as well as the uses of one's voice being a key component of Black feminist theory and critical race theory, oral narrative inquiry worked best with this research design in that it privileged the participants voice in naming their own experiences, through their own language, and allowed us to collectively engage in the topic together. According to Etter-Lewis (1993), oral narrative preserves one's words and perspectives in an authentic way. Duncan (2005) argues that the stories of people of color are necessary to disrupt dominant discourses around racial inequity in schools and in society, as well as challenging existing narratives about the schooling experiences and outcomes of students of color. Robinson (2013) used oral narratives to examine the educational experiences of Black women graduate students and how they deal with acts of racism and institutionalized oppressions.

An important part of my narrative inquiry was the elicitation of counter-stories. However, counter-stories do not have to be in opposition to dominant stories, rather they are a telling of different stories (Prendergast, 1998). Counter-storytelling, an essential feature of critical race theory, is used to expose and challenge dominant discourse (DeCuir \& Dixson, 2004). Additionally, critical race theory emphasizes storytelling and narratives as valid ways to examine race (Parker \&Lynn, 2002). Defined by Delgado and Stefanic (2002), counter-storytelling, is a method of telling a story that "aims to cast doubt on the validity of accepted premises or myths, 
especially ones held by the majority" (p.144). Solorzano and Yosso (2002) define counterstorytelling as a method of telling the stories of the marginalized, or those people whose stories are not often told, as a means of "exposing, analyzing, and challenging the majoritarian stories of racial privilege" (p. 32). Majoritarian stories, or master narratives, shape dominant discourse resulting in the acceptance of universal truths about particular groups. DeCuir and Dixson (2004) add, "the use of counterstories allow for the challenging of privileged discourses of the majority, therefore serving as a means of giving voice to the marginalized" (p.27). Counterstories illuminate the experiences of people of color, offering insight into their world while deconstructing and challenging dominant assumptions and beliefs about people of color.

In this critical inquiry, I drew on theories the highlight the existence of racism and sexism (and other oppressive identities) in the lives of Black women and drew on methodological theories and approaches that allow us to learn about how these oppressions manifest for Black undergraduate women. This critical approach demanded that I seek out methodologies that also challenged the tradition of researching on participants rather than with participants. Here culturally responsive narrative research helped me to engage with participants in ways that honored their knowledge and their interests and that would produce work that could inform on ways to improve social conditions for Black undergraduate women and the Black community overall.

An important aspect of this research study was the intentionality behind the research design. I sought to center the voices of Black women and their lived experiences. This research study utilizes the frameworks of Black feminist theory and critical race theory because they challenge the "naturalness" of whiteness and guided me to hear the stories of the Black undergraduate participants in their own voices. In this study, I employed the use of qualitative 
methods, specifically interviews, where the women offered first-hand accounts of their lived experiences.

\section{Methods of Study and Procedures}

\section{Participants}

Thirty women volunteered their time to discuss their college experience. Some of the women in this study were current college students, while others graduated over twenty years ago. Participants eligible for this study met the following criteria: (a) identified as Black/African American, (b) identified as female, (c) were enrolled at the time of the study or a graduate of an undergraduate program, and (d) were at least 18 years of age. Many of the participants in this study attended post-secondary institutions in California, but there were participants from all regions of the United States. Of the thirty women, five attended historically Black universities for their undergraduate studies. This is an important distinction because the women's experiences from historically Black colleges and universities offer a great comparison to those of predominantly white institutions.

Purposive sampling was employed as a means to gather participants in this study. According to Tongo (2007), purposive sampling is used when deliberately choosing a participant based on the participant's qualities. In this case, this study sought a very specific group, Black undergraduate women. Participants were recruited through a recruitment flyer (see Appendix C) shared on various social media channels, such as FaceBook, Twitter, Instagram, and YouTube via personal accounts. The recruitment flyer did help to recruit participants, but snowball sampling proved to be the most useful strategy in recruiting participants. Snowball sampling is a sub-type of purposive sampling, where interviewees helped to identify other individuals who have similar experiences (Rosenthal, 2016). Participants shared the recruitment flyer within their own personal 
networks. Another sub-type of purposive sampling, convenience sampling was utilized where participants who met the criteria and were easily accessible were invited to participate. because I was able to identify

In Table 1, you will see the names of participants, the geographical location of their institution, the years they attended, and their major. To protect the identities of all participants, key identifiers, such as names and universities, have been replaced with pseudonyms chosen by the participant with institution names being omitted.

\section{Table 1}

Participant Profiles
Name Institution
Years
Attended
Major
Ann- Private university in 2019 - present Communications
Denise Southern California
Davis Private university in 2019 -present Screenwriting Southern California

Gemma Private university in 2018 - present Film production Southern California
Lisa Public university in 2008-2012 Southern California
African-American studies and English
Monroe Private university in 2008-2012 Southern California
Communications with a minor in Film


Ashley Public university in 2008-2012 Interdisciplinary Studies Northern California

Tiffany Historically Black $2004-2008 \quad$ Child development and Psychology college in the Georgia

Destiny Private university in 2016-2020 Music

Southern California

Danyelle Private university in 2017 -present Accounting and Business Southern California Administration

Lydia Private university in 2019 - present History with a minor in Honors Southern California

Angela Private university in 2019 - present Integrated Educational Studies Southern California

Renee Public university in 2006-2010

Communications and Fine Arts in Ohio Electronic Media

Maya Pubic university in 2004-2009 Journalism and Theater Illinois

Stacy Private university in 1997-2001 English with a minor in Spanish Northern California

Nicole Performing arts 2014-2017 dance university in Philadelphia

Jaslyn Public university in 2009-2013 Sociology and Social Welfare Northern California 
Nikki Public university in 2008-2012 African-American Studies Northern California

Susan Private university in 2008-2012 Theater New York
Shardae Historically Black 2006-2010 Speech language pathology and university in audiology with a minor in community Washington D.C. development

Moesha Liberal arts college in 2009-2013 Psychology and Africana Studies Southern California

Zelda Historically Black 2014-2019 Communications college in Alabama

Jayonce Private university in 2007-2011 Political Science with a minor in Art Southern California/Historically Black university in Washington D.C.

Ciara Private university in 2015-2019 Biomedical Engineering New York

Anna Public university in 2016-2020 Social Work Florida

Rachel Public university in 2010-2014 Broadcast Journalism Montana

Daisy Historically Black $1999-2003 \quad$ Elementary Education university in Alabama 


Camille Public university / $1997-$ present Human Services
community college in
Virginia

Misty Public university in $2005-2009 \quad$ Health and Policy Administration
Pennsylvania

Samantha Public university in 2006-2013 Business Administration Southern California

Crystal Private university in 2008-2012 Applied Psychology with a minor in New York Sociology and Anthropology

\section{Semi-Structured Interviews}

The original research design included one individual interview with each participant and $\mathrm{x}$ number of participants. Following the individual interviews, the plan was to conduct five focus groups within which participants would watch clips from popular TV programs depicting Black female characters. However, after conducting seven in-person individual interviews, a stay-athome order was placed on the state of California, due to the pandemic that took over the world during the year 2020. As a result, the research design had to be modified. The number of participants was increased to thirty Black women. The focus groups were scratched because the pandemc caused a great deal of fear and anxiety for many people who were dealing with loved ones getting sick, economic difficulties and other social concerns. I felt that the best way to ensure completion of data collection was to make the study as straightforward as possible. I also felt that participants already had much to deal with in managing their lives during the pandemic and did not feel that ethically I could ask them to give me any more of their time given the circumstances. 
Instead of the focus groups to watch the video clips, I showed the video clips to each participant within the context of the individual interviews. These individual interviews were semistructured and involved participants sharing their collegiate experiences and the participant and myself watching clips from three popular sitcoms featuring a Black woman lead character. Each of these interviews ranged from ninety minutes to two hours. and were conducted on the videoconferencing platform, Zoom. The increase in participants was largely facilitated by the accessibility of Zoom.

Interviews were hosted on the Zoom platform, in a private, password-protected virtual meeting, and were audio-recorded using a Homiar digital voice recorder. The artificial intelligence voice application, Otter.ai, was also utilized because of its ability to instantly transcribe audio recordings, which made it easier to review transcriptions and make any speech corrections, if necessary. The use of Zoom had its advantages and disadvantages. Zoom was a great research tool because it allowed communication with participants despite geographical location. Zoom was a widely accessible platform for all participants where they were able to join the virtual meetings from a variety of devices, such as a smartphone or a laptop, and was extremely user-friendly in the sense that if they were able to access the software there was little else that the participant had to do. Additionally, Zoom allowed me to share my screen, which allowed participants and I to collectively watch clips. With most technological software, there were instances where there were connectivity issues, where participants were unable to hear me or me being unable to hear them. In these cases, we would have to restart the application and Zoom meeting. The women were extremely flexible and understanding whenever faced with technology troubles.

Within a virtual space, it was important for me to make sure that the women were mentally prepared to speak on and revisit college experiences which may have been traumatic for some. 
Each interview began with a simple, but powerful question, "How are you doing?" Each participant was handling the pandemic in a myriad of ways and I did not want participation in this research study to be an added layer to their stress. I also wanted them to have a moment to share how they were feeling and unburden themselves, if necessary. It was through these simple interactions that I was able to build rapport virtually. Building rapport with the participants is one way to ensure they are comfortable enough to share their opinions (Goldberg \& Allen, 2015; Karnielli-Miller, Strier, \& Pessach, 2009). Establishing rapport helped to ensure a safe and comfortable environment that demonstrated my respect for and trust in the information the participants shared with me (DiCicco-Bloom and Crabtree, 2006).

Before beginning the interview, participants were informed of their rights as participants and the expectations of the interview (see Appendix A for interview guide). The participant and I reviewed the informed consent document, where I extended any explanations and answered any questions. Interviews began with obtaining demographic information such as what institutions were the women attending or had attended, what they studied or were studying, and in when they completed their undergraduate studies or current year in college. Many conversations naturally led to discussing how the women selected their institutions and areas of study. Some of the conversations also led to discussing their upbringings and high school experiences as it informed what led to their undergraduate institutions.

Semi-structured interviews were the best method for this research study because this approach does not require a rigid protocol, which offered flexibility to account for new discovery or elaboration during the interview process (Bailey, 2006; Gill, Stewart, Treasure \& Chadwick, 2008; Qu and Dumay, 2011). For example, one participant's analysis of a selected clip helped to inform a new line of inquiry that I did not previously consider. Semi-structured interviews also 
offered a shift in power away from the researcher onto the participant by allowing participants to influence the direction of the conversation (Karnielli-Miller, Strier, \& Pessach, 2009). For example, one participant used our interview time to also ask me questions, making the interview less structured and more conversational. The flexibility of semi-structured interviews allowed for this to take place. However, all participants were asked a version of the following questions as it saw fit within our conversations. The questions asked throughout the interviews were formulated based on the experiences of Black women presented in the literature. Sample questions and prompts included:

- What are your opinions about Black women representations in the media?

- How do you define Black womanhood? Which media characters exist, if any, that you believe represent Black womanhood?

- Tell me about an experience where you felt as though you might be playing into or fighting against stereotypical portrayals of Black women.

- Can you describe your experiences on campus as a Black woman?

The open-ended questions were intentionally designed to elicit answers that are longer than a single word (Bailey, 2006). By asking participants to revisit previous experiences through questions similar to "tell me about an experience where...", centers their own lived experience, which acts a counter-story to normative college experiences. In African American Literacies, Richardson (2003) argued Black women have a special knowledge, which out of necessity, was used to develop literacy and language practices to resist white supremacy and negative images. Baker-Bell (2017) contends that it is through these powerful literacy and language practices that Black women use storytelling to reflect on their multiple consciousness. The women in this study 
used storytelling of their lived experiences to share their experiences of being a Black woman on campus.

To understand how media portrayals of Black women influence Black undergraduate women, we collectively watched television clips and discussed how the scenarios in the clips were similar or different to their experiences as Black undergraduates. I established a criterion to narrow down the selection of shows. This criterion for show selection included: (a) features a Black woman lead character, (b) in current production or still on air, and (c) easily accessible on streaming platforms like Netflix, Hulu, and HBO Max. Women who participated in interviews prior to the stay-at-home order shared some of the shows that they currently watched and were considered when selecting the shows from which clips were to be shown. Using the criteria and the shows that I knew participants were watching, I selected three shows: Insecure (HBO), Mixedish (ABC), and This Is Us (NBC). Specific episodes were selected based on the character situations. Milkie (1999) found Black girls rely on other images of Black women as a source of comparison. Therefore, episodes were selected with the expectation that as Black undergraduates watched these shows they would be able to draw upon further similarities and/or differences between their experiences and the experiences of the television characters. Using the shared screen feature in Zoom, I displayed three sets of clips from each show (see Table 2 for episode summaries). In between show clips, participants and I would stop to discuss. Following each clip, we began our conversations with participants sharing what stood out to them in the clip. Due to the nature of semi-structured interviews, conversations varied by participant. For example, the clips shown elicited a different response in some participants in comparison to others. This allowed the interview to flow in whatever way the participant saw fit. 


\section{Table 2}

Television Clip Titles and Summaries

\begin{tabular}{|c|c|}
\hline Show and episode title & Summary (taken from network) \\
\hline $\begin{array}{l}\text { Insecure - Season 1, Episode } 3 \\
\text { "Racist As Fuck" }\end{array}$ & $\begin{array}{l}\text { Lawrence and Issa have a hard time returning } \\
\text { to their old ways. Lawrence learns that he } \\
\text { might have to take a lower-entry job and Issa } \\
\text { overhears her coworkers badmouthing her } \\
\text { beach day event behind her back. Issa's beach } \\
\text { clean-up event is a huge success and proves her } \\
\text { coworkers wrong. }\end{array}$ \\
\hline $\begin{array}{l}\text { Mixed-ish - Season 1, Episode } 3 \\
\text { "Let your hair down" }\end{array}$ & $\begin{array}{l}\text { After a teacher tells Rainbow to make sure her } \\
\text { hair is "neat" for picture day, she becomes self- } \\
\text { conscious and begins a complicated } \\
\text { relationship with her hair; Johan and } \\
\text { Santamonica struggle with their own hair } \\
\text { identity. }\end{array}$ \\
\hline $\begin{array}{l}\text { This Is Us - Season 4, Episode } 7 \\
\text { "The dinner and the date" }\end{array}$ & $\begin{array}{l}\text { In the present, Deja accepts Malik's invitation } \\
\text { to skip school for a personalized tour of } \\
\text { Philadelphia. Deja is grounded: in an attempt }\end{array}$ \\
\hline
\end{tabular}




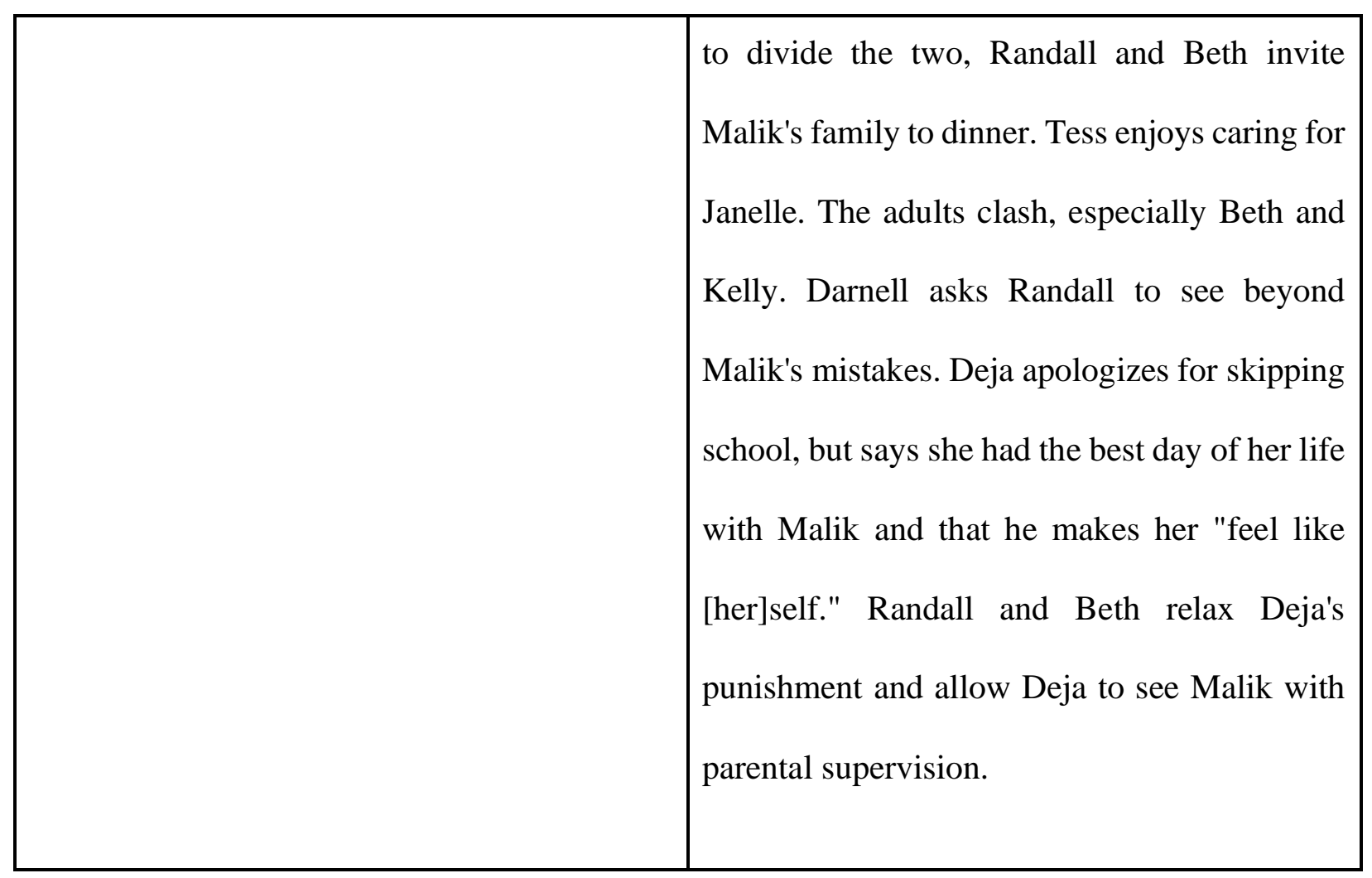

Following all single interviews, all participants were invited to participate in one of two virtual focus groups. Unlike the initial design wherein the focus groups had been planned for the purpose of showing and discussing the video clips, in the final design, the focus groups were added to provide space for further discussion of the clips and other discussion had during the individual interviews. Five participants participated in the first focus group and two participants participated in the second focus group. Women participating in focus groups were also advised to maintain confidentiality by not disclosing what was said during the virtual meeting with anyone else. Focus groups have been used in previous examinations when conducting qualitative research with Black women and the perceptions of the media. To analyze body image and societal pressure, Poran (2006) utilized focus groups with fifteen Black students. Few and Stephens (2007) utilized focus groups to examine Black preadolescents acceptance and usage of sexual scripts. According to Solorzano, Ceja and Yosso (2002), focus groups help to gain greater understanding of participants' 
experiences and beliefs about a particular topic. Collins (2000) contends Black women's relationships with other Black women contribute to self-definition practices, which can be affirming. The focus groups served as safe spaces for participants to continue the conversations from the single interview, while also building community with other Black women. The use of focus groups helped to redistribute power away from the researcher and to the participants. During the focus groups, I assumed the role of moderator. While I did have prompts to guide the conversation, the conversations flowed freely. Questions used to guide the focus group included:

- What connections can you make between the characters and your own experiences?

- How do you relate to these characters as Black women?

As in the individual interviews, during the focus groups I sought to remove or at least minimize my title as the "expert" and, instead, relied on and learned from the experiential knowledge of my participants (Auerbach \& Silverstein, 2013). Due to the nature of the conversations, where we were able to talk about topics about Black women candidly. The women who participated were also able to network amongst one another, in which they shared their social media handles to continue conversations amongst themselves. It was also asked to continue the virtual meetings, which is something that I have considered.

\section{Data Analysis}

To analyze the data from the interviews and focus groups, I conducted thematic analysis (Braun \& Clarke, 2006). According to Braun \& Clarke (2006), thematic analysis is a method of identifying, analyzing, and reporting themes within the data. When revisiting their initial approaches to thematic analysis, Braun and Clarke (2019) created a typology that encompasses three forms of thematic analysis which are coding reliability, codebook, and reflexive approaches. 
Reflexive thematic analysis acknowledges the researcher is a part of the research process (Braun \& Clarke, 2021). I utilized the six stages outlined by Braun and Clarke (2006) which include familiarization, coding, generating initial themes, review of themes, defining of themes, and reporting. The use of thematic analysis differs from other forms of analysis which are structured, rigid, and require the use of codebook but instead is more fluid and flexible (Braun \& Clarke, 2019).

In the first stage of analysis, I began by familiarizing myself with the data through transcription (Ritchie \& Spencer, 2002). With the help of artificial intelligence application, Otter.ai, I transcribed all interviews and reviewed them myself for accuracy. Following the transcription, I organized the data by identifying initial codes (Bailey, 2006) through line-by-line coding. According to Strauss and Corbin (1998), line-by-line coding is a form of analysis that involves a close examination of the data which allows for categories to be created quickly. After line-by-line coding a batch of transcriptions, recurring codes began to appear with different participants. Due to the size of the sample, I was able to utilize elements of constant comparative analysis. According to Glaser (1965), constant comparative method is a systematic approach to jointly coding and analyzing data. While constant comparative analysis is often associated with grounded theory, constant comparative analysis works well with a reasonably homogeneous sample (Boeije, 2002) where in this case the participants shared similar gendered and racial background. While there is no one way to conduct constant comparative analysis, I used comparison between interviews within the same group as outlined by Boeije (2002), where I identified patterns in the data. The intersecting identities of race and gender are important to the experiences of Black undergraduate women. I used thematic analysis to identify patterns around Black womanhood, attitudes about women in the media, and interactions with peers and faculty on campus. Themes were defined after careful review and will be reported in the next chapter. 


\section{Research Positionality}

The formulation of this research study stemmed from my own experiences as an undergraduate student attempting to navigate higher education. It was through the multiplicative experiences of being a Black woman that I came to understand my position in society

In this research study, I held an insider-outsider position in relation to my participants. I brought into the research my own experiences as a Black woman. As a Black woman researcher, I share commonalities of being Black and a woman with my participants. Johnson-Bailey (1999) reflected on her research process as a Black researcher working with Black participants and revealed race and gender fostered a sisterhood between herself and her participants. However, the experiences of Black women are not static and differ based on class, age and even colorism (Johnson-Bailey, 1999). My role as the researcher situates me as an outsider. Acknowledging this dual positionality allows for me to disclose where "self and subject become joined" (Peshkin, 1988, p. 17). For many Black researchers, their work is, what Lindsay-Dennis (2015) refers to as "an intellectual and spiritual pursuit of purpose" (p. 512). I entered this research process with my own understanding and internalization of how negative media portrayals of Black women constantly played in my head whenever I was engaged in class discussions or interacting with peers and faculty, thus affecting my actions within these spaces. I had my own assumptions that all Black women would have a similar experience.

Self-disclosing my own collegiate experiences as a Black woman helped to establish a trusting relationship with my participants (Few, Stephens, \& Rouse-Arnett, 2003). To create comfortability with the participants, I would offer my own experiences to affirm and agree with the participants' experiences. For example, I did not withhold reactions when a participant said something that I agreed with nor when I found something funny or disheartening. I did this 
sparingly so that my own experiences did not taint the research process or cause the participants to recoil. Sharing a similar identity of being a Black woman, who has and is navigating higher education, with my participants was advantageous because we saw the world through a similar lens or share the same worldview (Mercer, 2007). That is understanding that Black women are subjected to an additional layer of discrimination that unwillingly has outcomes on our daily experiences. Yet, this shared status, of being a Black woman pursing a post-secondary degree, did not guarantee that I would be viewed as an insider (Few, Stephens \& Rouse-Arnett, 2003; Jankie, 2004). While the experiences of all Black women are not static, according to Black feminist theory, a shared experience does exist (Collins, 2000) where my race and gender helped to create an unsaid connection. There is an underlying assumption that as a Black woman I would innately understand cultural colloquialism, such as many of the non-verbal cues that Black women often display. When conducting research in her native community, Jankie (2004) found her participants often positioned her as an insider in terms of the collective knowledge and beliefs they shared and was affirmed with colloquial language such as "you know", which also happened often throughout the interviews. Participants were also able to speak candidly and freely without judgment, which I attribute to sharing racial and gendered identities. Throughout this research study, participants alluded to a level of comfort with me that allowed them to share their most honest responses about their experiences. For example, many of the interviews concluded with participants sharing how therapeutic and empowering it was to share their own experiences because they had gone unheard for so long. This research process has been therapeutic for me as well because it affirmed that I was not alone in my experiences. Additionally, it allowed me to create a space that brought Black women together. 


\section{Trustworthiness}

A research relationship with participants is more than an exchange of information (Ferguson \& Ferguson, 2000). I established trust with my participants by being transparent about all aspects of the research process including their rights as participants. Participants completed an informed consent form, which outlined the purpose of the study and made participants aware of the risks associated with taking part in this study. Participants were also be given their rights and their options for opting out. Lastly, participants identities were protected through the use of pseudonyms. Participants picked their own pseudonyms to protect their identities, as well as to foster a relationship where participants felt comfortable to be open and honest. Each participant was emailed their signed copy of the informed consent document for their records. Transcriptions from this study were stored on a secured computer and will continue to be stored for up to one year following the completion of the research study.

I entered this research process knowing that much of the research on Black women is framed from a deficit lens. The data from this research was carefully analyzed to ensure that it was representative of the women that took part within this study. According to Schwandt (2001), triangulation is a way to check the integrity of the data through the use of multiple data sources, methods, investigators, and theoretical perspectives. The use of semi-structured individual interviews, watching television clips, and focus groups were used to ensure the data collected reflected the experiences of the Black undergraduate women who participated. I worked closely with my dissertation chair to ensure that the themes presented in the next chapter accurately represented the lived experiences of Black undergraduate women. To ensure I maintain the participant's authentic voice, participants were sent my analysis of the data collected to member check, or ensure, what was said during all previous interviews (Karnielli-Miller, Strier, \& Pessach, 
2009). Member checks are utilized to ensure truthfulness and authenticity, as well as adequacy (Reilly, 2013).

This research study was an extension of creating community and building relationships with other Black women. Many of the women in this study felt that sharing their experiences was therapeutic, particularly because their feelings and experiences were finally being heard. Due to the sensitivity of the conversations, it was important to establish trust with the participants. It was important for me to create relationships with my participants. To my advantage, being a Black woman researcher conducting research with Black women, I know participants felt comfortable being their most truthful and honest with me. Various participants expressed how easy it was to share their true feelings during our interviews. While all were not the most receptive, I have maintained open communication with the majority of the women that participated in this study, mostly via social media networks. For example, one participant contracted COVID-19 prior to our individual meeting, and I have and continue to make sure that she is well.

\section{Summary}

Qualitative methods were employed in this study because it best illuminated the experiences of Black women by honoring their distinct and unique voice. This research approach challenges dominant approaches to research and, instead, places the voices of the marginalized at the center. Through interviews and focus groups, I placed emphasis on the authentic voices of my participants. In the next chapter, I will present the findings of this research study. 


\section{Chapter 4 - Findings}

This study sought to better understand how Black undergraduate women define themselves, how they navigate collegiate spaces, and how these experiences align to media portrayals and scenarios of Black women. Being that people have preconceived notions about Black women based on their portrayals in the media and treat them accordingly (see Chapter 2), I wanted to examine how Black women confront such stereotypes and its influence on their undergraduate experience. This curiosity led to the formation of the research question that guided this study. The overarching research question was: How do media representations of Black women influence the behaviors of Black undergraduate women? This research question was operationalized by answering the following sub-questions:

1. In what ways did the Black undergraduate women define Black womanhood?

2. How did they feel about the representations of Black women in the media? In what ways did they respond to and/or resist specific tropes in educational spaces?

What were some of the coping mechanisms deal with negative portrayals?

3. In what ways did they feel supported, as Black women, by their institutions?

Through semi-structured individual interviews, I spoke with thirty Black women about their undergraduate experiences. We discussed their collegiate experiences and they shared stories that demonstrated an important savviness about media stereotypes and how these shaped their many experiences in college and with peers and faculty. We also watched clips from three current television series, Insecure, Mixed-ish, and This is Us, that feature Black women lead characters (see full description in Chapter 3).

It was clear to me from the data that Black undergraduate women occupy a unique social space wherein they are Black, a woman, and a student. The discussions I had with participants 
suggest that each of these roles were paramount in their lives. The participants' undergraduate experiences could not be divorced from their Black and female identities since these were often perceived to be related to societies' perceptions of Black women. I constructed various themes from analyzing the data. A strong theme had to do with Black undergraduate women believing that Black womanhood is multi-layered and multi-faceted, encompassing strength, struggle, and nurturing. Another theme was that there is a lack of Black media characters and that Black undergraduate women in this study felt they were constantly fighting “The Angry Black Woman" trope. A hopeful finding is that the Black women expressed that there is a shift happening, with greater and more nuanced characters of Black women being developed. Thus, women in this study were able to identify media characters that fit their ideals about Black womanhood, which revealed an emerging trope amongst the women in this study, The Proud Black Woman.

Themes related to their educational experiences carry significant policy implications. These related to how they navigated their existence on campuses and the extent to which and how they were and were not supported through their undergraduate institutions. As a result of constantly fighting the preconceived notions about themselves, the Black women in this study constantly negotiated between being invisible and hyper-visible on campus. Ultimately, the institutions for some of the participants did not sufficiently provide support that catered to their Blackness and Black womanhood, and, thus, they had to create spaces for themselves.

It is important to note that many of the participants attended predominantly white institutions. The themes were constructed with that framing in mind. The experiences of participants that attended Hispanic-serving institutions and historically Black colleges and universities was used in comparison to the other participants. 
"Being a Black woman is lit" - Lisa

\section{Black Womanhood is Multilayered and Multifaceted}

As discussed in Chapter 2, Black women have been characterized and stereotyped based on media representations that have been generally developed by white men, and to a lesser extent white woman, who create the stories and characters that shape information. Thus, in this study I sought to begin by giving participants' the space to define themselves as a collective group in whatever ways they chose. I asked all of the participants to define Black womanhood. For some of the women in this study, this was a difficult task where they stumbled over their responses unable to come up with a succinct answer. For others, adjectives flowed similar to an endless stream of consciousness. The variance in responses illustrates the nuances of Black womanhood.

One participant, Rachel, compared Black womanhood to Mother Earth drawing a parallel between the way in which Black women are treated and the way we as a society have pillaged the environment. She said:

All these great things come from Black women like how all these great things come from Mother Earth yet are treated poorly and it's deteriorating, and it's not appreciated, but we still keep giving and giving and giving all that we have. There's some advocates for it until there's not.

Here, Rachel is referring to the poor treatment of Black women, where so much is expected of us and taken from us, all the while not rightfully nor outwardly appreciated. Rachel acknowledges the support for Black women wans and fluctuates but nonetheless Black women have an understanding of who they are. Additionally, Rachel's comparison to Mother Earth signifies Black women as creators - creators of life, creators of trends. Another participant, Susan, shared a similar thought. She said, 
We are the creators of everything. Black womanhood is like the great mystery. It's a great mystery that people think they're solving with the way that they portray us or the way that they think they're advocating for us. We are the frickin well. The well that everyone thinks doesn't run dry. Black womanhood is expansive. It is vibrant. It is soft, and we must be allowed to be soft to really get back to our center, to be able to create.

In Susan's words, from the vantage point of non-Black people, Black womanhood is an unknown that people, including media makers, are unable to accurately depict or champion. Additionally, Susan also supported Rachel's point of Black women constantly being used without receiving anything in return with the analogy of Black womanhood being "a well", where things are taken from Black women but not replenished. Despite constantly being taken from, Susan recognized the variability among Black women - that we can be high-spirited and energetic but also faint and subdued.

Participants described Black womanhood as multi-layered and multi-faceted, with each Black woman having her own unique experiences but also understanding the experiences shared between Black women. The most salient shared characteristic of Black womanhood that participants referred to was strength, struggle, and nurturing.

Many participants expressed that the Black woman experience is not monolithic because it does not account for the nuance within the Black experience. Participants interchangeably used the terms multi-layered and multi-faceted to reference Black women's various identities, abilities, and experiences. In other words, all Black women cannot be singularly categorized because we all do not subscribe to the same ideals nor have the same experiences. For example, one participant, Nikki said,

There's so many types of Black women from different social backgrounds, economic backgrounds, cultural backgrounds, religious backgrounds, so what connects the theme of 
Black women is the struggle of not being heard or seen, and made to feel angry. A clear definition? I don't know. Because even me and you have different aspects of what is a Black woman but we have a shared experience as being Black women.

Here, Nikki points to the significant diversity that exists among Black women, which are fundamental differences that can affect experiences, opportunity structures, values and beliefs. However, she affirmed her belief in a shared experience between Black women that she believes is based on our experiences of oppression. In other words, racist, sexist, classist acts connects Black women to one another.

For Moesha, Black womanhood could be compared to "an onion because it comes with so many layers". Similar to an onion, Black womanhood is a complex structure with each layer revealing a different aspect of Black womanhood but each layer also acting as protection from the outside world. Another participant, Jaslyn, shared Black womanhood is “... dynamic and complex. Everyone is different but no one has just one layer to them. We all have these different parts of ourselves that exist but are not uniform at all." When asked her definition of Black womanhood, another participant, Maya said "It is diverse. It is beautiful and refreshing because of our different views, talents, and skills".

Many participants could not define Black womanhood in a single definition. The choice of words used to describe Black womanhood illustrates the complexities of being unable to narrowly define what it exactly means. This suggests the intricacies of Black womanhood. For example, one participant, Tiffany said, "Black womanhood is strange, it's power, it's empowering. It is subtle, it is resilient, it is loud, boisterous, it's quiet. It's so many things in a lot of ways. Some oxymorons." Another participant, Nicole, also shared many adjectives to define Black womanhood such as "power and resilience, patience, struggle, beautiful [and] unique". As Tiffany said, some of the 
words used together present as oxymorons, which attest to the existence of Black womanhood not being one-sided and encompassing varying aspects.

For some participants, there was an existing assumption that all Black people share similar experiences. However, class differences were particularly noted in college. After watching a clip from This is Us, where stark socioeconomic differences between Beth Pearson and Kelly Hodges ignites a verbal brawl, one participant, Davis, attributed class as a defining factor when trying to make friends with other Black women on campus. She said:

We had a Black History Month event last February and I met someone there. It was nice. We were from this same city or at least the city where my mom moved to recently, so we have that but it was still different because yeah we're both Black woman, but our experiences are different because of money, you know, which sucks. I feel like it's layers being here because, it's being a woman, it's being Black but it's also like I can't tell you about trips to Italy, or to Europe because I can't do that stuff. That felt like a block in our conversations because I couldn't relate to that aspect of her privilege, even though, in the base of it, it should be the same, but it wasn't.

Another, participant Shardae, recalled experiencing "culture shock within [her] own culture" while attending her historically Black college and seeing the range in economic and social hierarchies. She said,

I had this idea in my head of what Black people were like, just for my small community on the west side of Chicago. We all going to struggle, we all talk like this, we all dress like this, so I had this very stark idea in my mind. When I got to [college], I was in culture shock in my own culture. I was so surprised by the amount of rich Black people I was around, and I was friends with. All these folks from the Caribbean and I'm like, what are you even saying right now. Just the eclectic behavior and thoughts and being in classes 
with them it was, it was astounding to me. So that social aspect, I was ready to engage with anybody that I could, because I was such in this box, coming from one environment to [college] because I just assumed all Black people were one way. [College] totally dispelled that and I was eager to learn, and just explore friendships that were totally different than what I had.

For Shardae, her experience at her institution revealed a greater economic diversity among Black people than she had previously assumed. The exposure to different types of Black people uncovered different aspects of Blackness that she had previously not known, which affirm the within group differences between Black women supporting Black womanhood is multilayered and multifaceted.

Five participants in this study were second-generation American. Ethnic differences also contributed to illuminated the many facets of Black womanhood. One participant, Jaslyn, shared how her East-African parents raised her to believe that she was different from other Blacks but her college experience affirmed, no matter her cultural heritage, in this country she would be viewed as a Black girl. She expressed:

Before I got to college, my parents instilled 'you're not Black, you're Eritrean. We're different than these people. These people are bad. These people are dangerous.' My parents came to America not knowing anything so all that was based on what they've seen in the world and watching the news. I go to [college] and I show up as me, people don't see African, they don't see immigrant, they see Black girl. That was a harsh realization. It made me understand how powerful stereotypes can be. People didn't know me at all but that was assumed of me and it was how I had lived my life; my parents lived their life since they've been in the country [as] somebody told me this and therefore this is true. Being on the Afro floor, especially, just seeing how big and wide the Black spectrum is from immigrant to 
descendant of slaves, there was all of this stuff in this one space. But there's still this unifying factor that we're experiencing this world similarly where we're all being thrown all this extra problematic shit and it affects no matter who you are as long as you are of African descent.

College acted as a site of better understanding what it means to be a Black woman and how expansive Black womanhood is. As a result of their differing experiences, Black womanhood is multi-layered and multi-faceted. Yet, embedded in the experiences of being a Black woman is the notion that they encompass an innate strength. Additionally, for some of the woman in this study, their experiences in college revealed how nuanced Blackness can be. It is not one-dimensional and serves to include the identities, beliefs, and experiences of the entire diaspora.

\section{Black Womanhood is Strength}

Strength and strong was a recurring response amongst the women in this study. These two terms were used to describe the ways in which Black women are expected to maintain so many tasks at once. For example, Camille explained,

As women, we absorb differently than men do. We have to prioritize every feeling so that whatever happened at work, I didn't take it out on my family. If my family is going through something, I don't let it affect my job. We absorb a lot of energy, even when we try to block everything. I think to be a Black woman, you have to be so strong mentally to be able to compartmentalize everything that we have to go through.

For Camille, strength is displayed through her ability to juggle when and how she shows up for others. One participant, Anna, expressed a dislike for the word strong. Despite a dislike for the word, , strong was the first thing that came to mind for Anna in defining Black womanhood. She said, 
Being strong. I hate that word so much. I think that word is overused and is used to invalidate your feelings. For example, I went to counseling and after expressing my issues she was like, 'Oh, you're so strong. You're a strong educated woman'. That's not the problem. I hate that word, but strong comes to mind.

As she said, in her experience, strong was directly used to diminish and invalidate her feelings. Strong, although used here to encourage her, was used at a time when she needed support showcasing how Black women are not extended that luxury or grace. Ashley shared something similar by saying:

So strength, although unfortunately sometimes it feels like we always have to just be strong. Like 'get through it'. You don't really have time to sit down and cry or sit down and be like, 'Oh, man, let me just take a day' You what? A Black woman takes today the world may stop if we all took a day at the same time.

Here, Ashley alluded to the fact that Black women are unable to be anything other than strong. She illustrated how seeing oneself as strong and being seen as strong can be exhausting and can sometimes lead to being treated as if you are superhuman. This leads to Black women's inability to being seen as a regular human being.

The strength of Black women is both necessary and displayed at the intersections of being Black and being a woman. Destiny stated this well:

"all women should take no shit, but I feel more [for] Black women just because we have the thing about being a woman and also being Black. You have to be resilient and strong and fearless."

Stacy said something similar:

Black women have to wear so many hats in life that I feel like Black women are the strongest people on Earth. No other ethnic group has it harder than Black people and I think 
women have it harder than men, so I really think that Black women are the strongest people on the planet.

Angela, a freshman at a public university, shared a similar sentiment and added,

We have the pay gap, you got to worry about walking outside late at night, even walking around here. Then just being Black, racism. You got to be really strong to be one of us.

There is a particular expectation that is placed on Black women specifically that requires them to live up to the ideal of being strong. The women in this study acknowledge this. Although the word is not always favorable, strength succinctly describes Black women's ability to carry the burden of so many tasks while still being able to show up for themselves and others. The Black women in this study viewed strength based on how much Black women could endure while acknowledging that no other group of people possess the same strength. For the women in this study, in addition to their strength is their struggle, where it is understood that Black womanhood is challenging but are allowed to display their resiliency in the how they manage their burdens.

\section{Black Womanhood is Struggle}

As explained in the previous section, Black womanhood embodies an innate strength. Being that Black women are always expected to be strong, some of the women in this study expressed the various struggles that accompany being a Black woman. One participant, Lisa, shared,

We can understand your struggle. Sometimes we take on your struggle, which is not always the best, but we do. But we can just adapt to whatever, whoever and we are just literally amazing.

One participant, Lisa, explained our ability to connect with others and other experiences comes from an understanding of knowing what it means to struggle. Another participant, Tiffany, shared feelings of constantly having to prove herself. She said, 
Sometimes I feel like I'm fighting an uphill battle. I'm dispelling myths on Black people, Black women. You know, having to prove myself. I have a graduate degree. I am worthy to be in this space, to be in whatever job I have. I don't feel like we're given a lot of acknowledgement on some of our accomplishments. We're kind of pushed to be behindthe-scenes on a lot of stuff, not giving credit for some things and so, while there have been improvements made, I think we're always fighting to have our place and our voice be heard.

This never-ending fight that Tiffany described is a result of Black women being charged with having to exercise their strength in carrying the weight of so many things and living up to unwanted expectations. One participant, Jayonce, shared the strength of Black women comes from bearing the burden of the entire race, such as "the burden of Black men, bearing the burden of educating people about Blackness, [and] educating our own people about issues." Black women are constantly expected to teach others about the Black experience.

The struggle that Black women endure reaps no benefits. For this reason, the women in this study expressed feelings of being overlooked and undervalued. For Renee, being a Black woman is burdensome because we are "under-appreciated by everyone, White people, Black people, people of other races." Renee also added, "we're the last people on everyone's mind, but we always find a way to preserve and continue to do our jobs in excellence, all the time, even though we don't receive the praise or the support that we deserve." Another participant, Gemma, shared a similar opinion, "a lot of Black women do so, so, so, so much and they're only gonna get recognized for one thing or they get put down below people.” In Danyelle's words,

We're hard workers. I can tell you that every Black woman I know is a hard worker. Sometimes we're looked at a certain way and so we always have to fight the hardest to just prove that we deserve to be there and work harder than anybody else because for some 
reason we're underestimated when I feel sometimes we have the most to give in certain situations.

Black women are tasked with so many responsibilities that, no matter their performance, there is still the belief that they have to prove themselves others. The struggle for many of the women in this study is fighting the tension of over-achieving and succeeding with never receiving the proper recognition and applause. The expectations that are placed on Black women make Black womanhood tiring according to Crystal. She said,

I think Black womanhood is tiring. And not that it's a bad thing, I just feel everything we do, we get tired. She's the builder of the house. She's the strength of the house. She's what holds us together. She's the glue. She can do everything. She can cook. She can clean. She can work her ass off. It's tiring.

Lydia, a freshman at a public university, defined Black womanhood as tumultuous but acknowledges the ways Black women are able to turn turmoil into triumph. She said, Black womanhood is “very tumultuous, but I wouldn't have it any other way. I hate to fetishize pain or suffering, but it's just truly admirable to see how we consistently rise above, regardless of the circumstances." While Crystal expressed the exhaustion of being a Black woman, Lydia counters her point by illustrating the resiliency of Black women.

The strength of Black women creates what Zelda called a divine struggle, where Black women are seen as "the most hated and unprotected" while simultaneously seen as "being the most educated group in the country, being trendsetters, and providers". As Zelda eloquently stated, Black womanhood is in a constant state of being diminished while being praised and fighting through that tension. The Black women in this study associated strength with carrying the burden of maintaining the family and enduring pain. Despite the strength and struggle, there is a sense of nurturing within Black womanhood, where Black women care and support others. 


\section{Black Womanhood is Nurturing}

Another recurring response to defining Black womanhood was nurturing, which was often discussed in conjunction with strength. The women in this study expressed an admiration for Black women's selflessness where they are willing to support others even when that means they go without or are disadvantaged. Black women's strength is often showcased through our innate desire to care for others. Danyelle, a junior at a public university, said,

We're nurturers at heart. We're always trying to uplift other people even when sometimes we're the one that's getting the short end of the stick. We still find a way to nurture people. Another participant, Daisy, said

Naturally, too sometimes our downfall, you always want to take care of people. You always want to help people. I know many of us will give our last so someone else can succeed. Danyelle and Daisy revealed some, perhaps many, Black women innately want to help and take care of others even if it is to our own detriment. As both discussed, in our desires to care for others we often surrender everything we have, even if it means we give up our own desires.

Some of the participants in this study shared how their ideals of Black womanhood are a direct result of the nurturing from other Black women.

Many traditions, customs, and rites of passage are passed down from on Black woman to another. For Camille, her ideal of Black womanhood, comes "from years and years of being taught from this Black woman to this one, and you pick up a bag or two from them. So my daughters are picking up a bag from me. I'm picking up a bag from my mom." The bag references the acquired knowledge from one woman to another. For Monroe, Black womanhood is a type of nurturing that is often invisibilized and silenced. She said,

...this power that Black people who identify as women and Black femmes have to nurture themselves and nurture their people around them, sometimes it's viewed as weak. I don't 
believe that, I believe that there's this deep power in nurturing and protecting and of carrying a legacy.

Another participant, Shardae, eloquently shared the responsibility carried from one Black woman to another to build upon an existing legacy. She stated,

I think there is an asked and unasked responsibility to being a Black woman. You have to reflect on our past, in order to truly dissect where we are and the influence we're going to have on those after us. Be very intentional about how we're posturing ourselves in the moment or throughout our lives, to be the image of what we want those see come after us and that comes with a lot. That comes with the way in which we approach our families and households, the way in which we decide to walk and the way in which we enter a space even physically. A lot of it creates a narrative that we're either adding to somebody's narrative, we're creating our own narrative, or debunking another. So, it's multi-layered.

Here, Monroe, Camille, and Shardae illustrated that Black womanhood is not singular but instead comes from a lineage based in the care and well-being of others. From one woman to another, we are taught how to carry ourselves, how to maintain our homes, but more plainly, how to be a woman, with each woman adding her own to the existing story. As Black women age, we pass along information, or "bags" to other Black women, which serve to exemplify what it means to be a Black woman while offering the space for growth and development.

Although sometimes the expectation to care for others is placed on Black women, one participant, Ciara, believed that Black women need to begin to prioritize the self. She said, "For me, Black womanhood is really redefining the self, and definitely making sure that health, in terms of spiritual health, mental health, and financial health, emotional health is at the forefront because it's easy to let one of them slip." Black women always want to help others without prioritizing themselves. Ciara sends the charge to all Black women to become selfish. 
In summary, Black womanhood is not singular. For Monroe, there is collective power in our different experiences. Black womanhood encompasses an innate strength, struggle, and nurturing, which can be burdensome but showcases the resiliency of Black women. Additionally, Black womanhood is not one-dimensional but is multi-layered and multifaceted and connects Black women with one another through a shared experience.

\section{Black Women in the Media}

"I don't fit any of those stereotypes. I don't see myself in these characters" - Anna

Participants expressed the role the media played in creating the stereotypes and beliefs about Black women that they contend with in society. Lack of representation and distorted or monolithic representations are particularly problematic because they have an influence on the perception of all Black women. One participant, Destiny, explains "It's annoying because obviously the media plays a huge role in how those people who have never been around anyone else form their ideas about who you are". Tiffany, another interviewee, supported Destiny's point and added, "being a Black woman, I think that it affects us in a way that we feel we always have something to prove against that. You're fighting to not be those negative stereotypes and it can be draining". Additionally, Samantha discussed that media producers use Black women "as pawns to make money that pits us against one another" and presents Black women negatively. Another participant, Danyelle, shared a similar feeling about the way Black women are represented but added, "with some of the shows, I feel they're just making the cultural headcount." In these supporting roles, it seems as though media makers are trying to meet a quota as Danyelle explained. In doing so, these roles do not validate the Black women consuming this media. There is an apparent disconnect between Black women and current media characters that represent different types of Black women. 
Participants had difficulty identifying with and/or finding commonalities with present television characters. Some participants had trouble recalling Black women characters with whom they believed they shared commonalities. This trouble could be attributed to age, where the younger women in this study had a harder time identifying Black women characters with whom they could connected. The older women in this study typically referenced commonalities with the same few characters. This affirmed the lack of diversity in the ways that Black women are portrayed. Nevertheless, our conversations about Black womanhood seemed to provide participants with a process by which participants could identify media characters they felt exemplified their ideals about Black womanhood. Following conversations about Black womanhood, participants were asked if they felt any media characters, past or present, represented their ideals about Black womanhood. Many participants expressed that there has been and is a growing shift in the representations of Black women. For example, one participant, Crystal, said, I think that people are really stepping out of their comfort zones to show, yeah, we are loud, but it comes with this. Yeah, we are fighters, but we also nurture. We also do these things where we're this big bundle of everything. So, I do see the shift and the change in it.

Crystal's comment suggested that this shift has also led to the acceptance and celebration of Black women's bodies. One interviewee, Ann-Denise, shared, “It sounds really weird but I feel like Black women's bodies are being celebrated a little bit more. People are starting to appreciate a fuller-figured woman and seeing that it can be much more than just flat, stick figured women." Another participant, Misty, adds that there seems to be a shift in media producers as well by saying, "I do feel it's getting better because we have more Black women leading, and directing, writing, producing things", which offers better roles for Black women. 


\section{Media Characters Who Represent Participant Ideals of Black Womanhood}

Despite the changing media landscape, the women in this study still had difficulty creating connections with Black women media characters. As stated above, participants initially had difficulty naming media characters they could identify with but after discussion in our conversations, they were able to name one or more media characters they felt exemplified their own definitions of Black womanhood. Of the characters mentioned, a common characteristic amongst them all was their strength, ownership, femininity, and being a "bad ass". For many of the women, the character that exemplified Black womanhood was Claire Huxtable from The Cosby's. One individual, Samantha, felt Claire Huxtable was her "ideal Black woman because she was poised, and visibly showed acceptance of her family in whatever circumstance". Another participant, Crystal, said, "a lawyer, married to a doctor, all these kids, always got it together, always looking good, house clean, and she's always teaching life lessons. She did no wrong ever in the show". Claire's ability to maintain a reputable career, a stable marriage, mother multiple children all while maintaining a calming but warm posture supported the ideal that Black women are superhuman. Her character depiction was so flawless that viewers were left feeling as though she was inescapable of error. However, this is an unrealistic expectation of being able to juggle many tasks that is placed on all Black women.

The women of Living Single were referenced by some participants because the show displayed a group of Black women that were all completely different but were unified by their friendship. For example, one participant, Misty, shared Living Single "really show how being Black, especially being a Black woman, is not a monolith. You can be quirky and weird, you could still be really sexy, you could be the cool chick, who's into hip hop, you can also be a domineering career focused woman as well". For Monroe, the women in Spike Lee's movies personified her ideals of Black womanhood because they "speak up and speak out and have all of these opinions and are not afraid to say them". Another participant, Renee, shared a connection with Annalise 
Keating of How to Get Away with Murder and Molly from Insecure because they shared the same profession as well as "those women really work hard. They grind a lot, but they didn't necessarily see a lot of praise or support or consideration being heaped upon them in their stories".

Issa Dee from Insecure, a more contemporary portrayal of a Black woman, was a relatable character for many women in this study. For example, Moesha said, "she really shows how women are dynamic and come with these challenges and she's highlighted the life of a Black woman and it doesn't need to be like 12 Years A Slave". Another participant, Zelda, said she relates to Issa in her professional pursuits but also finds comparison in the moments where she minimized herself and did not see her own potential.

On the other hand, some participants identified certain Black woman characters, such as Rainbow from Blackish and Gina Waters from Martin, who had a privilege that they did not resonate with, particularly when discussing class. Class status aids in differentiating life experiences amongst Black people. With many of the women in this study being from workingclass families, class and social markers influenced their connection to certain media characters. For example, Lisa shared,

I love Bo. I do. I love her character on the show, but I don't identify with her as a Black woman. There are some things that I identify with her about, like the free-spirited Black person and not always being this stereotypical Black character who groups up one way and is always trying to fight that struggle. I didn't fight but there's a certain privilege in the show that she has, and I don't think sometimes she even notices it.

For Lisa, it was difficult for her to connect with Rainbow from Black-ish because of her privileges. Rainbow Johnson is presented as a bi-racial woman who often acts oblivious to the Black experience. This disconnect with her own identity is her privilege that goes unnoticed, according to Lisa. Another participant, Samantha, shared that Gina Waters "played the fence, in a way. Her 
parents were of privilege, but she wanted the reality of real life with Martin". Samantha alluded to Gina coming from an upper-class family but choosing to neglect the opinions of her family to be with Martin, who was from a lower social status. In this instance, Samantha felt Gina Waters was attempting to stake claim in two social classes, the upper middle-class, from which she was raised, and the working class, which her partner, Martin, represents. Participants in this study sought commonalities with Black characters who shared similar experiences to their own. When the commonalities were not present, there was a disconnect between the characters and the women in this study.

\section{The Influence of Media Portrayals on Black Women}

Participants expressed that there is a lack of diversity in the representation of Black women in the media. Static portrayals leave Black women minimized to simple categories. One participant, Stacy, felt there were two types of Black women showcased in the media, "the super ghetto or the exact reverse of the extremely bougie with no in-between". Bougie, short for bourgeoisie, is used here to describe a woman from the upper social class who, seemingly, exudes being well-mannered and having high standards. The antithesis of bougie, ghetto, is a colloquialism often used to describe the lack of manners and status, that is typically associated with people of color, but particularly Black people. Additionally, society automatically tends to view Black women through a ghetto lens. One participant, Lydia, felt that she was constantly fighting the stereotype of being ghetto, "whatever that means". In Destiny's words, "It's annoying because all of us not are Shaquiesha from the hood. I do like Hot Cheetos but we're not all her". The previous section illustrated the nuances of Black womanhood, but for Black women, everyday activities are demonized. As Destiny explained, it's possible to enjoy activities and, even the food, like Hot Cheetos, that would be deemed ghetto without the stigma being placed on all Black women. 
For Lydia, Black women characters seem to be "one dimensional and used as comedic relief". For example, Davis felt Black characters were comedic relief "to benefit white protagonists". She continues, "I don't think those further benefit us in feeling confident or valid in a room or in a space”. Black women characters, according to Lydia and Davis, have lacked depth and typically act as an accessory to white lead characters. The most salient stereotype Black undergraduate women are battling is the "Angry Black Woman", where the women in this study shared working harder to counteract stereotypical portrayals of Black people. To overcome the stereotypes placed on them, the women in this study worked harder, chose when and when not to code-switch, and were no longer subscribing to societal ideals about their physical appearance.

\section{Fighting Against the "Angry Black Woman.}

The "Angry Black Woman" is a looming trope that follows Black women across various spaces, but, in particular, during their schooling experiences. As we collectively watched clips from popular sitcoms, the women in this study were able to identify comparisons between some

of the scenarios and their own experiences as Black women in college. The Black undergraduate women in this study felt they were constantly fighting against the "Angry Black Woman" stereotype, which is analogous with the Sapphire trope. One participant, Monroe, shared, "any assertion of yourself is labeled as angry or aggressive by a world that doesn't create space for you, that's nuts. It can make you feel crazy".

According to the women, anger was always imposed on their words and actions, no matter what the women did or what they said. The women in this study were constantly aware of coming off angry during interactions with faculty, staff, and peers. One participant, Camille, stated Black women "can't have any other emotion but just being happy”. As a result, Black women have to be aware of their demeanor, words, and delivery so they are not perceived as angry. One participant, Lisa, shared, "Even if I say it with a smile, I'm cautious about the way I look. The way I come at 
things sometimes I have to lighten the blow because if I don't, I'm aggressive and I was rude and I was mean". Freshman student, Lydia, said, "it's like I have to bend over backwards to prove that I'm not gonna bite anyone's head off. I'm not aggressive or intimidating." Following a disagreement with a roommate, Angela, also a freshman student, felt her white roommates had preconceived judgments about her and was advised by her dad, “don't let them place you in the, 'oh you're the loud Black girl [box]"”. Another participant, Ann Denise, said, "there were a couple of times where I was like "don't be the angry Black woman", or "keep your voice down". If anything, "no I have a right to be upset and I have a right to be listened to."' These women have to self-monitor their actions so to not bruise the fragile ego of their peers. It left them questioning their own actions. For example, Crystal, who shared feelings of people being intimidated by Black women that are outspoken and vocal, questioned, "Why would I get angry? What have I done to let you have that idea of me or that perception of me that you can't come and just talk about something that we've discussed as a team?" The label of being angry forced the women in this study to internally mediate between when to speak up for themselves and others and when to remain silent as to not be perceived as angry or combative.

The participants understood that in their respective colleges, they often involuntarily become the spokesperson for all Black students because they were often the only person of color to occupy predominately White spaces. This looming stereotype of being hostile created a sense of self-doubt that the women in this study constantly had to negotiate. They had to make the distinction of when and when not to speak up to avoid being labeled The Angry Black Woman. For example, Jaslyn, felt she had to be hyper-aware of her words and actions in the classroom. She said, "I have to present myself in very particular ways. Let me not speak out in class. Let me not tell you that what you're saying is problematic because I don't want to be the angry one or fulfill those stereotypes because maybe I shouldn't be here in the first place”. Another participant, Davis, 
said she is always mindful of "not being the loudest in the room and [thinking] 'oh no, that might have come off as angry",. She continued,

It's really irritating being in classes and being the only Black person because I don't want to always have to be the person to educate an entire room. It's annoying when something happens, and everyone looks to me like "ooh is she okay with that" and I have to be the spokesperson. So that's annoying but at the same time I understand you have to say something if you want something to change.

Another participant, Ashley, expressed she also experienced instances of self-doubt, which stemmed from a fear of saying the wrong thing, but eventually stepped into speaking up by centering her own experiences. She shared:

I just do not like being the voice of [Black people] and I made it very clear when I did choose to speak because sometimes, I didn't want to say something wrong. Even in office hours, where it should be a safe space for all students to ask questions. be vulnerable, get the help you need, I would want to ask this, but I don't want to sound dumb, and then the next student would ask, and it would be the same question. But them being from whatever background, they didn't even have to second guess themselves. So, I would be very selective when I did speak, until later on in my undergrad career. I stepped into my thing like, "Look, this is my experience as Ashley and I'm not speaking for all of the Black women in America, in the world, but this is what I experienced. And I know some of my friends may have similar stories, if it is something that's similar". But then again, we're not everybody. There's a lot of finesse with the lingo that you say so that they know, or I try to make it clear, I am not the voice of the people. I'm for the people, but you can't literally take everything I say as this is what it is for everybody. 
As a student on the premed track, Ashley took many courses that looked at the racial disparities within healthcare. When disheartening statistics about Black people were presented, her peers often looked to her to offer some insight or explanation. Ashley had to make it clear that she was not the spokespersons for all Black people, but instead could speak to her experience as a member of that group. Both Davis and Ashley shared feelings of disliking being considered the spokesperson, but they also realized that being vocal, speaking from their own experiences, acts as a means to inform others and enact change.

For Renee, a graduate from a mid-western university, her professor seemed to be shocked by her choice to speak up when she challenged misinformation presented by the professor. In a discussion about civil rights protests, Renee's professor, who was also the head of the department, felt that Dr. Martin Luther King Jr. would be happy that cameras were able to document the injustices they were experiencing. When Renee spoke up against the professor's statement, she felt the professor was “taken aback by [her] vocalness and got very flustered”. She added, "but I felt like I had a duty to say something or she would have probably continued to have that belief and teach students that." Here, Renee's choice to speak up was to, not only benefit herself, but to discontinue a false narrative that the professor was presenting. Particularly, Renee challenged someone who was in a position of power but knew the outcome would cease the spread of false information.

Additionally, some women in this study chose to speak up as a way of teaching their nonBlack peers how to navigate moments and interactions with other Black people and, in a sense, protecting them from potentially bad encounters. Gemma, a sophomore student, said, "my passion gets confused with anger. I'm not mad at what you've done. I might be frustrated, but I'm trying to make sure that this doesn't happen again". One participant, Ann-Denise, shared a moment when 
she had to correct a friend after saying a racially insensitive joke, which turned into "a learning moment". Another participant, Moesha, also experienced teachable moments with peers. She said, It allowed me to be a teacher, and many times that I necessarily didn't want to be, but I said if anyone's going to teach you about a component of Blackness, I would want to be responsible for that and push you to dismantle some of those thoughts you have. Don't you ever come to me talking about chicken. I will correct you right away. or 'Wow, did you cut your hair?' Girl, I have added [hair extensions] and I take it out, do not ask me again. And guess what, next week it's gonna be different. It might be red. I don't know. And don't ever ask anyone else that either. It allowed me to just be like, 'No. Cut that shit out.'

It is commonplace for their non-Black peers to make insensitive jokes or comments, which leave Black women feeling as though they need to speak up to educate. As illustrated by the previous quotes, the Black women chose to utilize their voice in these instances of teaching their peers how to communicate with other Black people. In this instance, no matter how direct or straightforward the message, they had to make it known that it was not right, and that the behavior was corrected.

Ultimately, for the women in this study, speaking up can be frustrating and exhausting. Another participant, Destiny, has learned through interactions with peers that "a lot of people are just ignorant, and I can't get mad over things that they don't know". Another participant, Rachel, acknowledged that she experienced a shift in college where she was completely aware, nor did she care, that she was being perceived as angry. She said, "y'all don't care how uncomfortable I am so I don't care how me forcing you to say what you actually feel like saying makes you uncomfortable". Following her undergraduate experience, Ciara said, "I'm not explaining anything to any more people because I am not a spokeswoman for all Black people. We all have different experiences". Additionally, Shardae, an HBCU graduate, said, "I'm too many thousands of dollars in debt for these degrees to show you some level of proof that I'm worth what you're 
asking for". Prioritizing their own peace by not engaging in "teachable moments" with others, allowed the women to focus on their mission of being a student. For many of the women in this study, they internalized the notion that they had to work harder than others to, not only dispel being angry, but to also prove that they belonged at their colleges and universities.

\section{Working Harder to Dispel Deficit Frames of Black Women.}

Participants discussed having to work harder in college than their white peers due to the deficit portrayals of Black women in the media. With few examples of professional and/or educated Black women, students and faculty often perceive Black women as less capable or less motivated than their white counterparts. To combat this perception, the women in this study shared instances of over-achieving and taking initiative, particularly in group projects.

Similar to Issa's experience with her co-workers in the Insecure clip, Black undergraduate women are sometimes excluded from group projects, or their abilities are often underestimated, and rationalized by not knowing how they would react. Being that the most salient stereotype effecting Black women students is "The Angry Black Woman" the women in this study willingly take initiative in group projects which leaves no room for exclusion as a means of confronting the stereotype. "Working twice as hard to get half ahead" is rhetoric that is indoctrinated into most Black children. As a result, the Black undergraduate women in this study have internalized the notion that we must work twice as hard. Although she doesn't agree with it, one participant, Daisy, understands that it is a reality for a lot of Black people to work twice as hard. She said, "you definitely have to work twice as hard to get half ahead just so that people see that you are not at the table to fill a status quo but that you are equally qualified and intelligent and knowledgeable to perform the duties and the tasks." For Danyelle, her initiative, which is often mistaken for being angry or stern, is how she showcased her dedication to her peers to dispel any preconceived ideas about her. She said, 
Since I feel I have to work harder to show what I'm doing is not slacking off, I have to be like 'Hey, let's do this'. People underestimate us so much, and you just get fed up. I'm here. I'm doing it but you can't show that. We're underrepresented and then when we find our way up, they're like she is mad [and] angry.

In this instance, Danyelle explains Black women are tired of the prejudgment particularly because it is inescapable. Even when they work hard, Black women are subjected to scrutiny and mislabeled.

On the other hand, some participants expressed not believing in the idea of Black women having to work harder. One participant, Moesha, believed in being hard-working "but not for the white gaze, or white approval". In other words, Black women should never do anything for the approval of others especially white people, opposed to what some of the women previously expressed. Nicole said, "it's not fair. but I feel like we do [have to work harder] in a sense. We don't get away with everything that some of our white peers do because we are not raised in a white culture built on racism and oppression". For Monroe, she challenged the "work twice as hard" narrative because "It doesn't place any accountability or responsibility, on the systems in place that have you where they have you. You have to figure out as an individual how to garner the strength and the ability to navigate that, which is something that I think is really alienating, and it can be something that makes you feel alone in your experience". Monroe and Nicole both acknowledge greater systems that interplay in the maintenance of keeping Black people, specifically Black women in subordinate positions.

\section{Choosing When and When Not to Code-Switch}

The women in this study are constantly negotiating when to present their most authentic selves. This tension is most apparent for women who attended predominantly white institutions. Danyelle, a junior, said, 
I gotta change my personality based on who I'm around because I just don't know how they're feeling or what they're doing. I just don't want those additional things against me because I'm already in the minority in a lot of places. I just don't want to keep having more things counted bad about me.

Here, Danyelle is aware of the negative presumptions that her peers have already crafted about her. She constantly alters her personality so that her peers are unable to hold her actions against her. Another participant, Gemma, was aware that she is "always trying to deliver herself in a way that is more palatable for white people". For the women in this study, the ways in which they speak and how they present themselves physically are constantly scrutinized by their collegiate peers. As a result, some of the women choose to alter their speech to protect themselves from constant scrutiny.

In the clip shown to participants, Molly advised the intern Rasheeda that she should switch it up in order to be successful at the law firm, directly talking about her speech and mannerisms. When asked if code-switching was necessary to be successful, participants shared mixed feelings about the need to code switch. For Crystal, altering her speech is to prove that she is "educated as fuck", showcasing that she is knowledgeable and that you will listen to what she has to say. Choosing when to and when not to use curse words was seen as a form of code-switching for Nikki. For Destiny, she consciously did not use the $\mathrm{N}$ word around her white friends. One participant, Camille, shared, “yes, I do feel like it's necessary, but that doesn't mean that you lose who you are or you forget who you are just because you put on a white tongue, that doesn't change the color of your skin". In other words, Camille illustrated the way in which you speak does not change the fact that you're Black and that is how the world will see you. While Tiffany, a HBCU graduate, wasn't code-switching to appease white peers, she still found herself altering her speech between friends and professors. Her institution placed great emphasis on professionalism which 
was extended to speech, the way you dressed and, even behaviors like not walking on the grass. Code-switching was a device commonly used to switch in and out of professional settings. It was also revealed that code-switching was used when speaking with other Black people.

Participants watched a clip from HBO's Insecure which showed Black women also tend to alter their speech when talking to other Black people albeit consciously or unconsciously. For many women in the study, there was a level of comfort established that allowed them to relax their language and include more African American Vernacular English (AAVE). For example, Shardae said she is bilingual in AAVE and standard English where she unconsciously alters her tone and language with other Black women because "there's a level of comfort there I feel that we are going to connect on certain terms I use." Here, Shardae illustrated that she can toggle between standard English and AAVE because our language establishes a comfort and connection with one another. Another participant, Monroe, shared a similar sentiment where she felt that she did not change her speech when talking to other Black people but instead changed her speech to the outside world. She said,

When I'm speaking with folks who are family, friends and from my community, I don't feel like I'm going to be judged so harshly from what I'm saying. I feel like there's a level of understanding, and I can let down my guard. But I feel like the change is a way of putting your guard up so that you don't get any unwarranted attacks or pokes at you.

For Zelda, a homegirl-type relationship is established based on the fact there is another Black woman in the room. Another participant, Lisa, agreed by saying, "I don't consciously change it, but now that I'm comfortable, I'm gonna be my real self because if you judge me I don't care because in my mind we're one in the same". For Nikki, she said, "I want to be able to speak however shit comes out. I don't want to have to tailor my words to make somebody feel comfortable. [Black women] have a connection via language". Just as the women in this study 
switch their tone and words to protect themselves from those that do not understand, they also alter their speech when talking to other Black people because there is an assumed level of comfort.

When watching the clip of Molly advising Rasheeda to tone down herself in the workplace, many women in this study acknowledged the tension Black women face when trying to maintain professionalism while also being their authentic self. For example, Tiffany said,

Unfortunately, I think for so long we've made that work for us, code switching and fitting into these areas because we weren't allowed to be in those spaces before. I can see the history behind it. I can see its purpose but I think that at this point it'd be nice to move beyond that because you have other people of different colors and stuff who act differently who aren't super professional and they're accepted so why can't we.

It has been indoctrinated in Black students that we must alter aspects of ourselves when navigating in these white spaces. As a result, the impact of constantly code-switching was stressful for some women. For Davis, it made her sad and was still something she was adjusting to. One participant, Nikki, recalls code-switching helped her navigate through her institution but caused isolation when trying to take her new knowledge back to her hometown, where she was told "now she was acting white”. Access to higher education, grants a new privilege to all Black students but particularly for those that come from underserved communities. In an effort to try and educate the members of her community, Nikki was told she was no longer being their version of Black, which leaves Black undergraduate disconnected from school, and now, home. To combat having to alter herself, Ciara chooses to only give people pieces of herself, or what she calls breadcrumbs, so that others are not surprised by her true actions. She said,

I give people pieces of me. I give them a little bit information about my background, or I tell stories a lot. I definitely do tell a lot of stories so that when you see me act like my normal self, it's not surprising because I told you about myself because I gave you little 
pieces about myself. It's kind of like leaving breadcrumbs. I leave my breadcrumbs and then if something surprises you, I'll ask you 'why does this surprise you? I brought this up.' That's my way of navigating my way around white spaces.

Ciara slowly revealed parts of herself instead of having to alter aspects of herself around her peers. By doing this, Ciara is able to remain true to herself without having to negotiate between which version she has to be present depending on the space.

Code-switching is still seen as necessary for some women because perception is important for social upward mobility. For example, Danyelle said,

I just don't want to be seen like that, as bad as it sounds, in front of white people because I feel they have so many connections in this world that when you put a bad taste in their mouth, you kind of screw yourself because these are the people that potentially you'll be asking for help one day and you don't want the stereotypical Black language and Black culture or stuff that they're not used to or seen as unprofessional to be in their mind when they think of me.

Danyelle believed she will need to rely on the connections with her collegiate peers and does not want to ruin those relationships by not appearing professional. One participant, Rachel, believed code-switching is still necessary by comparing it to a job-interview. She said, "you're gonna say all the right things to make whoever is listening to your interview, hire you." She added, "if you're trying to get to a space and you need these people to feel some type of way to get you there, unless they're down for the cause, code-switching is necessary." Here, Rachel spoke to altering yourself to get what you want. Unlike Danyelle's reasoning, Rachel suggested doing and saying what you need to in order to get into the space you desire. Unfortunately, Rachel's suggestion does not speak to how one remains true to oneself once you're in the space. 
Lisa, who described herself as having a large personality, felt herself shrinking in her undergraduate class. Lisa recalled it being a struggle to show up authentically as an undergraduate which left her questioning, "Why did I think that I needed to change? What was it about these classrooms that I was allowing them to make me feel small? Why did I not think I was good enough?" She then began to affirm her place within the university. The women in this study utilized affirmations to encourage them throughout their undergraduate experience. For Ashley, she recalled reciting "This is our university!", a chant created during social protest on campus, to affirm her presence because "we're here to learn and this is MY university". Another participant, Samantha, affirmed herself in every space by telling herself that she is "a cool ass Black woman", which is used to diminish any previous perceptions about Black women.

\section{Challenging the Policing of Black Hair and Bodies}

Black women's hair and bodies seem to also be under public scrutiny. The residual effects of the Jezebel trope leave Black women's bodies often hypersexualized. Additionally, Black women have to be aware of their physical appearance to avoid being mislabeled by society. Hair is one way in which Black women express themselves and this is showcased through various styles. Being raised on the idea to believe that straighter hair was more professional and accepting. There was an apparent shift in ideals, where participants in this study no longer held onto previous

notions around hair. In doing so, they came to accept their hair in every form. For example, AnnDenise said,

For the first time in my life, I'm comfortable with my hair. I got it cut and I dyed it. I did all this stuff. I feel like because we're seeing Black beauty mainstream. Not as much as it should be, but definitely more than when I was in those really insecure ages, like junior high, high school. 
Ann Denise's newfound acceptance of her hair came as a result of Black hair being more outwardly celebrated in the media. This liberated her to experiment with her hair, such as cutting and dying it. Davis, a freshman, would travel back home to do her hair to shield herself from embarrassment and interrogation from her white roommates. She said, "I was embarrassed to have my full-on wash days or to bring my little extensions and work on it in my room because I don't like answering those questions. 'Oh my god that's so cool. What is that? That's not your hair?' You know, shut up." She later realized that she was accommodating the feelings of others and no longer goes home to do her hair.

Eurocentric standards of beauty became the criteria for women in all spaces, which left Black women's bodies overpoliced and unable to just be. Many of the women shared experiences where their bodies were unable to just be, particularly because it is something that they cannot control. For example, Crystal recalls an instance where there was discussion around banning an article of clothing because of the way it looked on Black women. She said,

My body is my body. We had White girls wearing bodycons. But they can wear it because there's no figure in it, so it looks like a very straight dress. If I put that dress on, you would tell me to go home because you're seeing boobs, you're seeing thighs, you're seeing legs, you're seeing all of these things, that's not fair. If you're going to ban an article of clothing, ban an article of clothing. A bodycon dress is a bodycon dress no matter who puts it on. For Crystal, there was a lack of fairness that was not given to Black women's bodies. Because Black women tend to have more voluptuous body types, this leaves them more exposed to sexual assault. For example, one participant, Misty, shared,

I have witnessed where things have gone too far for Black women who were just trying to have a good time and expressing themselves through whatever they want to wear and it's 
perceived from other people in a hypersexualized way, and they feel they can take advantage of that.

As Misty shared, Black women are unable to experience joy without the possibility of assault, which is a direct result of the narrative that is imposed on Black women's bodies.

\section{Racially Undesirable in Dating}

Participants watched a clip for HBO's Insecure which showed a group of men and women discussing dating in Los Angeles. In the clip, the men insinuated that Black women are too controlling which makes them harder to date. However, the women in this study shared feelings of being invisible which was made most apparent within social spaces, specifically in regards to dating. The troubles in dating left many women in this study questioning themselves as Black women and whether or not they were attractive. Crystal questioned "what's wrong with me? Can I not keep a man?" Destiny, a student in Southern California, shared men "will walk past me, not even make eye contact, nothing. Is it because I'm ugly or is it because I'm Black? Then I realized that it's definitely not the ugly part, no."

Moesha also questioned her attractiveness and added that the media instilled into Black men a particular image of a particular type of Black woman being beautiful. She compared her experiences of being a student in Los Angeles to her time being a graduate student in the Midwest and felt the media instilled into Black men that Black women must be mixed to be beautiful. She said:

They were looking for a specific type of girl. Even the Black girls that they chose were lighter skin, curlier hair, pretty eyes. They're most likely mixed. So, if Black girls were being dated, those were the type at the college that I went to and [men] came with the perception of 'I'm gonna be in LA and have this view [of dating and relationships]'. I think 
the media has influenced that a little bit of what it's like to be in LA and have 'this little mixed chica on the side'. I actually heard them say things like that.

Moesha was afforded the opportunity of being able to compare the experiences of dating as a Black women in two different geographical regions. Yet, her undergraduate experiences were very similar to Destiny's and the other women in this study. They were left questioning their attractiveness because they were constantly overlooked by men of all races. For example, Gemma shared, “white guys aren't interested in Black women, the Black guys aren't interested in Black women. Nobody is looking at the Black women here" and as a result her and her friends are discouraged from engaging in larger school social events.

\section{The Proud Black Woman}

An important finding is that although participants had many different ways of defining Black womanhood and recognized negative stereotypes exist, all of the participants spoke about Black womanhood with pride and reverence. It appeared from their comments that even though being a Black woman is a hard business, they appreciated being Black women.

Despite the obstacles and challenges that Black women face, and unlike what was present in the media, the women in this study made it very clear in distinguishing that they are proud to be a Black woman. One participant, Anna, shared,

[It] was instilled in me as a child... be Black and proud. Don't be scared to be who you are. Don't let anybody talk down to you because of who you are. Being Black and proud was instilled into me as a child because God made you like this, and you need to be proud of what you are.

Here, Anna shared how her parents and the women figures in her life, such as her grandmother, made sure to instill in her the confidence to be secure in her Blackness. Therefore, a new portrayal 
of Black women that emerged from the data is the Proud Black Woman. This portrayal is crafted to illuminate the ways in which Black women love their Blackness.

For some women in this study, they acknowledged that their Blackness takes precedence over their other identities. While the women in this study understood that the multiplicative relationship of identities, they shared that their Blackness is the first marker acknowledged by society. Lisa shared,

For me, being Black comes first. Because it's a shared experience. Being a woman, it's not that it comes second, but my Blackness is what I solely operate in first and foremost because I guess it's a shared experience. It's something that connects me to people across the way. Before I see a woman or a man, I see you're a Black person. You're Black body. Somebody, who is always being governed by the color of your skin.

Lisa implies that being a woman does not create a connection with women of other racial groups therefore she is able to connect with other men and women because of their shared Blackness. Ashley supports Lisa's point in describing how the 'Me Too' movement was co-opted by white women.

Even with the 'Me Too' movement. IT was started by a Black woman, who didn't even get her credit. There were people who were trying to do marches and bring awareness and then it turned into the Women's March. And who was the face of the Women's March? Although it took a Black woman and Black people to do all the work. Put it on their back. As always it goes back to strength and to power and to protecting and all of those words that I used in the beginning [to define Black womanhood]. But the Women's March, it's white. And feminism and the face of feminism is white so I am Black first and then I'm a woman right immediately after that.

Lisa and Ashley highlight how their Blackness informs their womanhood. As Ashley shared, feminist interests don't necessarily support her Blackness, but she also acknowledges that her 
womanhood comes right after. Therefore, their pride in being a Black woman comes from the relationship between being both Black and being a woman.

The women in this study displayed their love of being a Black woman by centering Blackness in their lives, as well as appreciating the differences and versatility within Black womanhood. As previously explained, the women in this study were challenging the policing of their bodies and their hair. These feelings of no longer succumbing to Eurocentric ideals of beauty were realized through validating the versatility of our hair and appearance. As one participant, Camille, shared, "as far as Black hair, we can be creative, and I love that we can have a different hairstyle every day of the week. I love it. I love our versatility.” Monroe shared her appreciation of how other Black women aided in her being proud and secure in her beauty.

I am so in awe of the variety. I've always been in awe of the variety and versatility. Like "how she get her hair to do that? I can't do it." And then in all the knowledge that can be passed down. I had somebody a couple years ago finally show me how to lay down my edges. And it was, not this moment of me being like, "I need to do this every day". It was this moment of like, "God, this is like an art form. How did I not know?" or the ways, growing up, our friends would just try to make themselves feel beautiful and at the same time, wantin all of my friends to feel beautiful in themselves. Not have to conform to any standards. I feel very lucky and fortunate that I was surrounded by friends and a family that really supported me and my difference and I don't know why but just not capable of fitting in, but having friends that really had my back about it and would tease me a little bit about it, but it was all love and it was never from a place of hate. So I felt comfortable exploring and just being me, even though I knew that a lot of people around me didn't feel that 
comfortable and they felt they had to look and be a certain way in order to be presentable or attractive or conform to some standard of beauty that was not them.

For Monroe, her pride in being a Black women came from the support that she was given by family and friends in not having to conform to beauty norms and free to explore her womanhood without constraint.

\section{This Is Not My Space}

For many of the women in this study, it was made very clear that their institutions were designed and operated on their exclusion. The women in this study felt isolated and did not feel comfortable in these collegiate spaces, including spending time on campus and living in the residence halls. For example, Danyelle said,

It's weird to say, I feel uncomfortable when I'm here because this is just ot my space, and I feel it's made obvious that it's not. It's made obvious and in the most nonchalant way that this is not my space, because they're just not a lot of people like me here. It's the whole environment. I just don't see a lot of people like me in class, walking around campus. At times, it makes me feel empowered that I made it here and I get to break through these barriers and be the Black person that these white people or Mexican or Asian people get to see.

Danyelle, a student at a predominately white institution in Orange, CA, shared how her school does not make the effort to make her feel comfortable. The disconnect for Danyelle is the lack of people of color on campus, specifically Black people. The exclusion of Blackness on campus is a clear indication, for Danyelle, that Blackness is not welcomed and valued. However, she felt uplifted and proud to be a model for those they do not interact with Black people regularly. Lydia pointed to the fact that in predominantly white colleges, the faculty and students are interacting with Black students based on media representations. She said: 
Given the demographics at the school and the amount of wealth at the school, at least it feels like, but I'm very confident that this is the case, a lot of these students are interacting with Black people for the first time or they rarely have. Because of that, all they know about Black people is what they see on TV or on social media. Either they're scared of you or they think you're ghetto, ratchet, this, that. Or they think you're stupid or they're just straight up terrified of you.

Here, Lydia highlighted the racial and class segregation in our society, where there are few opportunities for non-Black students to interact with Black students. For Ann-Denise, the lack of visible Blackness could be intimidating. She said, "When you're going in and out of the buildings and you're seeing a lot of successful older white men who help establish the university or whatever. It can be a little intimidating". Here, Ann-Denise spoke about how the statues and figures on her campus only gave praise to white men. This created a disconnect between her and her institution that was daunting and discouraging. As the only non-traditional student in this study, Ann-Denise's age adds another dimension to her not feeling connected to her university. She shared being a nontraditional student, someone who did not have a linear path to college, is something that she struggled with because "When I walk around campus, everyone's clearly much younger than I am, and they're either figuring things out or they knew what they want to do when they were five and now they're here getting it done." For Ann-Denise, she felt as though her institution did not offer the best support for non-traditional students. The feelings of their colleges and universities not being their space was also revealed through macro-aggressive and micro-aggressive experiences on campus, which aids in the hypervisibility of Black undergraduate women.

\section{Spectrum of Violence}

Institutions are also complicit in diminishing the lived experiences of Black women on campus. Through macro and micro-aggressive behaviors from peers, faculty, and administration, 
Black undergraduate women are left feeling isolated and exposed. These institutions sell a facade of the college experience when in reality Black women have to cope with racist and sexist faculty and administration. In the Mixed-ish clip, we watched Rainbow's teacher use language that left Bow questioning her hair styling and texture, where she likened her curly hair to that of an animal. The teacher's comments are "something that children can carry with them for the rest of their lives", as one participant, Tiffany, said. Many women in this study related to this scene and recalled macro-aggressive and micro-aggressive experiences of racism and sexism with faculty. For example, Davis recalled feelings of isolation after having a professor who would openly say the $\mathrm{N}$ word and rationalize racist comments because she adopted a Black daughter. Another participant, Anna, had a professor who made headlines for sending controversial tweets challenging systemic racism following the death of George Floyd. Despite protests from the student body, the university is honoring the professor's first amendment rights and is taking no action to terminate the professor.

In another case, Nikki, shared an incident that happened in her women's only dormitory that left her feeling shaken. Someone wrote the n-word on the floor's whiteboard. Being the only Black student on the floor, Nikki alerted her resident assistant, who called a floor meeting. Her peers tried to diminish the incident and her feelings by saying it was not a big deal. Nikki's peers blatantly disrespected her in a space that is expected to be her refuge at the end of the day. Even when following the proper protocols by notifying her resident assistant, there was still no resolution in her experience. She ended up leaving that dorm because her objections went unheard and her feelings dismissed. This experience left Nikki feeling alone.

More common were experiences of being dismissed by professors or peers. For example, Jayonce, an HBCU graduate, recalled a professor singling her out to share her opinion about a popular rap song. When she gave her opinion, the professor told her that she was wrong and did 
everything to diminish her opinion. She said, "in that moment, they wanted me to make a stance for the Black in the room and that was a weird moment to have...I really liked that professor and once he did that, that really set him aside, to me, as one of everybody else". Jayonce continued, "I feel like I'm constantly being dismissed in [college department]. It's just one of those moments where I'm not allowed to be too angry. I'm not allowed to be too sad. I have to remain completely neutral in order to be heard". It seemed to be commonplace for these institutions to turn a blind eye to the insidious behavior of some faculty and students. Ultimately, this leaves Black students vulnerable and exposed.

\section{Feeling Alone on White College Campuses}

Participants expressed that they often felt out of place in white campuses because of the fact that they were so few Black students. Coming from a Black neighborhood, Nikki shared not feeling comfortable on campus because she did not know how to navigate being around white and Asian peers and, in turn, they were very standoffish. She said, "the cultural and racial differences challenged me to feel closed off," which ultimately this led her to majoring in African American Studies to get a sense of belonging.

For many of the women in this study, the decision to attend a predominantly white institution arose because the universities misrepresented their level of diversity. Campus brochures and marketing materials led many of these women to believe that there would be greater numbers of Black people on their campuses, but also a mixing of races that is sometimes believed to be access to new opportunities. The lack of diversity became apparent in their everyday experiences. Black students are also used as models to push diversity initiatives. For example, one participant, Lydia shared, "They love using us for their diversity initiatives but when it comes to actually giving us a space here and feeling like we're supported they are very, very lacking." Monroe adds, "you look at the flyers and it be two, three Black people, a couple Asian folks, you're just like, wow, it's 
super diverse. Then you have to question what diversity means and who it supports". Here, Monroe and Lydia, illustrated the ways universities created a fictive image of their campus demographics, which persuades many student's decision to attend. This idea of diversity ultimately swayed many participants against attending historically Black schools, such as Howard University and Spelman College. For example, Crystal recalled,

My mom just being unaware of everything she was like you sure want to go to an all Black school? What do you mean mom? She was like, you don't want diversity? No, I want to be with people who I feel comfortable with and I know. My mom totally made that decision for me in going to [university in New York] because of the diversity, which ended up not being diverse so that was a big punch in the gut when I got there. It was disappointing because, from wanting to go to Howard and seeing those type of things and then coming to this school and not even grazing the surface or having the opportunities to pick and choose from different groups, I was like "what am I going to do now?"

Despite her personal desires to attend an HBCU, Crystal was swayed by her mother to attend a local school In NY under the guise she would gain more exposure to different groups. However, the lack of diversity left Crystal sad and upset.

\section{Hypervisibility}

For many of the women in this study, they attended institutions with a limited Black student population. As previously explained, many of the women were only among the few, if not the only, in their classes and residence halls. This left the Black women feeling over-exposed, hyper-aware and hyper-visible. For example, Davis said, "being aware that as a Black woman on campus there's not many of us, or just being a Black person in general. Every time I enter spaces, I'm aware of ME, of what that is and that there's no one else." Davis expressed a heighten 
awareness of her presence on campus because, as a Black woman on campus, there are not many. Stacy, a graduate from a predominately white university in Northern California, shared,

I was acutely aware that I was Black, and I was acutely aware that I was not in the majority. I was also acutely aware that lots of people didn't think I deserved to be there and or assumed that I was there because I was Black and I was filling a quota.

For Davis and Stacy, as well as many of the women in this study, it was a blatant realization that they were a Black student on campus. However, interactions with peers and faculty made this observation more real.

Following racially-charged incidents, Black students become spotlighted and are finally visibly seen on campus. For example, Ann-Denise felt after racially-fueled incidents that the invisibility cloak is removed and Black students become more visible on campus. She said, "When situations like that happen with the [white student yelling racial slurs], it's almost like they see you for the first time. I felt they were starting to see me and other Black students on campus. I started to notice we actually do have quite a few, young Black students here." For Ann-Denise, who is a non-traditional commuter student, felt racial incidents helped her to see her Black peers on campus but also helped her non-Black peers to see her as well.

Rachel felt Black students, especially her fellow Black athletes, are tokens for entertainment purposes, such as showing others popular dance moves. She says, "they were welcoming when it was for entertainment but not if I check somebody for saying the N word".

On the other hand, the hyper-visibility of Black students allows them to stand out and be remembered by their faculty and peers. One participant, Destiny, offered an interesting perspective where she felt that, 
It definitely sucks just not having a lot of people to relate to, but at the same time people are going to remember me because I am the only Black person. It even gives you a higher platform to do you because people are watching you because you're the only one.

Here, Destiny shared her belief that the hyper-visibility she experienced as one of few Black people on campus gave her greater access to be seen and heard.

\section{Creating a Sense of Belonging}

From our conversations about their college experience, it was apparent the ways in which Black women did not fit into their institutions, but they also shared what has worked. In particular, the women who graduated from historically Black colleges and universities felt their Blackness was affirmed in all parts of their college experience. For the women who attended predominately white institutions, Black organizations and clubs were an integral part of their college experience because it allowed them to the space to see and fellowship with individuals that looked like them and had similar experiences. Ultimately, Black college women seek institutions that offer spaces and faculty that are supportive.

\section{HBCUs Affirm Black Identity}

The women in the study who attended historically Black institutions felt their schools did affirm their Black identity and created a sense of belonging. Lisa, who went to a predominately white institution for her undergraduate studies and attended a historically Black university for her graduate work, was able to see clear differences in how she was treated by professors within both institutions. One of her English professors at her undergraduate institution showed no empathy for Lisa when she shared her grandmother was ill by telling her "I'm sorry, but that's just your grandma not a parent so I don't see what the problem is". In comparison, her Black professors at her HBCU acted as a second family even extending invitations during holidays. She knows that would have never happened as a student at a predominantly white institution. Jayonce, who transferred during 
her undergraduate career from a Jesuit school in Los Angeles to a historically Black college, felt faculty and administrators were more accessible. Tiffany, a graduate of an all-women's college, appreciated the women's studies and African diaspora courses she was required to take because it allowed her to better understand why certain ideals about Black people still exist. Additionally, Tiffany, who was often the only Black student growing up, shared how her institution was a space for her to feel nurtured and see many variations of Black. She said,

It spoke a lot to what it means to be, not only Black, but, socially, our economic status, what it means to also be a heterosexual, what it means to be a Black homosexual woman. There were all these kind of dynamics that just kind of showed that we're not all this one monolithic group. We felt at home with each other and we nurtured and cared for each other but there were various ways and these various types of us in general that we needed to recognize. I also learned a lot as well. I saw a lot of different types of Black women, too. That was also really dynamic and empowering in general.

For Tiffany, her HBCU exposed her to different aspects of Blackness that were new for her. Her institution affirmed that the Black experience is not one-dimensional. As a result, her institution provided her the space that welcomed her version of Black as well as others. Another participant, Daisy, shared her HBCU experience also allowed students "to be Black but you're also allowed to be the version of Blackness that you want to be." For students like Tiffany, who come from upbringings where they are often the only Black student, it is encouraging to attend an institution that places no ramifications on your version of Blackness.

\section{The Importance of Black Clubs and Orgs}

Black women relied heavily on campus clubs and organizations, such as Black Student Unions (BSU) and Black Greek-lettered Organizations, as refuge and a space that affirmed their identity. These organizations acted as safe spaces for Black students to connect with one another 
and to seek refuge from the greater college community. Without BSU, Gemma said "I would be a lot more isolated, because of that I probably would have gone back [home], which is something I don't even want to think about right now." For Lydia, she believed that she would not have survived her first semester without BSU. She said,

I do have a really close circle of Black friends here that I'm so grateful for. That is the only reason I am able to maintain my sanity. White people are exhausting in large doses. If it weren't for BSU, I don't think I would have made it through my first semester at all. So that's definitely my medicine here.

For Gemma and Lydia, BSU was a place where they felt welcomed on campus. On the other hand, for Destiny, she was disappointed during her time in BSU because she did not want the constant reminder "that it sucks to be Black at this campus" without tangible solutions. Destiny expected BSU to celebrate Blackness more but many of their meetings were grieving sessions. As a result, she was not as involved in the organization as her peers. This supports the notion of the Black student experience not being singular, suggesting Black students need access to a variety of organizations that affirm their identity, not just BSU. After being rejected from a fashion club on campus, Nikki created her own club because she wanted a club where herself and others felt accepted. She said "since I couldn't find something to be a part of, I made something to be a part of". She was forced into creating space for herself because Nikki felt students of color seemed to "only have little pockets in certain places around campus".

Black Greek-lettered organizations (BGLO), or The Divine 9, are important to the women in this study because they helped to expand their network and they helped to forge relationships that lasted longer than just their undergraduate years. In her freshman year of college, Stacy joined a Black Greek-lettered organization and continued her membership throughout her undergraduate career and beyond. She said, "I think that it has to do with the fact that I was in that the longest 
that those remain my most long lasting and most important relationships that I have in college". Daisy shared,

It just amazes me every day that you are in this organization with women who cover all gamuts of a career spectrum, and all are professional. So, it just creates this ability to network within itself. There's everything that you can possibly imagine within this organization. That continues to be the awe for me. It's that these are all educated Black women who are thriving in their careers to kind of change the narrative.

Membership in a Black Greek-lettered organization directly altered the experiences of Black undergraduate women. In seeking spaces that affirmed their identity, BGLO placed like-minded women together and built a support network.

However, many predominantly Black clubs and organizations were susceptible to scrutiny from their institutions which was commonly displayed by not receiving adequate funding comparable to peer clubs and organizations. For example, Ciara recalls her school reducing funding for Black clubs and organizations with the rationale that there were not enough Black students. She said, "But that's not our fault that there's not enough of us. That's the school's fault". Despite the number of Black students, Moesha felt her Blackness was appreciated and supported by her institution through financial support and the support of prominent campus administrators attending BSU events.

Additionally, Black women in this study relied heavily on peer-to-peer support of other Black women to survive their college experience. For example, Lisa said, "I think as a Brown-skin woman it's natural for me to understand the plight of another Brown-skin woman, of another dark skin woman". Another participant, Ashley, felt that she created closer bonds with her Black friends on campus because the number of Black students was so small. She adds, "it can get messy real 
quick because there's a lot of crisscross but at the same time it can be a real sisterhood if communication is there."

\section{Seeking Supportive Faculty, Administration, and Spaces}

"It wasn't just the whole 'I'm a freshman and school's hard', it's also "I'm a freshman, school's hard, and there's nothing here to support me" - Davis

It was expressed by the women in this study that they sought supportive faculty and administration and spaces that affirmed their identities. Many of the women understood that collegiate spaces were not made for them. The women who attended predominantly White institutions felt that their colleges and universities were not welcoming of their Blackness or Black womanhood. For example, Ciara questioned, "how can you give love to something that you don't fully understand?" Another participant, Crystal, recalled, "I don't think anything catered to being a Black woman. There was nothing. Literally nothing on it”. The lack of support given by their institution triggered a survival instinct of getting what was deserved. For instance, Ashley felt her institution did not do the best to support her but she did gain the ability to go out there and don't take no for an answer, "find a new way. If this doesn't work, do this a different way. Create resources. Create that network".

Institutions seemingly diminished racist and sexist incidents on campus. For example, Zelda shared that her roommate was killed on campus and was advised by her institution to not speak about the incident publicly nor did receive any type of counseling. Another participant, Tiffany, a graduate of a HBCU in Georgia, recalled alleged reports of rape were often swept under the rug, which contradicted the school's mission and purpose. Another participant, Renee, shared her institution was "good at making it seem like they were listening to our concerns but never really instituting any real change". Particularly after incidents of racial injustice, there was limited 
Black faculty and staff to seek support. For Gemma, she identified only one administrator that believed offered support as a Black student.

Many women in this study shared the need for more Black faculty to serve as a motivator and mirror of finding success in academia. For example, Gemma is grateful for the sole administrator for Black students at her institution because "he is really good at validating our experiences". As a Black woman in STEM, Ciara felt excluded throughout her entire undergraduate career and only now feels supported in graduate school because of her Black principal investigator.

In addition to needing support, there is also the need for acceptance of each other. For Samantha, she felt, "there wouldn't be a term considered crabs in a barrel if people accepted the fact that we could all be on the same level and all be something". Another participant Maya added, "I think this pandemic that we're experiencing is bringing us on the same level across the board more than anything else ever has. It's affecting everybody and breaking everyone's old, normal structures up, so I think people are way more compassionate now”.

\section{Summary}

This qualitative study sought to explore how media portrayals of Black women influence the behaviors of Black undergraduate women. From both predominately white institutions and historically Black colleges and universities, ranging in ages from current students to twenty-year graduates, thirty Black women spent nearly two hours sharing their college experiences through semi-structured individual interviews. Within the two-hour time frame, we watched clips from three popular sitcoms and later discussed the commonalities participants shared with the Black women media characters. Analysis of the transcripts revealed the themes presented in this chapter.

The Black undergraduate women were provided the space to define for themselves what Black womanhood meant. The women in this study understood and appreciated that their 
womanhood is unique and different but do not see this appreciation from the media nor their colleges and universities. They felt Black womanhood was multifaceted and multilayered because it cannot be described singularly. The most prominent layers to Black womanhood include strength, struggle and nurturing. According to the women in this study, Black women possess an innate strength. Along with this strength comes a struggle, wherein Black women are always able to showcase their buoyancy. Additionally, Black womanhood is nurturing because Black women fulfill an obligation to always care for others.

The women in this study felt that the representation of Black women in the media is diminished to very static representations. Yet, the women were able to identify a few Black women characters they believed exemplified their ideals of Black womanhood. The influence of media portrayals affected Black undergraduate women in a myriad of ways. Black undergraduate women were constantly fighting against being "The Angry Black woman" and the scrutiny that comes from their peers. In the face of many negative portrayals, Black undergraduate women worked harder to dispel deficit perceptions. They also had to choose when and when not to present their most authentic selves. Black undergraduate women are also challenging the policing of their physical appearance by do what they please with their hair and bodies. Additionally, Black women depictions in the media leave Black undergraduate women feeling unattractive and undesired by their collegiate peers.

Given the influence of negative media portrayals and interactions on campus, Black undergraduate women attending predominately white colleges and universities felt as though these institutions are not spaces meant for them. This is made clear through macro and micro aggressive experiences on campus with faculty and peers. These acts of violence leave Black women exposed and more visible than desired. 
Despite some of their negative experiences in college, the women in this study created a sense of belonging for themselves. This included joining clubs and organizations that celebrated and affirmed their identities, as well as seeking faculty and administrators that did the same. For the women who attended historically Black colleges and universities, their institution fostered a sense of belonging by prioritizing their Blackness.

In the subsequent chapter, I will provide additional meanings and a theoretical discussion of what was previously presented. 


\section{Chapter 5 - Discussion}

The purpose of this research study was to examine the impact of media portrayals of Black women on Black undergraduate women. Using Black feminist theory and critical race theory to examine media's influence revealed the media portrayals of Black undergraduate have a resounding effect on Black undergraduate women, which greatly influenced their interactions with peers and faculty, involvement on campus, but most importantly how they view themselves. The findings of this research study presented in the previous chapter revealed four key themes, which build upon much of what is present in the literature but adds a new dimension by centering the lived experiences of Black undergraduate women, a population that often goes unnoticed on college campuses (Banks, 2009; Patton \& Croom, 2017).

Overall, four major themes emerged with each theme having a set of subthemes. The first theme is Black womanhood is multi-faceted and multi-layered, which encompasses strength, struggle, and nurturing. The second theme revealed the women in this study believed that there is a lack of diverse representation of Black women in the media but acknowledged things are changing. They connected with Black women characters that they felt exemplified their ideals of Black womanhood. Of the dominant stereotypes, Black undergraduate women felt they were constantly fighting against "The Angry Black Woman" trope. A counterstereotype, The Proud Black Woman, emerged from the data, which supported participants ideals of Black womanhood. To overcome the dominant stereotypes placed on them, the women in this study worked harder, chose when and when not to code-switch, and were no longer subscribing to societal ideals about their physical appearance. Third, Black undergraduate women understood that college campuses were not their space. They were hyper-aware of their feelings of isolation and being considered undesirable in regard to dating. This leads to not being comfortable on their campuses because 
they are often excluded or experienced aggressive acts from faculty and peers, leaving these women overexposed and vulnerable. Lastly, Black undergraduate women created their own sense of belonging. For the women who attended historically Black colleges and universities, these institutions affirmed their Black identity by actively dispelling stereotypical notions of Blackness and proving that Blackness is not one-dimensional. Black undergraduate women attending both predominantly white institutions and historically Black colleges and universities, utilized Black organizations, such as Black Student Unions and Black Greek-Lettered Organizations to carve safe spaces for themselves on campus. In the subsequent sections, I will further explain the findings of this research study.

\section{Black Womanhood}

To understand the ways Black undergraduate are influenced by the media, I wanted to provide space for Black undergraduate women to define Black womanhood for themselves. Black undergraduate women defined Black womanhood as multi-layered and multi-faceted. The nuances within Black womanhood cannot be narrowly defined therefore they felt Black womanhood was multi-layered and multi-faceted. Yet, strength, struggle, and nurturing were the three most recurring characteristics used to describe Black womanhood by the participants. Black feminist theory encourages Black women to self-define ourselves and our everyday experiences (Collins, 2000). Therefore, it was important to provide the women in this study the space to name and define Black womanhood. The ability to self-define Black womanhood shifts the conversation from victimization to empowerment (Njoku \& Patton, 2017) in that they are able to name it for themselves as opposed to just a reiteration of societal beliefs. Self-definition also allows an assertion over Black bodies, language, and attitudes, which is instrumental in shaping public perception and presenting a narrative that includes their choices (Njoku \& Patton, 2017). 
Despite a dislike for the term, many of the women in this study referred to Black womanhood as strong. Similar to the findings of West et al. (2016), strength was associated with Black womanhood but the woman in this study understood the paradox that exists within being considered strong in that it doesn't allow for Black women to be vulnerable. The idea of Black women being strong stems from slavery in which Black men and women were given the same amount of work and labeled the same on the auction block. As hooks (1992) wrote, "the black female was exploited as a laborer in the fields, a worker in the domestic household, a breeder, and as an object of white male sexual assault" (p.52). On the other hand, Black women are accustomed to seeing and experiencing a legacy of Black women that display strength. I would argue, from the experiences of the women in this study, that the Black woman's definition of strength differs from the societal expectation of being a labor mule in that there is an appreciation expressed of Black women who were able to carry the burden and carry it well. As the literature (Corbin, Smith, and Garcia 2018; Robinson, Esquibel, and Rich, 2013; Davis, 2015) suggest, Black undergraduate women utilize this strength to combat aggressive acts on campus and to protect them in a space where their multiple identities are often under attack. More so, it is a continuance of African traditions where women have rights, responsibilities, and obligations that are independent of men (Gammage, 2016). It is in the counter-storytelling and self-defining that changes the narrative of how Black women view their strength.

The notion that Black womanhood is nurturing is also congruent with ideals around the Mammy trope of being caretakers (West, 1995). This trope is rooted in racist and sexist ideology that maintains white patriarchal superiority by asexualizing Black women and keeping them in subordination (Slaton, 2014; hooks, 1981). However, the Mammy stereotype was the least referenced stereotype amongst the Black college women in this study. This could be because the trope is often associated with motherhood and domesticated work (Sealey-Ruiz, 2013). For Black 
undergraduate women, their display of characteristics that resembled that of the Mammy trope was their empathetic actions, which stemmed from the care that was given to them from the Black women in their lives. As one participant, Camille, shared there is a generational sharing of knowledge, or "bags", within her family that have been passed down from generation to generation which helps to create this idea of communal mothering, where women figures that exist outside of the traditional mother-child roles are still instrumental in child-rearing (Collins, 2000). It is against this backdrop of experiences thatBlack women come to understand care for themselves and others which is extended into their experiences within social institutions. For Black undergraduate women, their empathetic response is to take on responsibilities that they are not expected to or required to do, such as teaching their non-Black peers how to interact with people of color and working harder to dispel the myths about Black students.

An important aspect of the Black woman's standpoint is the legacy of struggle, in which Black women's experiences are interconnected through the struggle against racism and sexism (Collins, 1997). It is revealed through the lived experiences of Black undergraduate women that it is not an easy task being a Black woman. Even more so, being Black, a woman, and a student comes with its own set of challenges (Banks, 2009). One participant, Tiffany, felt that she was constantly fighting an uphill battle, where her voice, her presence, and her accomplishments were constantly diminished. Yet, the understanding of Black womanhood being a struggle did not deter the sense of pride that the women in this study shared about being a Black woman. As Jerald et. al (2016) found, individuals with a greater sense of ethnic belonging are buffered from internalizing negative tropes. The display of being a proud Black woman can also be seen as an act of resistance towards the dominant narratives that exist about Black women in the media. In tandem with selfdefinition is the importance of self-valuation and respect (Collins, 2000), which Black undergraduate women display by being proud of their Blackness and Black womanhood. 
The social construction of Black womanhood and its display in the media appears to influence how Black undergraduate women define Black womanhood for themselves. As Collins (2000) argued Black women's realities exist between two contexts, their personal experience and the expectations and stereotypes that are imposed on Black women. In defining Black womanhood, Black undergraduate women referenced strength and nurturing, which are also two ways in which society has defined Black women through the Mammy and Strong Black Woman tropes. According to Collins (2000), this is an ever-present tension in the construction of Black womanhood. The self-definition of Black womanhood by Black undergraduate women seems to be incongruent with what is portrayed in the media and how institutions navigate their approaches in supporting Black college women, where the multiple identities of Black undergraduate women is largely ignored. The naming of these characteristics by Black women, strength, struggle, and untiring, exists from a different perspective than what is portrayed in the media and perceived by others. It is, in a sense, a reclaiming of knowledge that is also empowering (Collins, 2000). Societal beliefs of womanhood and femininity have historically derived from white women, where myths and stereotypes were created to differentiate Black women from the symbol of perfect womanhood, white women (hooks, 1992). Black feminist theory offers value to the production of knowledge by Black women through their lived experiences and personal points of view (HowardHamilton, 2003). Black undergraduate women enact an "oppositional gaze” (hooks, 2003), where Black women consume media understanding that it is a system "of knowledge and power reproducing and maintaining white supremacy" (p.95). It is through their agency that Black undergraduate women resists the negative images of Black women and the discriminatory practices that maintain these images, which in this study, is perpetuated in the media and within institutions of higher education. The media and higher education do not acknowledge the intersectional identities that Black women possess, which is shown through their depictions and 
treatment within these social institutions, which will be discussed in a subsequent section of this chapter.

\section{Black Women in the Media}

hooks (1992) argued that the devaluation of Black womanhood is perpetuated through mass media, but particularly television. This affirms how the media is complicit in the perpetuation of such beliefs about Black women. It is estimated that television programming generated $\$ 400$ billion dollars in 2020. With this capitalist power there must be a critical examination of the neutrality and objectivity within media and how it maintains what is increasingly being referred to as a racialized capitalist system (Monthly Review, 2020). Monzó (2020) pointed out industrialization and the advanced capitalism that defines the U.S. were spurred on by the racist economic systems of colonization and slavery. Furthermore, Monzó pointed out that a system of human hierarchies based on race was established to justify the existing inequality that defines capitalist social relations. As a billion-dollar industry, the U.S. media has a vested interest in maintaining the myth of equal opportunity and the stereotypes of Black women that support white supremacy.

In Representations of Black Women in the Media: The Damnation of Black Womanhood, Gammage (2016) posited ideological, social, and institutional devaluing of Black women manifests within media systems, which shape public discourse about Black women and Black womanhood. Not only does media have the ability to impair knowledge about Black women, but media productions can colonize the images of Black women being that media is a primary way information is transmitted through society, which work to maintain a racial hierarchy (Gammage, 2016). In other words, media can be viewed as a structure of racism that systemically denies rights and opportunities to people of color while privileging the power and wealth of white people, resulting in both economic and other social inequalities as well as an internalized oppression within 
people of color (Monzó, 2016). Critical race theory offers race as a normative part of society in which a social racial hierarchy is in place to maintain the subordination of the 'other'.

The opinions of the women in this study revealed there is a tenuous relationship between the Black undergraduate women experience and the media in that they did not identify with many of the contemporary portrayals of Black women. Our intersectional experiences reveal and support that the Black womanhood is not static but there is a collective experience that Black women share (Collins, 2000). The women in this study were aware that all Black women were not the same but knew that the identities of being Black and a woman connected them. This understanding of Black womanhood then informed Black undergraduate women's connection with current media characters, where they felt there was a lack in representation. However, the women in this study acknowledged that a shift is happening where Black hair and bodies are being more widely acknowledged and accepted. Public figures, like Rihanna, Lizzo and Issa Rae, exemplify the acceptance of Black womanhood and its differences. Nonetheless, Black undergraduate women had difficulty identifying Black women characters they felt exemplified their ideals of Black womanhood. This disconnect makes it difficult for women to connect with current media portrayals of Black women.

When trying to name media characters that fit their ideals of Black womanhood, the women had trouble naming contemporary portrayals. The default character commonly referenced by many of the women in this study was Claire Huxtable of The Cosby's, who was praised for being an allencompassing portrayal of a Black woman. However, Claire Huxtable also portrayed a particular ideal of Black womanhood that maintains heteronormative standards of femininity. All of the women in the study, except for one, openly acknowledged a heterosexual status, which can be one of the reasons why there was a connection to the character. However, it does reveal the ways in which media conglomerates are complicit in creating and maintaining racialized and gendered 
expectations of Black women that influence how Black women are perceived in real life. As one participant, Crystal, shared, Claire "did no wrong", but it is also this line of thinking that causes Black women to strive for a white supremacist patriarchal standard (hooks, 1992), which expects and requires so much of Black women. In turn, this can cause a potential negative impact on mental health and for, Black women specifically, develop "impostor syndrome", or the feelings of doubting one's abilities (Collins, Price, Hanson \& Neaves, 2020).

Black undergraduate women acknowledged that a shift was happening where we, as media consumers, are getting a broader and wider range of characters. Issa Dee, played by Issa Rae on Insecure, was referenced when acknowledging more contemporary portrayals of Black women that met their ideals of Black womanhood. Issa is a brown-skinned woman, who wears her natural hair and is navigating relatable scenarios. Issa's characterization offers a fresh perspective that differs from previous portrayals, which seems to resonate with Black women. Nonetheless, the static representations of Black women in the media continue to presume an expectation on all Black women to act a certain way. As Patricia Hill Collins (2000) described, these controlling images, which are created to make racism, sexism, classism, and other social injustices appear normal and a part of everyday life, have crafted a narrative about Black women which causes difficulty in creating a positive self-image (hooks, 1981; West, 2008). Even more so, the racist and sexist underpinnings of these stereotypes are used to keep Black women at the margins of society (Lundy, 2018). The trouble with Black women portrayals in the media is that they are disproportionally crafted by non-Black people. As Hunt (2017) found less than 5\% of showrunners are Black. Through a critical race theory lens, mediated messages must be interrogated to uncover how these portrayals function within a system designed to protect whiteness and the maintenance of power over Black women. It is through the counter-storytelling of the Black undergraduate 
women in this study by which I am better able to understand how media portrayals impact their collegiate experiences.

Black undergraduate women felt they were constantly fighting against the "Angry Black Woman" trope more than any other dominant representation of Black women. Participants in this study shared instances in which they inhibited self-regulatory practices, such as being mindful of the ways in which they spoke, to be more palatable for their white peers and to not be perceived as angry or upset. This finding is congruent with the literature in that the most salient stereotype of all Black women is "The Angry Black Woman" (Henry, Butler, \& West, 2011). This stigmatization creates an internal battle for Black women, who then must negotiate when and when not to display emotions. This causes the pendulum to swing in either direction of being seen as angry or being seen as strong, where Black women are unable to just exist without commentary. Mathais (2016) argued that an attempt to suppress one's emotion is how whiteness maintains its power. In the maintenance of power, this trope specifically is used to silence Black undergraduate women. This silencing is used to diminish their presence and opinions within these academic spaces. The intersections of race and gender in the classroom is used to disempower Black undergraduate women (Winkle-Wagner, 2009). The women in this study had to make the decision on when to utilize their voice to speak up for themselves or out against injustices. When Black undergraduate women chose not to speak up for themselves, they experienced self-doubt, where these women did not feel comfortable asking academic questions because of the effects of stereotyping. On the other hand, when they did speak up, they were met with either mistrust or agitation. As one participant, Renee, shared, her professor was shocked that she chose to speak up against the professor's misteaching. Within this interaction, it was clear by the teacher's reaction of being flustered that she did not expect for this Black woman to speak up. Collins (2000) argued speaking up is one way for Black women to survive disrespect and assaults as a result of these 
stereotypes and it is at this moment "when silence becomes speech, when stillness becomes action" (p.96). In this instance, Renee spoke up not only for the benefit of herself but to end a perpetuation of a false narrative about Black history. This act of resistance is to the benefit of not only herself but others.

The effects of fighting these tropes resulted in Black undergraduate women internalizing the notion that they must work harder and choosing when and when not to code-switch. It is indoctrinated in most Black children that we must work twice as hard to get half as far. Despite meeting the prerequisites for admission to many of the elite colleges and universities across the nation, the Black undergraduate women in this study continued to carry this guidance with them throughout their college experiences and even into their post-graduate work and careers. While Black students use this belief as a guiding principle to motivate our persistence within these oppressive systems, it ignores the systemic racism that is embedded within education and the inequities that only benefit white students (Hiraldo, 2010).

Code-switching is intrinsically problematic because it is rooted in assimilationist ideals where Black people are expected to conform to white behaviors, attitudes, and standards. The system of education has maintained this notion of meritocracy, where it is believed that education is a great equalizer if you work hard, but this neglects to address the racist and sexist oppression intertwined in that discourse (Patton, 2016). As one participant in this study, Monroe, felt in resisting the ideology of working harder stated, “it doesn't place any accountability or responsibility on the systems that have you where they have you." Instead, it makes Black undergraduate women prove their worthiness of being in a space that is designed for their exclusion. As Jones and Shorter-Gooden (2003) offered, Black undergraduate women are constantly shifting, which is utilized as a defense mechanism to protect their public and private identities. Black undergraduate women are aware that shifting between identities is necessary in 
order to be successful. As one participant, Rachel, created the analogy between code-switching and a job interview, one will do and say anything to get hired. With this understanding, Black undergraduate women do what is necessary because they are aware that higher education offers access to skills and knowledge that will not only uplift themselves but uplift Black women as a collective (Collins, 2000).

Additionally, Black undergraduate women resist the residual effects of these tropes specifically by challenging the policing of their hair and bodies and by showing up for themselves authentically. As we continue to see a variety of representations in body types and hair textures, Black undergraduate women, like Ann-Denise, expressed having a greater appreciation of her hair. In the Black community, hair has always been a site of contention, in part because it is always juxtaposed against Eurocentric beauty standards. Black hair has been used as a means of discrimination to maintain a racial hierarchy, which yields emotional, personal, political, and professional consequences for Black women (Greene, 2010). As Greene (2010) outlined in her study, Black women's hair has been weaponized through our legal system by ruling against Black women wearing particular hairstyles, such as braids and blonde hair color. Only recently has there been a movement to reverse many of these institutional practices, like California's passing of the C.R.O.W.N. (Create a Respectful and Open World for Natural Hair) Act. As hooks (1981) suggest, it is difficult for Black women to create a positive self-image against ever-present stereotypes of Black women. However, Black undergraduate women are redefining their own self-image by openly accepting all aspects of their appearance and showing up as they wish.

The Jezebel trope insinuates that Black women utilize their bodies for sexual gain (McKoy, 2012). For Black undergraduate women, they are aware that their bodies are more heavily policed in comparison to their peers. As one participant, Crystal, shared, Black women tend to have a particular body shape where articles of clothing make Black women's bodies appear more 
pronounced. Historically, Black women's bodies have been subjected to unwanted gaze. Most famously, Sarah Baartman was put on display through Europe and labeled a freak because her body type was othered. The women in this study shared how the display of Black women's bodies also leaves them susceptible to sexual assault. As in slavery, where the Jezebel stereotype originated, Black women were unwillingly subjected to sexual advances by slave masters. This lack of autonomy over their own bodies has resulted in years of Black women's bodies being on display for public consumption. The permanence of racism has politicized Black women's bodies while celebrating those same features on women of other ethnicities, and in doing so, Black women are constantly reconciling their beauty against mainstream beauty standards (Awad et al., 2015). However, Schooler et al (2004) found Black women have healthier perceptions of Black women's bodies when consuming Black media.

Unlike the Jezebel trope, or the hyper-sexualization of Black women, there seems to be an inverse effect on Black undergraduate women, where they are often seen as racially undesirable by their peers. Black undergraduate women shared experiences of being undesirable by their peers, where they were not pursued by men of all racial groups. Following policy changes in admitting, colleges became sites for dating with socializing outside of the classroom becoming a key part of the educational experience (Holland \& Eisenhart, 1990). Colleges are believed to be optimal sites to find a partner being that both parties would have similar educational attainment. However, for Black undergraduate women interested in Black men, their desire to date within their race and find a partner with similar educational attainment will leave many Black women single (Commodore et al., 2018). Dating is virtually non-existent for many Black undergraduate women. This left the women in this study with feelings of being unattractive and questioning their ability to withstand lasting relationships. Within higher education, Black women exceed Black men by nearly twentyfive percent (Espinosa, Turk, Taylor, \& Chessman, 2019). Henry (2008) found Black women are 
not interested in dating outside of their race, which reduces their dating pool to the limited number of men available on campus, which was also true for some of the women in this study. As previously stated, sexual preferences were not disclosed but this finding also illuminates how Black women's undesirability extends beyond the collegiate context. A recent study (Boyd, Stephens, Eaton, \& Bruk-Lee, 2020) found highly educated Black women experience similar issues when dating due to wanting a Black partner with similar educational attainment but are left to choose from a limited pool of candidates. Sexual preference was not a focal point of this research study, but it is important to note how heteronormative thinking has framed much of the research around dating. Homosexuality is juxtaposed to heterosexuality where lesbian, bisexual, and transgendered women are seen as a deviant other (Collins, 2000). In doing so, it excludes a subgroup of Black women from sharing their lived experiences.

Black women in the media have traditionally been portrayed in very one-dimensional ways. These portrayals influence the existing narratives around Black womanhood and what it means to be a Black woman, particularly in America. For the women in this study, there was an understanding that Black women have a unique experience, while also acknowledging that they would not forfeit that experience for anything else. It is within this understanding that Black undergraduate women display pride in being a Black woman. The emergence of The Proud Black Woman trope naturally came from the data, highlighting the ways in which the women in this study showed pride and reverence for being a Black woman. The women in this study understood that they have a unique set of experiences that are specific to being both Black and a woman. Even more so, the pride that Black women possess stems from the ability to show up authentically. A major tenant of critical race theory is counter storytelling. The conversations about the existing media representations revealed there was a lack of diversity and need for more authentic portrayals of Black women. As Delgado and Stefanic (2002) argued, counter-storytelling is utilized to debunk 
so-called universal truths and myths. The Proud Black Woman trope differs from other portrayals that cast a deficit lens on the Black woman experience. The need for a positive portrayal of Black women is critical for Black women and girls to develop a positive self-image (hooks, 1981). Additionally, the Proud Black Woman aids is diminishing the within group differences that tend to be divisive amongst Black women, such as colorism and classism. Instead, it acknowledges the intersections of being Black and woman without pathologizing the experiences that exist at this intersection. It builds upon a legacy of other Black women that has carried tradition of showcasing what it means to be a Black woman through their strength, struggle, and nurturing amongst other things.

\section{Black women being supported by their institutions}

Black undergraduate women occupy a unique space of being an "outsider-within", where many postsecondary institutions function to maintain whiteness. The multiplicity of the oppressions that Black college women experience of being Black, being a woman, and being a student adds to the psychological stress they experience while being at these institutions (Commodore, Baker, \& Arroyo, 2018). The system of higher education is based on the exclusion of others, particularly students of color. It is not a coincidence that Black undergraduate women do not feel welcomed or supported by these institutions when many were founded, and have been maintained, on the exploitation of others, in the physical makeup of student and faculty populations, as well as through curriculum, campus policies and campus spaces (Patton, 2016).

Despite being known as these great equalizer, higher education does not insulate Black women from racist and sexist oppressions (Davis \& Brown, 2017). For the women who attended predominately white institutions, it was made apparent through peer interactions that they did not belong within their campus communities, which ignited feelings of being alone and being hypervisible. For Black undergraduate women attending historically Black colleges and universities, 
their Black identities were affirmed by their professors, peers, and campus organizations. Black undergraduate women relied on Black student organizations as a means of support within institutions of higher education.

These portrayals of Black women in the media aid in keeping Black undergraduate women in a periphery positioning where they are unable to feel as though they truly belong within their institutions. For the undergraduate women attending predominantly white institutions, they were often forced into the role of being the spokesperson for all Black students, where they were turned to by faculty and peers to explain the Black perspective, because they were either the only or one of the few within their classes and social spaces. This creates an external pressure, where Black students do not want to misspeak because their behaviors are representative of the entire race, which can influence the perception of Black people by their peers. As Steele and Aronson (1995) found widely known stereotypes can alter an individual's characterization when they are at risk of confirming to the stereotype. The outcome of the pressure of being a Black student is greater psychological and emotional stress. As West, Donovan, and Daniel (2016) found, endorsement of stereotypes, like the Strong Black Woman, negatively impact the mental health of Black undergraduate women. Henry, Butler, and West (2011) also found the three most prevalent psychological issues facing Black undergraduate women is anger, anxiety, and depression. Ultimately, these pressures work to keep Black undergraduate women at the margins, which leaves them feeling isolated on campus.

The women in this study felt disconnected from their institutions in part because of experiencing acts of violence from faculty and peers. Happening on both a macro and micro level, these acts of violence often left the women in this study feeling overexposed and vulnerable to additional attacks. With many institutions of higher education being founded on the exclusion of Black students, Black undergraduate women are aware that they are moving within a system that 
is designed for the maintenance of whiteness that does not value their presence or their knowledge. As one participant, Jayonce, shared, after being singled out to share her opinion about a Black musician, her professor tried to argue that her opinion was incorrect. Instances like this reveal the ways in which the knowledge of Black undergraduate women is not valued. The disproportionate amount of Black people, specifically, Black women that exist within the academy in leadership roles also reveals how racist policies continue to keep Black people in subordination. In her analysis of women aspiring to be HBCU presidents, Commodore (2019) found institutional hiring practices to be oppressive in that they create internal conflicts of self and ultimately limit the hiring pool of women.

On the contrary, students who attended historically Black colleges and universities felt their Blackness was openly appreciated and celebrated. HBCUs were established to educate Black students who were excluded from other institutions of higher education simply based on race. HBCUs met that need and do a great service to the racial identity of Black women but still neglect certain aspects of their gendered identity. Although the women in this study did not share these attitudes about their HBCU experience, the literature suggests that this may be the case for other Black women. As Bond (2011) found, Black women experience similar marginalization. Njoku, Butler, and Beatty (2017) add that HBCUs perpetuate heteronormative ideals and gender roles that reinforce white supremacy through politics of respectability. The women in this study did acknowledge incidents on HBCU campuses around sexual assault were diminished or silenced. These incidents of assault leave Black women to be alone to grapple with the physical, emotional, and mental pain within a system that already dehumanizes them (Njoku, Butler, \& Beatty, 2017).

The one-size-fits-all approach that is generally used for Black students does not acknowledge the intersectional differences that exist within groups and does a disservice to Black 
undergraduate women. Black feminist theory acknowledges the collective experience that is shared but understands that Black women are not a monolithic group (Collins, 2000). Therefore, institutional programming that does not met the varied needs of Black students will always be a disservice to some. With schools being sites of domination, Allen (2015) contends individuals and collective groups are able to resist the "cultural and structural dominance of schooling" (p.72) through agency. As one participant, Nikki, explained she had to create her own student organization because she was intentionally excluded from an organization of interest. Predominately white institutions continue to be spaces that do not make Black students feel welcomed. The reliance on safe spaces for Black students, such as Black Student Unions and Black Greek-lettered organizations, positively impacts the college experience of Black women is also supported by literature (see Howard-Hamilton, 2003). The women in this study shared that positive and impactful collegiate experiences were contingent on their participation with these Black organizations. Black students create academic and social counter-spaces which allows them to be comfortable with individuals that look like them (Solorzano, Ceja \& Yosso, 2000). As Patton (2006) found, Black cultural centers helped Black students adjust to campus environments that offered safe spaces for Black students to feel comfortable. Additionally, the women in this study who are members of Black sororities shared how their membership to these organizations exceeded beyond college by creating a network that they could always rely upon. As Greyerbiehl, \& Mitchell (2014) found membership in a Black sorority highlighted the intersectional experiences that met the needs of being a Black woman without privileging one identity over the other. Yet, racial hierarchy within institutions of higher education often left these organizations at the outskirts of institutional policies. University sanctions make it difficult for these organizations to thrive. For example, in comparison to their white peers, the women in this study shared Black organizations often received reduced funding because of their limited numbers. A few participants in this study 
shared their desire of being members of Black-Greek lettered organizations but due to the limited number of Black students on campus these organizations were unable to charter chapters. This reveals an institutional issue that reveals skewed admission and institutional practices which hinder the college experience of Black students.

With participants in this study spanning across twenty years yet still sharing commonalities in their collegiate experiences reveals institutions of higher education has done very little to change oppressive, institutional practices that leave Black women feeling unheard and unseen. Black students were only given access to these institutions less the two centuries ago, which was nearly two centuries following the inception of the first university in America. As critical race theory offers, race and racism is a pervasive part of this country that functions to keep Black people at the margins and must be examine to excavate the systems that maintain racist oppression (McCoy, \& Rodricks, 2015). It also reveals that media has also done very little to change the narrative of Black women. Through Black feminist thought, Black women are able to self-define Black womanhood which empowers them and informs their lived realities. In the next section, I provide my recommendations for both institutions and media makers. 


\section{Chapter 6 - Implications, Future Research, and Conclusion}

At the beginning of this paper, I shared a glimpse of my personal experience navigating higher education as a Black woman. For me, media, particularly television shows and movies, were such a salient influence on my expectations of college. Even more so, media portrayals of Black women impressed, not only on myself, but as well as on my peers, an expectation of Black woman. Entering this research study, I expected for all Black women to be on one accord in expressing our dislike for the way Black women are represented in the media, not considering the nuances amongst Black women and within Black womanhood. An examination of Black women's college experiences revealed the ways in which media portrayals of Black women work to justify and support their (mis)treatment within higher education. Through a critical race theory perspective, higher education and media works as systems that maintains a social order that privileges whiteness and the subordination of people of color but specifically Black students. Black feminist theory encourages and supports Black undergraduate women in defining and naming their lived experiences. Black undergraduate women are navigating within these institutions that are designed for their exclusion but resist oppressive forces through the reclamation of their public image.

This research study sought to explore the impact media portrayals have on the college experiences of Black undergraduate women. Through a combination of semi-structured interviews and focus groups, thirty Black undergraduate shared aspects of their college experience. We collectively watched clips from three current programs, Insecure, This is Us, and Mixed-ish, to illicit emotions and feelings about the portrayals of Black women and how the scenarios are representative of their own lived experiences. As illustrated in chapter 4, it was revealed Black undergraduate women are negotiating between their perceived identities and their identities of self. 
Black undergraduate women's self-definition of what it means to be a Black woman are not present in contemporary portrayals of Black women in the media. This causes a disconnect between their identities and what they watch, where they acknowledge that there is a lack of representation that showcases a variety of Black women. But they also noticed that a shift is happening in how Black women are represented. Yet within collegiate spaces, the women in this study felt that they were constantly fighting against the negative portrayals of Black women in the media but specifically “The Angry Black Woman". As a result, Black undergraduate women found themselves selfmonitoring their actions to not play into the negative tropes. Despite an incongruence in their selfdefinition and portrayals in the media, Black undergraduate women perform acts of resistance to combat the deficit perceptions from their peers. This aids in the silencing and erasure of Black undergraduate women within higher education.

Adding to the limited qualitative research that centers the lived experiences of Black undergraduate women, it is a hope that this research encourages further research that examines the lives of Black women but, most importantly, a change in the treatment and handling of Black women within higher education. Therefore, the findings of this research study can be used to inform institutional practices that can better suit the needs of Black undergraduate women. Additionally, the findings of this study can also be used to encourage media makers to be more conscious of the depictions of Black women and Black life, as the portrayals in the media have an influence on how Black people are perceived in real life. The subsequent sections will suggest ways in which institutions and their key players can aid in positively impacting the experiences of Black undergraduate women. Additionally, I will suggest ways in which media makers and producers can aid in disrupting static portrayals of Black women. The limitations of this study will also be explored with recommendations for future research being a way to address areas that can strengthen the work presented in this paper. Lastly, I will also offer recommendations to other 
Black women navigating higher education and Black women conducting research with Black women.

\section{Implications for Institutions}

The research study supports that predominantly white institutions continue to be hostile spaces for Black students (Ross, 2016) but especially for Black women. Black undergraduate women navigate collegiate spaces as Black, as a woman, as a student, as well as other identities that were not deeply explored in this particular study, such as sexuality. Black undergraduate women experience their identities simultaneously, where oppressions work in multiplicative manner acting upon one another (King, 1988). Institutions of higher education have been complicit in the maintenance of keeping Black students at the margins. Institutions must begin to undue the many years of oppression and exclusion, which many of these schools was founded on. In doing so, institutions must acknowledge the ways they maintain racial hierarchy that keeps Black women students in subordination. The findings of this research imply institutions of higher education should create more inclusive spaces for Black students which can happen through more nuanced programs for Black students, an increase in the number of Black faculty and administrators, diversity trainings, and specific to historically Black colleges and universities, they must acknowledge the existing gendered oppressions Black undergraduate women experience on campus.

\section{More Inclusive Spaces}

The Black women in this study revealed feelings of not being connected to their institutions. An aspect of making many colleges and universities feel more inclusive for students of color begins with recruitment and retention strategies. Recruitment and retention strategies reveal the universities commitment to accepting but also retaining and ensuring the success of Black students. Part of feeling isolation on campus and being involuntarily positioned as a 
spokesperson is due to the lack of fellow students that look like them on campus. Universities making a better effort in recruiting Black students can aid in curbing the feelings of isolation. Recruitment of students of color requires collaboration between the school and the admission department in developing a recruitment plan (Eakins \& Eakins Sr, 2017). Dumas-Hines, Cochran, and Williams (2001) suggests pipeline recruitment strategies encouraging elementary and middle school students to pursue postsecondary degrees, as well as financial incentives such as scholarships and grants.

Getting Black students to attend the institution is one thing but keeping them through the duration of their studies is another. One participant in this study transferred from a predominately white institution to a historically Black university during her undergraduate career because she felt that she lacked support and in transferring institutions was able to see a noticeable difference in her college experience. An important aspect of retaining Black students, but Black women specifically, is by providing inclusive spaces. Institutions can make Black undergraduate women feel more welcomed by offering more inclusive spaces for Black students. While most institutions have a Black student union, this assumes that all Black students are a singular group. One participant in this study shared how the Black Student Union on her campus only further illuminated the problems of being a Black student on campus. Therefore, there is a need for various spaces that allow for Black students to be whatever version of Black they want to be. Implementation of gendered specific programs is one way to specifically retain Black women, such as Black sororities and mentorship programs with Black faculty (Eakins \& Eakins Sr., 2017). There is a necessity that university create more nuanced programs to fit the needs of the Black women on campus. 


\section{Creating More Nuanced Programs}

The women in this study felt that their institutions did not openly welcome their Blackness and visibly made them feel uncomfortable when on campus and within the classrooms. The findings of this research study suggest institutions need to make a concerted, proactive effort to make Black students, specifically Black women, feel welcomed, accepted, and supported at their institutions. As some of the women in this study shared, Black clubs and organizations are often subjected to the same policies as their peers despite the difference in student population percentages. Institutional policies, such as participation minimums, often limit the functionality of Black organizations. Imposing such policies on Black organizations knowing they are unable to meet these requirements is not only cruel, but also signifies clear messaging that Blackness, in all its facets, is not welcomed on college campuses. Black womanhood is nuanced, as the women in this study shared, where Black women are not a monolithic group and because of such they should not be treated as a group with singular beliefs. Due to the complexities amongst Black women, colleges and universities should cater programs and provide space for Black women and all their varying identities. The women in this study shared current programming designed for Black students does not account for the intersectional identities that exist within those that identify as Black, such as sexuality and even specialized interests. As Commodore, Baker, and Arroyo (2018) suggest, institutions must begin to acknowledge the in-group differences amongst Black college women to ensure their needs are met (Commodore, Baker \& Arroyo, 2018).

\section{Increase in Black Faculty and Administrators}

The Black undergraduate women in this study expressed the need to see individuals that look like them in academic positions to motivate them to persist. This can be accomplished by increasing the number of Black faculty and administrators, but especially Black women faculty and administrators. Darden, Kamel and Jacobs (1998) found a positive correlation between 
representation of Black faculty and Black student enrollment. The women in this study shared how their Black professors or administrators held a key role in their collegiate experiences because they shared an understanding of what it was like navigating academia as a Black student. Institutions need to revisit their hiring practices to diversify the faculty pool. In a comparison to white counterparts, Black faculty are disproportionally underrepresented at U.S. universities where they are employed in non-tenure track positions at higher percentages (Modica, \& Mamiseishvili, 2010). The National Center for Education Statistics (2020) reports Black professors make up only six percent of all full-time faculty at degree-granting postsecondary institutions. Of that six percent, Black women make up only three percent of full-time faculty. Black faculty are important to Black students. Tuitt (2012) suggest Black faculty act as intellectual guides that place greater expectations on Black students to succeed. Beyond diversifying the faculty make-up of postsecondary institutions and acting as role models for Black students, Madyun, Williams, McGee, and Milner IV (2013) contend Black faculty also alter classroom experiences by helping students better understand cross cultural experiences, which also helps with their intercultural relationships. An increase in Black faculty, particularly Black women faculty, would positively impact the collegiate experiences of Black women students acting as a buffer within a long-standing oppressive system.

\section{HBCUs Acknowledge Gendered Oppressions}

Historically Black colleges and universities hold a unique space in that they are expected to be safe spaces for all Black students. The women in this study who attended HBCUs spoke highly of their institutions and their college experiences. As this research study illustrated HBCUs affirmed their Black identity. While the number of women who attended HBCUs that participated in this study were limited, they did share or knew someone who did have sexually charged experiences within these institutions. Participants briefly mentioned instances of sexual assault 
being diminished which reveals a need for HBCUs to do a better job of supporting and protecting Black women. Instances of sexual assault are too often swept under the rug, or diminished, to maintain the public image of the school. The experiences of the women in this study support the literature which suggest Black women experience similar marginalization at HBCUs (Commodore, Baker, Arroyo, 2018; Bond, 2011). Additionally, Kennedy (2012) suggest racial oppressions take precedent over the gendered oppressions experience by Black women attending historically Black colleges and universities, where their gendered experiences were never shared or discussed in the classroom. The gendered oppressions Black women experience need to be addressed to ensure their safety and protection but to also feel a part of the greater school community.

\section{Diversity Trainings and Anti-Racist Pedagogy}

Similar to the mandated trainings on alcohol and sex abuse employed by many colleges and universities, students and faculty can engage in diversity trainings which offer best practices when teaching and interacting with others from differing backgrounds and experiences. However, diversity trainings must explicitly address the discrimination experienced by people of color. As Dobbin and Kalev (2016) suggest, diversity trainings fail because they are often mandatory and do not yield organizational change. As these authors suggest, implementation of diversity trainings should be voluntary, where participants willingly want to engage in topics around discrimination and bias. These trainings will aid in dispelling preconceived notions about others and will diminish the threat of the stereotypes explored in this study. The women in this study expressed feelings that their peers were interacting with people of color for the first time. The hope for these trainings is to make individuals aware of their own biases when interacting with students of diverse backgrounds. In doing so, individuals can become aware of their blind spots to reduce aggressive acts against Black students and people of color. As the women in this study revealed, aggressive 
acts do not just come from peers but also from faculty, therefore institutions must make an effort to ensure that who they have selected to represent their institutions does not perpetuate any form of oppression. As a whole, institutions should foster an environment that inclusive for all students.

The findings of this research study also encourage implementation of anti-racist pedagogical practices. As Kishimoto (2018) writes, "anti-racist pedagogy is not about simply incorporating racial content into courses, curriculum, and discipline. It is also about how one teaches, even in courses where race is not the subject matter" (p.540). Anti-racist pedagogy is a response to the ways our educational system has been exclusionary by using a hidden curriculum to normalize dominant knowledge and values (McLaren, 2009). Freire (1970) suggest marginalized groups should not integrate into systems of oppression, but instead transform the structure so they can be themselves. Through anti-racist pedagogical practices, institutions of higher education are able to enact an "intentional and strategic organizational effort" (Kishimoto, 2018, p.551) to not only alter teaching but to also influence the application of anti-racist ideals to all aspects of the institution.

\section{Implications for Media Makers}

New contemporary communication platforms offer Black women a variety of unexplored spaces to deliver their unique stories to diverse audiences (Welang, 2018). The women in this study expressed the representations of Black women in the media do not accurately represent their experiences and this is in large part because there are not enough Black media makers showcasing a variety in Black experiences. Findings of this research study suggest media makers should resist using stereotypes to depict Black women. It can be assumed that an increase in Black media makers will help in curbing the negative portrayals of Black women. 


\section{Resist stereotyping}

This research study showcases how influential media is in the socialization process of both the individual being stereotyped and the perceiver (West, 1995). The ways in which the women in this study are able to name and acknowledge the internalization of negative media portrayals supports that Black women are not passive consumers of media. Therefore, media makers should be more conscious of the messaging put into the various forms of media. As illustrated in this study, the dominant representations of Black women are not representative of all Black women. While it is a large task to offer representation that satisfies all Black women, media makers can begin by deviating from the most static, recurring tropes. Variation in representations can include a display of various sexual identities, body types, hair styles and textures, skin tones, physical abilities, professions, and social classes. By resisting the negative stereotyping of Black women in the media, it allows for the everyday Black woman to see a positive version of themselves in public spaces, which can aid in developing a positive self-image.

\section{Increase in Black Women Media Makers}

At the time of the writing of this chapter, Issa Rae secured an eight-figure, five-year deal with Warner Media. Issa Rae deliberately and intentionally centers Black people in her work and ensures the hiring of Black creatives throughout the process. With the success of her HBO show, Insecure, Issa has solidified her position as a change agent in helping redefine the representations of Black women in the media. While other Black women, such as Regina King, Michaela Coel, and Shonda Rhimes, have been influential in changing the media landscape for Black women, they still only account for a small percentage of Black women in the field. There is an important need for more Black women to be a part of the media making process and dissemination of media images of Black women (Tindall, 2012). It is assumed that an increase in Black women media makers will lead to better representations of Black women. This is not always the case as we have 
seen some Black women media makers perpetuate the same stereotypes of Black women. However, as this research study suggests, media stereotypes and characterizations impact socialization and should thus be taken seriously.

\section{Strengths and Weaknesses}

This research study had some strengths and areas that need improvement. The utilization of semi-structured interviews allowed for participants voice to be heard. It was important to give Black women the space to share their experiences being that their experiences often lie at the margins. Privileging the participants voice allowed for dynamic conversation, which led the findings of this research study. Another component that strengthened this research study was the range in age of the women in this study. The commonalities that the participants shared across time reveals the need for institutions of higher education to address a long-standing problem of hostile racial and gendered climates for Black women.

This research was designed to gain a better understanding of the experiences of Black undergraduate women. In doing so, this study is not intended to act as a generalization for the experiences of all Black undergraduate women. Yet, the findings presented do offer insight into the experiences of Black undergraduate women ranging across twenty years. What is presented in this research study can transfer to similar situations (Merriam, 2002). Additionally, this research study focuses on the experiences of Black women in the United States. This does not mean that Black women elsewhere do not have similar experiences being that Blackness is a global issue. It is also important to note that the media selected for this study was intentionally chosen by the researcher and may not be indicative of the media that the women in the study are consuming on a regular basis. 


\section{Recommendations for Future Research}

It is my hope that this research study will encourage future research. Here I offer suggestions of ways researchers can further engage in this topic. Black undergraduate women are an understudied population that is often ignored (Banks, 2009). As illustrated in this study, Black womanhood is nuanced, however institutional programming tends to treat Black students as a singular group (Hughes \& Howard-Hamilton, 2003). Future research can further explore the ingroup differences amongst Black undergraduate women. For example, researchers can explore a closer examination of the differences in class, sexuality, and ability between Black women. Having a clear understanding of the differences amongst Black undergraduate women can aid in institutions doing a better job of meeting their needs.

Future research should consider conducting more longitudinal studies on the experience of Black women throughout their undergraduate, and even graduate, careers. The age range of participants in this study reveals the pertinent impact that media portrayals have on college experience. Participants in this study shared experiencing a changed in attitudes across their college careers. Exploring the change in attitudes can add to the literature of Black women resisting these stereotypes. Additionally, an ethnographic approach to studying the experiences of Black undergraduate where they are observed within collegiate spaces could reveal variation in the selfperception of Black undergraduate women and how Black undergraduate women are perceived.

While this study focuses on the impact of media portrayals of Black women on Black undergraduate women, future studies can explore how media portrayals impact women who did not go to college. This could be done by analyzing the ways group stereotyping impacts women within various spaces, such as the workforce. This research study used the term media broadly, where visual media was analyzed, specifically scripted television. Future studies should consider the effects different types of media have on Black women. Reality television, such as Real Housewives of Atlanta and Love and Hip Hop, have a large Black viewership (Grace, McCaskill 
\& Roussell, 2017), therefore future research should explore the ways television, that is perceived to be real with real scenarios, has on Black women. Additionally, within this current digital landscape where images are somewhat more accessible through various media channels, exploring the use of social media and its influence on Black undergraduate women can continue to push this topic further.

\section{Conclusion}

My wonderings about the shared experience between myself and other Black women sparked my interest in exploring this topic. The thirty women who shared their experiences revealed that although we were navigating many of these experiences alone, we were, in fact, not alone. Campus racism and sexism This research allowed for a

This research study was conducted at the height of the social uprisings in 2020 following the murder of George Floyd, Breonna Taylor, and Ahmaud Arbery, whose lives were all taken by the hands of the police. As Black Americans were consuming the media images of yet another killing of an unarmed Black person by the police, there was awakening that revealed how insidious racism is in this country. However, for many Black Americans, these were not new troubles that we are experiencing. It seems as though the women in this study were experiencing pandemic fatigue, but also racial fatigue from having to confront race relations in this country. Many of the attitudes expressed revealed Black women were no longer altering themselves due to the White gaze, a term popularized by Pulitzer and Nobel Prize winning author, Toni Morrison, who felt her work was written about and for Black people without the need for critic or approval of white people. Hooks (2003) contend the "gaze" is a site of resistance. The women in this study made it clear that they were no longer altering parts of themselves for the approval of white people. This is apparent in the endorsing of challenging previously held beliefs around Black hair and

appearance. However, we, as Black women, are also working through undoing years of 
indoctrinated messaging that our Black is not beautiful. Many of the women in this study, myself included, were raised on the ideals that code-switching was necessary, and our appearance must always be pristine in order to succeed. Some of the Black women in this study are choosing to show up for themselves authentically by redefining what that means. For some, that is the acceptance of wearing their natural hair, for others that is choosing to not alter their speech. However, similar to Rachel's analogy of code-switching being like a job interview, some women in this study code-switch in order to do what is necessary to be deemed successful. It is the conscious choice in actions which showcase Black women's ability to be strategic in order to attain a particular goal. Black undergraduate women understand that they are navigating an institution that is steeped in various oppressive forces and, therefore, do what is necessary to succeed. Unfortunately, institutions can escape responsibility for the conditions that have created expectations for Black women. Social institutions, like schooling and the media, have maintained and perpetuated perceptions of Black women. Black women are now resisting societal expectations.

I offer recommendations for Black women from the perspective of another Black woman who has navigated this terrain. As this research study illustrated Black undergraduate women are navigating spaces where all aspects of their lives are under scrutiny. With this understanding, I encourage all Black women to enter every space authentically, in whatever ways that means for you. As Malcom X once said, "The most disrespected person in America is the Black woman. The most unprotected woman in America is the Black woman. The most neglected person in America is the Black woman." We must show up for ourselves and one another. Please wear your hair however you please, wear your nails short or long with a design on every nail (if that is your thing), utilize the voice that was given to you. As a graduate of a predominately white university, from my own experience, I encourage Black undergraduate women to understand that these spaces are 
designed for our exclusion. Do not let academic spaces make your feel small. Find your tribe and those spaces, clubs, and organizations that allow you to be yourself. In doing so, you are resisting the dominant narratives of Black women by continuously, and graciously, breaking barriers that will make it easier for the Black women that are to come behind you. Lastly, I encourage you to use your successes to help your communities. I am forever indebted to South Central Los Angeles for molding and shaping my experiences as a Black woman and, therefore, I will always do what I can to uplift my community.

Ultimately, this research study reveals representation is important. This is a sentiment reiterated over and over again but is not sufficiently shown in the media we consume. As I reflected on my own undergraduate experience, I felt as though I did not have the college experience that was portrayed on television and in movies. This could be in part because as a first-generation Black student I did not see myself in any of the portrayals. My own feelings of being unseen, mislabeled, and simply uncomfortable as an undergraduate student was used as the fuel to conduct this research. This research study was a labor of love that adds to a growing body of research that analyzes media effects on Black women. It is my hope that colleges and universities prioritize Black students, but specifically Black women at all levels. This research study was for Black women and I hope I made you proud. 


\section{References}

Adams-Bass, V. N., Stevenson, H. C., \& Kotzin, D. S. (2014). Measuring the meaning of Black media stereotypes and their relationship to the racial identity, Black history knowledge, and racial socialization of African American youth. Journal of Black Studies, 45(5), 367-395.

Ancis, J. R., Sedlacek, W. E., \& Mohr, J. J. (2000). Student perceptions of campus cultural climate by race. Journal of Counseling \& Development, 78(2), 180-185.

Allen, Q. (2010). Racial microaggressions: The schooling experiences of Black middle-class males in Arizona's secondary schools. Journal of African American Males in Education (JAAME), 1(2), $125-143$.

Allen, Q. (2015). Race, culture and agency: Examining the ideologies and practices of US teachers of Black male students. Teaching and Teacher Education, 47, 71-81.

Awad, G. H., Norwood, C., Taylor, D. S., Martinez, M., McClain, S., Jones, B., ... \& Chapman-Hilliard, C. (2015). Beauty and body image concerns among African American college women. Journal of Black Psychology, 41(6), 540-564.

Ayiro, L. P. (2012). A Functional Approach to Educational Research Methods and Statistics : Qualitative, Quantitative, and Mixed Methods Approaches. Lewiston, N.Y.: Edwin Mellen Press.

Banks I. (2000). Hair Matters: Beauty, Power, and Black Women's Consciousness. New York and London: New York University Press

Banks, C. A. (2009). Black women undergraduates, cultural capital, and college success (Vol. 20). Peter Lang. 
Balkum, S. (2021). The Evolution of the Black Woman, Dissenting Voices, Vol. 9, Iss. 1, Article 7.

Bartman, Cynthia C. (2015) "African American Women in Higher Education: Issues and Support Strategies," College Student Affairs Leadership: Vol. 2: Iss. 2, Article 5.

Beasley, C. (1999). What is feminism?: An introduction to feminist theory. Sage.

Bell Jr, D. A. (1995). Brown v. Board of Education and the Interest Conversion Dilemma. Crenshaw, K., Gotanda, N., Peller, G., and Thomas, K. Critical Race Theory: The key writings that formed the movement, 20-29.

Berryman, M., SooHoo, S., Nevin, A., Ford, T., Nodelman, D. J., Valenzuela, N., \& Wilson, A. (2013). Culturally responsive methodologies at work in education settings. International Journal for Researcher Development.

Blake, J. J., Butler, B. R., Lewis, C. W., \& Darensbourg, A. (2011). Unmasking the inequitable discipline experiences of urban Black girls: Implications for urban educational stakeholders. The Urban Review, 43(1), 90-106.

Boeije, H. (2002). A purposeful approach to the constant comparative method in the analysis of qualitative interviews. Quality \& Quantity, 36, 391-409.

Bond, H. (2011). Black Females in Higher Education at HBCUs: The Paradox of Success. Emerald Group Publishing Limited. $\quad$ https://doi-org.libproxy.chapman.edu/10.1108/S14793644(2011)0000008011

Boyd, B., Stephens, D. P., Eaton, A., \& Bruk-Lee, V. (2020). Exploring Partner Scarcity: Highly Educated Black Women and Dating Compromise. Sexuality Research and Social Policy, 1-13. 
Braun, V., \& Clarke, V. (2006). Using thematic analysis in psychology. Qualitative research in psychology, 3(2), 77-101.

Braun, V., \& Clarke, V. (2012). Thematic analysis. In H. Cooper, P. M. Camic, D. L. Long, A. T. Panter, D. Rindskopf, \& K. J. Sher (Eds.), APA handbook of research methods in psychology, Vol. 2. Research designs: Quantitative, qualitative, neuropsychological, and biological (pp. 57-71). Washington, DC, US: American Psychological Association. DOI: 10.1037/13620-004

Braun, V., \& Clarke, V. (2019). Reflecting on reflexive thematic analysis. Qualitative Research in Sport, Exercise and Health, 11(4), 589-597.

Braun, V., \& Clarke, V. (2021). Can I use TA? Should I use TA? Should I not use TA? Comparing reflexive thematic analysis and other pattern-based qualitative analytic approaches. Counseling \& Psychotherapy Research, 21(1), 37-47. https://doi-org.libproxy.chapman.edu/10.1002/capr.12360

Brown, J. D., L'Engle, K. L., Pardun, C. J., Guo, G., Kenneavy, K., \& Jackson, C. (2006). Sexy media matter: exposure to sexual content in music, movies, television, and magazines predicts Black and white adolescents' sexual behavior. Pediatrics, 117(4), 1018-1027.

Brown Givens, S. M., \& Monahan, J. L. (2005). Priming mammies, Jezebels, and other controlling images: An examination of the influence of mediated stereotypes on perceptions of an African American woman. Media Psychology, 7(1), 87-106.

Brownridge, D. A. (2009). Violence against women: Vulnerable populations. Routledge.

Cabrera, A. F., Nora, A., Terenzini, P. T., Pascarella, E., \& Hagedorn, L. S. (1999). Campus racial climate and the adjustment of students to college: A comparison between White students and AfricanAmerican students. The Journal of Higher Education, 70(2), 134-160. 
Campbell, R., \& Wasco, S. M. (2000). Feminist approaches to social science: Epistemological and methodological tenets. American journal of community psychology, 28(6), 773-791.

Capper, C. A. (2015). The 20th-year anniversary of critical race theory in education: Implications for leading to eliminate racism. Educational Administration Quarterly, 51(5), 791-833.

Calmore, J.O. (1992). Critical race theory, Archie Shepp and fire music: Securing an authentic intellectual life in a multicultural world. Southern California Law Review, 65, 2129-2230.

Chavous, T. M., Harris, A., Rivas, D., Helaire, L., \& Green, L. (2004). Racial stereotypes and gender in context: African Americans at predominantly Black and predominantly White colleges. Sex roles, 51(1), 1-16.

Chen, G. M., Williams, S., Hendrickson, N., \& Chen, L. (2012). Male mammies: A social-comparison perspective on how exaggeratedly overweight media portrayals of Madea, Rasputia, and Big Momma affect how Black women feel about themselves. Mass Communication and Society, 15(1), $115-135$.

Collective, C. R. (1977). 'A Black Feminist Statement' (pp. 210-218). na.

Collins, P. H. (1997). Defining Black feminist thought. In L. J. Nicholson (ed.), The Second Wave: A Reader in Feminist Theory. Routledge.

Collins, P. H. (1998). Fighting words: Black women and the search for justice (Vol. 7). U of Minnesota Press.

Collins, P. H. (1999). Reflections on the outsider within. Journal of Career Development, 26(1), 85-88. 
Collins, P. H. (2000). Black feminist thought: Knowledge, consciousness, and the politics of empowerment ( $2^{\text {nd }}$ ed,). New York: Routledge.

Commodore, F., Baker, D. J., \& Arroyo, A. T. (2018). Black women college students: A guide to student success in higher education. Routledge.

Corbie-Smith, G., Thomas, S. B., \& George, D. M. M. S. (2002). Distrust, race, and research. Archives of internal medicine, 162(21), 2458-2463.

Corbie-Smith, G., Moody-Ayers, S., \& Thrasher, A. D. (2004). Closing the circle between minority inclusion in research and health disparities. Archives of Internal Medicine, 164(13), 1362-1364.

Corbin, N. A., Smith, W. A., \& Garcia, J. R. (2018). Trapped between justified anger and being the strong Black woman: Black college women coping with racial battle fatigue at historically and predominantly White institutions. International Journal of Qualitative Studies in Education, 31(7), 626-643.

Cosby, C. O. (1994). Television's Imageable Influences: The Self-Perception of Young AfricanAmericans. University Press of America.

Crenshaw, K. (1989). Demarginalizing the Intersection of Race and Sex: A Black Feminist Critique of Antidiscrimination Doctrine, Feminist Theory and Antiracist Politics. In University of Chicago Legal Forum (Vol. 1989, No. 1, p. 8).

Crenshaw, K. (1991). Mapping the margins: Intersectionality, identity politics, and violence against women of color. Stan. L. Rev., 43, 1241.

Creswell, J. W., \& Poth, C. N. (2017). Qualitative inquiry and research design: Choosing among five approaches. Sage publications. 
Dagbovie-Mullins, S. A. (2013). Pigtails, ponytails, and getting tail: the infantilization and hypersexualization of African American females in popular culture. Journal of Popular Culture (Boston), 46(4), 745-774.

Darden, J. T., Kamel, S. M., \& Jacobs, A. J. (1998). Black faculty in predominantly White US institutions of higher education: The influence of Black student enrollment. Equity \& Excellence, 31(2), 6-18.

Davis, S. M. (2015). The "strong Black woman collective": A developing theoretical framework of the communication process among Black women. Women's Studies in Communication, 38, 20-35. doi:10.1080/07491409.2014.953714

Davis, S., \& Brown, K. (2017). Automatically Discounted: Using Black Feminist Theory to Critically Analyze the Experiences of Black Female Faculty. International Journal of Educational Leadership Preparation, 12(1), n1.

Dawson, M. C., \& Bobo, L. D. (2009). One year later and the myth of a post-racial society. Du Bois Review: Social Science Research on Race, 6(2), 247-249.

Delgado, R. \& Stefancic, J. (2017). Critical race theory: An introduction. NYU Press.

Denzin, N. K., \& Lincoln, Y. S. (Eds.). (2011). The Sage handbook of qualitative research. Sage.

Dixon, T. L. (2019). Media stereotypes: Content, effects, and theory. In Media Effects. Taylor \& Francis.

Dobbin, F., \& Kalev, A. (2016). Why diversity programs fail. Harvard Business Review, 94(7), 14.

Dovidio, J. F., Gaertner, S. L., Kawakami, K., \& Hodson, G. (2002). Why can’t we all just get along? Interpersonal biases and interracial distrust. Cultural Diversity and Ethnic Minority Psychology, $8(2), 88-102$. 
Du Bois, W.E.B. ([1903] 1965 ed.). The Souls of Black Folk. London: Longmans, Green and Co. Ltd.

Dumas-Hines, F. A., Cochran, L. L., \& Williams, E. U. (2001). Promoting Diversity: Recommendations for Recruitment and Retention of Minorities in Higher Education. College Student Journal, 35(3), 433.

Eakins, A., \& Eakins Sr, S. L. (2017). African American Students at Predominantly White Institutions: A Collaborative Style Cohort Recruitment \& Retention Model. Journal of Learning in Higher Education, 13(2), 51-57.

Emerson, R. A. (2002). “Where my girls at?” Negotiating black womanhood in music videos. Gender \& Society, 16(1), 115-135.

Epstein, R., Blake, J., \& González, T. (2017). Girlhood interrupted: The erasure of Black girls’ childhood. Available at SSRN 3000695.

Espinosa, Lorelle L., Turk, Jonathan M., Taylor, Morgan and Chessman, Hollie M. (2019). Race and ethnicity in higher education: a status report. Washington, DC: American Council on Education.

Essed, P. (1991). Understanding everyday racism: An interdisciplinary theory. Newbury Park, CA: Sage.

Etter-Lewis, G. (1993). My soul is my own: Oral narratives of African American women in the professions. New York: Routledge.

Evans-Winters, V. E. (2019). Black Feminism in Qualitative Inquiry: A Mosaic for Writing Our Daughter's Body. Routledge.

Few, A. L., Stephens, D. P., \& Rouse-Arnett, M. (2003). Sister-to-sister talk: Transcending boundaries and challenges in qualitative research with Black women. Family Relations, 52(3), 205-215. 
Freimuth, V. S., Quinn, S. C., Thomas, S. B., Cole, G., Zook, E., \& Duncan, T. (2001). African Americans’ views on research and the Tuskegee Syphilis Study. Social science \& medicine, 52(5), 797-808.

Freire, Paulo. 1970. Pedagogy of the Oppressed. New York: Herder and Herder.

Gamble, V. N. (1993). A legacy of distrust: African Americans and medical research. Am J Prev Med, 9(6 Suppl), 35-38.

Garcia, G. A., Johnston, M. P., Garibay, J. C., Herrera, F. A., \& Giraldo, L. G. (2011). When parties become racialized: Deconstructing racially themed parties. Journal of Student Affairs Research and Practice, 48(1), 4-20.

Gill, P., Stewart, K., Treasure, E., \& Chadwick, B. (2008). Methods of data collection in qualitative research: interviews and focus groups. British dental journal, 204(6), 291.

Giddings, P. (1985). When and where I enter: The impact of Black women on race and sex in America. New York: Bantam Books.

Giroux, H. A. (2009). Youth and the myth of a post-racial society under Barack Obama. Policy Futures in Education, 7(5), 574-577.

Glaser, B. G. (1965). The constant comparative method of qualitative analysis. Social problems, 12(4), $436-445$.

Grace, C., McCaskill, A., \& Roussell, R. (2017). African-American women: Our science, her magic. The Nielsen Company.

Greene, D. W. (2010). Black women can't have blonde hair in the workplace. J. Gender Race \& Just., 14, 405. 
Greyerbiehl, L., \& Mitchell Jr., D. (2014). An Intersectional Social Capital Analysis of the Influence of Historically Black Sororities on African American Women's College Experiences at a Predominantly White Institution. Journal of Diversity in Higher Education, 7(4), 282-294.

Gusa, D. L. (2010). White institutional presence: The impact of Whiteness on campus climate. Harvard Educational Review, 80(4), 464-490.

Hannon, C., Woodside, M., Pollard, B., \& Roman, J. (2016). The meaning of african american college women's experiences attending a predominately white institution: A phenomenological study. Journal of College Student Development, 57(6), pp. 652-666.

Harper, S. R. (2009). Niggers no more: A critical race counternarrative on Black male student achievement at predominantly White colleges and universities. International Journal of Qualitative Studies in Education, 22(6), 697-712.

Harper, S. R. (2015). Black male college achievers and resistant responses to racist stereotypes at predominantly White colleges and universities. Harvard Educational Review, 85(4), 646-674.

Harris, F. C. (2014). The rise of respectability politics. Dissent, 61(1), 33-37.

Harris, J. (2015). Media literacy and perceptions of identity among pre-adolescent African-American girls. International Journal of Child and Adolescent Health, 8(4), 477.

Harris, T. W. (2015a). The sisters are alright: Changing the broken narrative of Black women in America. Berrett-Koehler Publishers. 
Harris-Perry, M. V. (2011). Sister citizen: Shame, stereotypes, and Black women in America. Yale University Press.

Haynes, C. S. (2019). There's no place like home? African American women in the residence halls of a predominantly white Midwestern University. Gender \& Education, 31(4), 525-542. https://doiorg.libproxy.chapman.edu/10.1080/09540253.2018.1484430

Henry, W. J. (2008). Black Female Millennial College Students: Dating Dilemmas and Identity Development. Multicultural Education, 16(2), 17-21.

Henry, W. J., Butler, D. M., \& West, N. M. (2011). Things are not as rosy as they seem: Psychosocial issues of contemporary Black college women. Journal of College Student Retention: Research, Theory \& Practice, 13(2), 137-153.

Hiraldo, P. (2010). The role of critical race theory in higher education. The Vermont Connection, 31(1), 7.

Hoffner, C., \& Buchanan, M. (2005). Young adults' wishful identification with television characters: The role of perceived similarity and character attributes. Media psychology, 7(4), 325-351.

Holtzman, L. (2004). Mining the invisible: Teaching and learning media and diversity. American Behavioral Scientist, 48(1), 108-118.

Hooks, B. (1981). Ain’t I a woman : Black women and feminism. Boston, MA: South End Press.

Hooks, B. (2003). The oppositional gaze: Black female spectators. The feminism and visual culture reader, 94-105. 
Holland, D. C. \& Eisenhart, M. A. (1990). Educated in romance: Women, achievement, and college culture. University of Chicago Press.

Howard-Hamilton, M. F. (2003). Theoretical frameworks for African American women. New directions for student services, 2003(104), 19-27.

Hughes, R. L., \& Howard-Hamilton, M. F. (2003). Insights: Emphasizing issues that affect African American women. New directions for student services, 2003(104), 95-104.

Hund, W. D., Mills, C. W., \& Sebastiani, S. (Eds.). (2015). Simianization: Apes, Gender, Class, and Race (Vol. 6). LIT Verlag Münster.

Hunt, Dean (2017). Color of Change Hollywood Race Report. Retrieved from: http://hollywood.colorofchange.org/

Hurtado, S. (1992). The campus racial climate: Contexts of conflict. The Journal of Higher Education, 63(5), 539-569.

Hurtado, S., Clayton-Pedersen, A. R., Allen, W. R., \& Milem, J. F. (1998). Enhancing campus climates for racial/ethnic diversity: Educational policy and practice. The review of higher education, 21(3), 279-302.

Jacobs, C. E. (2016). Developing the "Oppositional Gaze": Using Critical Media Pedagogy and Black Feminist Thought to Promote Black Girls' Identity Development. Journal of Negro Education, (3), 225. Retrieved from http://search.ebscohost.com.libproxy.chapman.edu/login.aspx?direct=true\&AuthType=ip,uid\&d b=edsbl\&AN=RN609682965\&site=eds-live 
Jerald, M. C., Ward, L. M., Moss, L., Thomas, K., \& Fletcher, K. D. (2017). Subordinates, sex objects, or sapphires? Investigating contributions of media use to Black students' femininity ideologies and stereotypes about Black women. Journal of Black Psychology, 43(6), 608-635.

Johnson, L. (2015). From the Anti-Slavery Movement to Now: (RE) examining the Relationship Between Critical Race Theory and Black Feminist Thought. Race, Gender \& Class, 22(3-4), 227-243.

Jones, M. C., \& Shorter-Gooden, K. (2009). Shifting: The double lives of Black women in America. Harper Collins.

Karnieli-Miller, O., Strier, R., \& Pessach, L. (2009). Power relations in qualitative research. Qualitative health research, 19(2), 279-289.

Keels, M. (2013). Getting them enrolled is only half the battle: College success as a function of race or ethnicity, gender, and class. American Journal of Orthopsychiatry, 83(2pt3), 310-322.

Kendi, I. X. (2012). The Black campus movement: Black students and the racial reconstitution of higher education, 1965-1972. Springer.

King, N. (2004). Using Interviews in Qualitative Research. Essential guide to qualitative methods in organizational research, 2.

Kishimoto, K. (2018). Anti-racist pedagogy: From faculty's self-reflection to organizing within and beyond the classroom. Race Ethnicity and Education, 21(4), 540-554.

Knight, M. G., Norton, N. E., Bentley, C. C., \& Dixon, I. R. (2004). The power of Black and Latina/o counterstories: Urban families and college-going processes. Anthropology \& Education Quarterly, 35(1), 99-120. 
Ladson-Billings, G., \& Tate, W. F., IV. (1995). Toward a critical race theory of education. The Teachers College Record, 97 (1), 47-68.

LaVoulle, C., \& Lewis Ellison, T. (2017). The bad bitch barbie craze and Beyoncé African American women's bodies as commodities in Hip-Hop culture, images, and media. Taboo: The Journal of Culture and Education, 16(2), 7.

Leavy, P. (2015). Method meets art: Arts-based research practice. Guilford Publications.

Lewis, J. A., Mendenhall, R., Harwood, S. A., \& Huntt, M. B. (2013). Coping with gendered racial microaggressions among Black women college students. Journal of African American Studies, 17(1), 51-73.

Lewis, J. A., Mendenhall, R., Harwood, S. A., \& Huntt, M.B. (2016). “Ain’t I a woman?” Perceived gendered racial microaggressions experienced by Black women. The Counseling Psychologist, 44(5), 758-780.

Lindsay-Dennis, L. (2015). Black feminist-womanist research paradigm: Toward a culturally relevant research model focused on African American girls. Journal of Black Studies, 46(5), 506-520.

Littlefield, M. B. (2008). The media as a system of racialization: Exploring images of African American women and the new racism. American Behavioral Scientist, 51(5), 675-685.

Lundy, A. D. (2018). Caught between a thot and a hard place: The politics of Black female sexuality at the intersection of cinema and reality television. The Black Scholar, 48(1), 56-70.

Macrae, C. N., Stangor, C., \& Hewstone, M. (Eds.). (1996). Stereotypes and stereotyping. Guilford Press. 
Mann, S. A., \& Huffman, D. J. (2005). The decentering of second wave feminism and the rise of the third wave. Science \& society, 69(1: Special issue), 56-91.

Malagon, M. C., Huber, L. P., \& Velez, V. N. (2009). Our experiences, our methods: Using grounded theory to inform a critical race theory methodology. Seattle J. Soc. Just., 8, 253.

Marbley, A. F. (2005). African-American Women's Feelings on Alienation from Third-Wave Feminism: A Conversation with My Sisters. Western Journal of Black Studies, 29(3).

McGee, E. O., \& Martin, D. B. (2011). "You would not believe what I have to go through to prove my intellectual value!" Stereotype management among academically successful Black mathematics and engineering students. American Educational Research Journal, 48(6), 1347-1389.

McLaren, Peter. 2009. “Critical Pedagogy: A Look at the Major Concepts.” In The Critical Pedagogy Reader, edited by Antonia Darder, Marta P. Baltodano and Rodolfo D. Torres, 61-83. New York: Routledge.

McKoy, B. (2012). Tyler Perry and the weight of misrepresentation. Mcnair scholars research journal, $5(1), 10$.

McCoy, D. L., \& Rodricks, D. J. (2015). Critical Race Theory in Higher Education: 20 Years of Theoretical and Research Innovations: ASHE Higher Education Report, Volume 41, Number 3. John Wiley \& Sons.

Mercer, K. (2000). Black hair/style politics. Black British culture and society: A text reader, 111-121.

Merriam, S. B. (2002). Qualitative research in practice: Examples for discussion and analysis. JosseyBass Inc Pub. 
Miller, R. A. (2014). An overview of campus climate: Dimensions of diversity in higher education. Texas Education Review 2(2), 184-190.

Monzó, L. D. (2016). “They don't know anything!”: Latinx immigrant students appropriating the oppressor's voice. Anthropology \& Education Quarterly, 47(2), 148-166.

Morris, E. W. (2007). "Ladies" or "loudies"? Perceptions and experiences of Black girls in classrooms. Youth \& Society, 38(4), 490-515.

Morris, M. (2016). Pushout: The criminalization of Black girls in schools. The New Press.

Muhammad, G. E., \& McArthur, S. A. (2015). "Styled by Their Perceptions”: Black Adolescent Girls Interpret Representations of Black Females in Popular Culture. Multicultural Perspectives, 17(3), 133-140.

National Center for Educational Statistics (2019). Percentage distribution of male and female undergraduate student fall enrollment in degree-granting institutions, by race/ethnicity: Selected years, 1976 through 2016, Table $306.10 \quad$ Retrieved from https://nces.ed.gov/programs/digest/d17/tables/dt17_306.10.asp?referer=raceindicators

National Center for Educational Statistics (2020). Total fall enrollment in degree-granting postsecondary institutions, by level of enrollment, sex, attendance status, and race/ethnicity or nonresident alien status of student: Selected years, 1976 through 2018, Table 306.10 Retrieved from https://nces.ed.gov/programs/digest/d19/tables/dt19_306.10.asp

Neal-Jackson, A. (2020). " Well, What Did You Expect?": Black Women Facing Stereotype Threat in Collaborative Academic Spaces at a Predominantly White Institution. Journal of College Student Development, 61(3), 317-332. 
Ngunjiri, F. W. (2007). Painting a counter-narrative of African womanhood: Reflections on how my research transformed me. Journal of Research Practice, 3(1), 4.

Njoku, N., Butler, M., \& Beatty, C. C. (2017). Reimagining the historically Black college and university (HBCU) environment: Exposing race secrets and the binding chains of respectability and othermothering. International Journal of Qualitative Studies in Education, 30(8), 783-799.

Njoku, N. R., \& Patton, L. D. (2017). Explorations of respectability and resistance in constructions of Black womanhood at HBCUs. Critical perspectives on Black women and college success, 31-43.

Noble, S. U. (2018). Algorithms of oppression: How search engines reinforce racism. NYU Press.

Ortiz, L., \& Jani, J. (2010). Critical race theory: A transformational model for teaching diversity. Journal of Social Work Education, 46(2), 175-193.

Padilla, M. (2019). Student wins $\$ 725,000$ in lawsuit over 'troll storm' led by the daily stormer. Retrieved from https://www.nytimes.com/2019/08/10/us/taylor-dumpson.html

Patton, L. D. (2006). The voice of reason: A qualitative examination of Black student perceptions of Black culture centers. Journal of College Student Development, 47(6), 628-646.

Patton, L. D. (2016). Disrupting postsecondary prose: Toward a critical race theory of higher education. Urban Education, 51(3), 315-342.

Patton, L. D., Crenshaw, K., Haynes, C., \& Watson, T. N. (2016). Why we can't wait:(Re) examining the opportunities and challenges for Black women and girls in education (Guest Editorial). The Journal of Negro Education, 85(3), 194-198. 
Patton, L. D., \& Croom, N. N. (Eds.). (2017). Critical perspectives on Black women and college success. Taylor \& Francis.

Peterson, S. H., Wingood, G. M., DiClemente, R. J., Harrington, K., \& Davies, S. (2007). Images of sexual stereotypes in rap videos and the health of African American female adolescents. Journal of Women's Health, 16(8), 1157-1164.

Poran, M. A. (2006). The Politics of Protection: Body Image, Social Pressures, and the Misrepresentation of Young Black Women. Sex Roles, 55(11/12), 739-755.

Read, B. (2011). Britney, Beyoncé, and me-primary school girls' role models and constructions of the 'popular' girl. Gender and Education, 23(1), 1-13.

Rehman, A. A., \& Alharthi, K. (2016). An introduction to research paradigms. International Journal of Educational Investigations, 3(8), 51-59.

Richardson, E. B. (2003). African American literacies. Psychology Press.

Robinson, S. J., Esquibel, E., \& Rich, M. D. (2013). " I'm Still Here:" Black Female Undergraduates' SelfDefinition Narratives. World Journal of Education, 3(5), 57-71.

Rodgers, K. A., \& Summers, J. J. (2008). African American students at predominantly White institutions: A motivational and self-systems approach to understanding retention. Educational psychology review, 20(2), 171-190.

Roithmayr, D. (1999). Introduction to critical race theory in educational research and praxis. Race is... race isn't: Critical race theory and qualitative studies in education, 1. 
Rosales, A. M., \& Person, D. R. (2003). Programming needs and student services for African American women. New Directions for Student Services, 2003(104), 53-65.

Schooler, D., Ward, L. M., Merriwether, A., \& Caruthers, A. (2004). Who's that girl: Television's role in the body image development of young white and Black women. Psychology of women quarterly, 28(1), 38-47.

Scholz, S. J. (2012). Feminism : A Beginner's Guide. Oxford, UK: Oneworld Publications.

Settles, I. H., Pratt-Hyatt, J. S., \& Buchanan, N. T. (2008). Through the lens of race: Black and White women's perceptions of womanhood. Psychology of Women Quarterly, 32(4), 454-468.

Sealey-Ruiz, Y. (2013). Learning to resist: Educational counter-narratives of Black college reentry mothers. Teachers College Record, 115(4), 1-31.

Shavers, M. C., \& Moore III, J. L. (2014). The double-edged sword: Coping and resiliency strategies of African American women enrolled in doctoral programs at predominately white institutions. Frontiers: A Journal of Women Studies, 35(3), 15-38.

Shields, S. A. (2008). Gender: An intersectionality perspective. Sex roles, 59(5-6), 301-311.

Shorter-Gooden, K. (2004). Multiple resistance strategies: How African American women cope with racism and sexism. Journal of Black Psychology, 30(3), 406-425.

Smith, S. (2004). Insider and outsider status: An African American perspective. New Directions for Adult and Continuing Education, 2004(104), 57-65. 
Solorzano, D., Ceja, M., \& Yosso, T. (2000). Critical race theory, racial microaggressions, and campus racial climate: The experiences of African American college students. Journal of Negro Education, 60-73.

Solórzano, D. G., \& Yosso, T. J. (2002). Critical race methodology: Counter-storytelling as an analytical framework for education research. Qualitative inquiry, 8(1), 23-44.

Springer, K. (2002). Third wave Black feminism?. Signs: Journal of Women in Culture and Society, 27(4), 1059-1082.

Stephens, D. P., \& Few, A. L. (2007a). The effects of images of African American women in hip hop on early adolescents' attitudes toward physical attractiveness and interpersonal relationships. Sex Roles, 56(3-4), 251-264.

Stephens, D. P., \& Few, A. L. (2007b). Hip hop honey or video ho: African American preadolescents' understanding of female sexual scripts in hip hop culture. Sexuality \& Culture, 11(4), 48-69.

Strauss, A., \& Corbin, J. (1998). Basics of qualitative research techniques. Thousand Oaks, CA: Sage publications.

Strayhorn, T. L., \& Johnson, R. M. (2014). Why are all the White students sitting together in college? Impact of Brown v. Board of Education on cross-racial interactions among Blacks and Whites. The Journal of Negro Education, 83(3), 385-399.

Sturdivant, C. (2017, May 1). Bananas found hanging in string nooses at AU. Retrieved from https://dcist.com/story/17/05/01/another-racist-incident-at-american/

Sue, D. W. (2010). Microaggressions in everyday life: Race, gender, and sexual orientation. John Wiley \& Sons. 
Sullivan, J. M., \& Platenburg, G. N. (2017). From Black-ish to Blackness: An analysis of Black information sources' influence on Black identity development. Journal of Black Studies, 48(3), 215-234.

Tate IV, W. F. (1997). Chapter 4: Critical race theory and education: History, theory, and implications. Review of research in education, 22(1), 195-247.

Tatum, B. D. (1997). Why are all the Black kids sitting in the cafeteria? And other conversations about race

Taylor, E., Gillborn, D., \& Ladson-Billings, G. (2009). Foundations of critical race theory in education.

Taylor, U. Y. (1998). Making waves: The theory and practice of Black feminism. The Black Scholar, 28(2), 18-28.

Taylor, U. (1998a). The historical evolution of Black feminist theory and praxis. Journal of Black Studies, 29(2), 234-253.

The Nielsen Company. (2015). Multifaceted Connections: African-American media usage outpaces across platforms. Retrieved from https://www.nielsen.com/us/en/insights/article/2015/multifacetedconnections-african-american-media-usage-outpaces-acrossplatforms/\#: :text=In\%20a\%20recent\%20Nielsen\%20report,occurring\%20outside\%20of\%20the $\% 20$ home.

Tillman, L. C. (2002). Culturally sensitive research approaches: An African-American perspective. Educational researcher, 31(9), 3-12. 
Tindall, B. (2012). Where is the Black Barbie? An Analysis of the Media Portrayals of Single Black Women. Ursidae: The Undergraduate Research Journal at the University of Northern Colorado, $2(2), 9$.

Tuitt, F. (2012). Black like me: Graduate students' perceptions of their pedagogical experiences in classes taught by Black faculty in a predominantly White institution. Journal of Black Studies, 43(2), 186206.

U.S. Department of Education, National Center for Education Statistics. (2020). The Condition of Education 2020 (NCES 2020-144), Characteristics of Postsecondary Faculty.

Wang, M. C., Haertel, G. D., \& Walberg, H.J. (1994). Educational resilience in inner cities. In M. C. Wang \& E. W. Gordon (Eds.), Educational resilience in inner-city America: Challenges and prospects (pp. 4572). Lawrence Erlbaum.

Ward, L. M. (2002). Does television exposure affect emerging adults' attitudes and assumptions about sexual relationships? Correlational and experimental confirmation. Journal of Youth and adolescence, 31(1), 1-15.

Welang, N. (2018). Triple consciousness: The reimagination of Black female identities in contemporary American culture. Open Cultural Studies, 2(1), 296-306.

West, L. M., Donovan, R. A., \& Daniel, A. R. (2016). The price of strength: Black college women's perspectives on the strong Black woman stereotype. Women \& Therapy, 39(3-4), 390-412.

Wilkins, A. C. (2012). Becoming Black women: Intimate stories and intersectional identities. Social Psychology Quarterly, 75(2), 173-196. 
Winkle-Wagner, R. (2009). The unchosen me: Race, gender, and identity among Black women in college. JHU Press.

Winkle-Wagner, R. (2015). Having their lives narrowed down? The state of Black women's college success. Review of Educational Research, 85(2), 171-204.

Woods, K. C. (2013). The strong Black woman archetype and intentions to seek therapy for depression: A cultural application of the theory of planned behavior. Michigan State University.

Woodard, J. B., \& Mastin, T. (2005). Black womanhood: Essence and its treatment of stereotypical images of Black women. Journal of Black Studies, 36(2), 264-281.

Wooten, T. (2019). PORTRAYALS OF BLACK WOMEN ON TELEVISION \& THE SHIFT IN THEIR REPRESENTATION: AN ANALYSIS OF SCANDAL \& INSECURE.

Zamudio, M., Russell, C., Rios, F., \& Bridgeman, J. L. (2011). Critical race theory matters: Education and ideology. Routledge. 


\section{Appendices}

\section{Appendix A}

\section{Single-Interview Script}

Hello, I am Kandace Branch from the College of Educational Studies at Chapman University. I am a doctoral candidate and your participation is helping me complete my dissertation work. I am conducting a research study that examines media representations of Black women and its impact on the experiences of Black undergraduate women. This research study will help me better understand the ways in which the media has an influence on people's behaviors and actions. The research will also help me better understand the experiences of Black women on college campuses.

Today you will be participating in an interview where I will gain perspective on your experiences. Your participation is voluntary. If you do not wish to participate, you may stop at any time. Your responses will be completely anonymous, with your actual name being replaced by a pseudonym. You will also have the opportunity to review your responses at the end of all interviews to verify that what you said was heard and understood correctly. It is important that I make you aware of the minimal risks associated with this study and interviews. There is a possibility that you will have to revisit experiences that may have been stressful or psychologically draining. I will do my best to help support you. Taking part in this interview is your agreement to participate.

\section{Interview Questions}

- What are your opinions about Black women representations in the media?

- Which television characters exist, if any, that you believe represent Black womanhood?

- Describe existing television characters that you closely identify with and why?

- How do you define Black womanhood?

- How do these characters influence who you are as a Black woman?

- Tell me about an experience where you felt as though you might be playing into or fighting against stereotypical portrayals of Black women.

- Can you describe your experiences on campus as a Black woman? 


\section{Appendix B}

\section{W CHAPMAN \\ $\triangle$ UNIVERSITY}

\section{ADULT INFORMED CONSENT TO PARTICIPATE IN RESEARCH}

\section{Title of Study:}

\section{Exploring media representations of Black women and the experiences of Black undergraduate women.}

\section{Members of the Research Team}

Student Researcher: Kandace Branch, MA Office: (310) 910-3893 Lead

Researcher: Lilia Monzo, Ph.D. Office: (714) 997-6781

\section{Key Information}

This research project explores how dominant media representations of Black women influence Black undergraduate women and their experiences in college. This study will audio-record individual and focus group interviews to gain firsthand accounts of Black women's undergraduate experiences.

You are being asked to take part in a research study. Research studies include only people who choose to take part. A member of the research team will explain the study to you and will answer any questions you might have. You should take your time in deciding whether or not you want to participate.

If you agree to participate in this study, the project will involve:

- Black women who are in college or have graduated from college

- Procedures will include one (1) individual interview, one (1) focus group, and one (1) follow-up interview to conclude the study

- These interview(s) will take between three to five hours total

- There are not risks associated with this study that exceed what would typically be encountered in daily life

- You will not be paid for your participation

- You will be provided a copy of this consent form

\section{Invitation}

You are invited to take part in this research study. The information in this form is meant to help 
you decide whether or not to participate. If you have any questions, please ask.

\section{Why are you being asked to be in this research study?}

You are being asked to be in this study because you are a Black or African American woman, enrolled in an undergraduate program, and living in or around Los Angeles. You must be 18 years of age or older to participate.

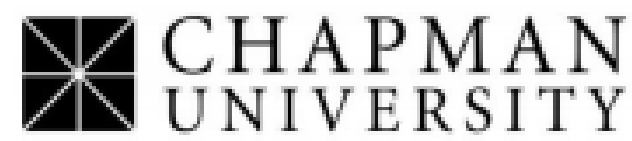

\section{What is the reason for doing this research study?}

This research study explores how dominant media representations of Black women influence Black undergraduate women and their experiences in college. Stereotypes in the media have the power to influence the perceiver and the individual being stereotyped. This study will add to the sparse, growing literature on Black undergraduate women, particularly in relation to media's role in their everyday experiences. This study will also help to improve the resources and conditions for Black women on college campuses.

\section{What will be done during this research study?}

A single interview will be conducted to gain insight into your college experience as well as your opinions about the portrayal of Black women in the media. During the interview, we will watch relevant television clips from shows like Black-ish, Insecure, How to Get Away with Murder, This is Us, and Mixed-ish. These television clips may be mildly distressing or contain strong language, violent content, or sexual content. The single interview will take about 90-120 minutes. The focus group meeting will be with a select number of participants from the study to discuss your experiences in college and their relation to media representations of Black women. Lastly, you will be invited to an individual meeting to ensure that your opinions are interpreted accurately and to conclude the study. This interview will be audio-recorded.

\section{How will my data be used?}

Any personal information that could identify you will be removed before the data is shared.

\section{What are the possible risks of being in this research study?}

As with any study involving collection of data, there is the possibility of breach of confidentiality of data. Other risks in this research include possible emotional and/or psychological distress because there is a possibility the interview process will ask you to revisit a past experience that was stressful or watch a television show that you may find distressing. It is possible that other rare side effects could occur that are not described in this consent form. It is also possible that you could have a side effect that has not occurred before.

\section{What are the possible benefits to you?}

You are not expected to get any direct benefit from being in this study but does not mean that a 
benefit is possible.

What are the possible benefits to other people?

The benefits to science and/or society may include better understanding of media effects and how the media can impact collegiate campus climates, particularly for Black women. Additionally, benefits include the opportunity to contribute to the growing knowledge of media's impact on Black undergraduate women by offering a first-person account. 


\section{- 2 -}

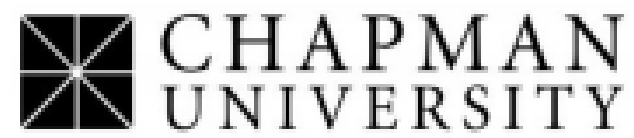

\section{What are the alternatives to being in this research study?}

Instead of being in this research study you can choose not to participate.

\section{What will participating in this research study cost you?}

There is no cost to you to be in this research study.

Will you be compensated for being in this research study?

You will not be compensated for your participation in this research study.

What should you do if you have a problem during this research study?

Your welfare is the major concern of every member of the research team. If you have a problem as a direct result of being in this study, you should immediately contact one of the people listed at the beginning of this consent form.

\section{How will information about you be protected?}

Reasonable steps will be taken to protect your privacy and the confidentiality of your study data.

The data will be stored in a locked cabinet in the investigator's office and will only be seen by the research team during the study and for one year after the study is complete.

The audio-recorded data will be stored electronically through a secure server and will only be seen by the research team during the study and for one year after the study is complete.

The only people who will have access to your research records are the members of the research team, the Institutional Review Board (IRB), and any other person, agency, or sponsor as required by law. Information from this study may be published in scientific journals or presented at 


\section{- 3 -}

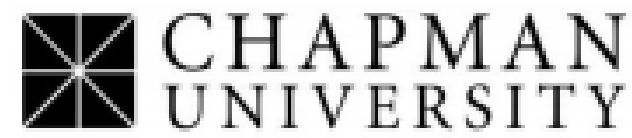

scientific meetings but the data will be reported as group or summarized data and your identity will be kept strictly confidential.

\section{What are your rights as a research subject?}

You may ask any questions about this research and have those questions answered before agreeing to participate in the study or during the study.

For study related questions, please contact the investigator(s) listed at the beginning of this form.

For questions concerning your rights or complaints about the research, contact the Institutional Review Board (IRB) at (714) 628-2833 or irb@ chapman.edu.

\section{What will happen if you decide not to be in this research study or decide to stop participating once you start?}

You can decide not to be in this research study, or you can stop being in this research study (i.e., "withdraw") at any time before, during, or after the research begins for any reason. Deciding not to be in this research study or deciding to withdraw will not affect your relationship with the investigator or with Chapman University [list others as applicable]. You will not lose any benefits to which you are entitled.

\section{Documentation of informed consent}

You are voluntarily deciding whether or not to be in this research study. Signing this form means that (1) you have read and understood this consent form, (2) you have had the consent form explained to you, (3) you have had your questions answered, and (4) you have decided to be in the research study. You will be given a copy of this consent form to keep.

Printed Name of Participant or Legal Guardian

Participant or Legal Guardian Date

Signature of 


\section{-4 -}

\section{AUDIO RECORDING:}

I have received an adequate description of the purpose and procedures for audio recording sessions during the course of the proposed research. I give my consent to allow myself to be audio recorded during participation in this study, and for those records to be reviewed by persons involved in the study, as well as for other professional purposes as described to me.

Yes, I agree to allow the research team to audio record my interview(s). __ No, I do not wish to have my interview(s) audio recorded.

Signature of Participant or Legal Guardian Date 
Appendix C

Recruitment Flyer

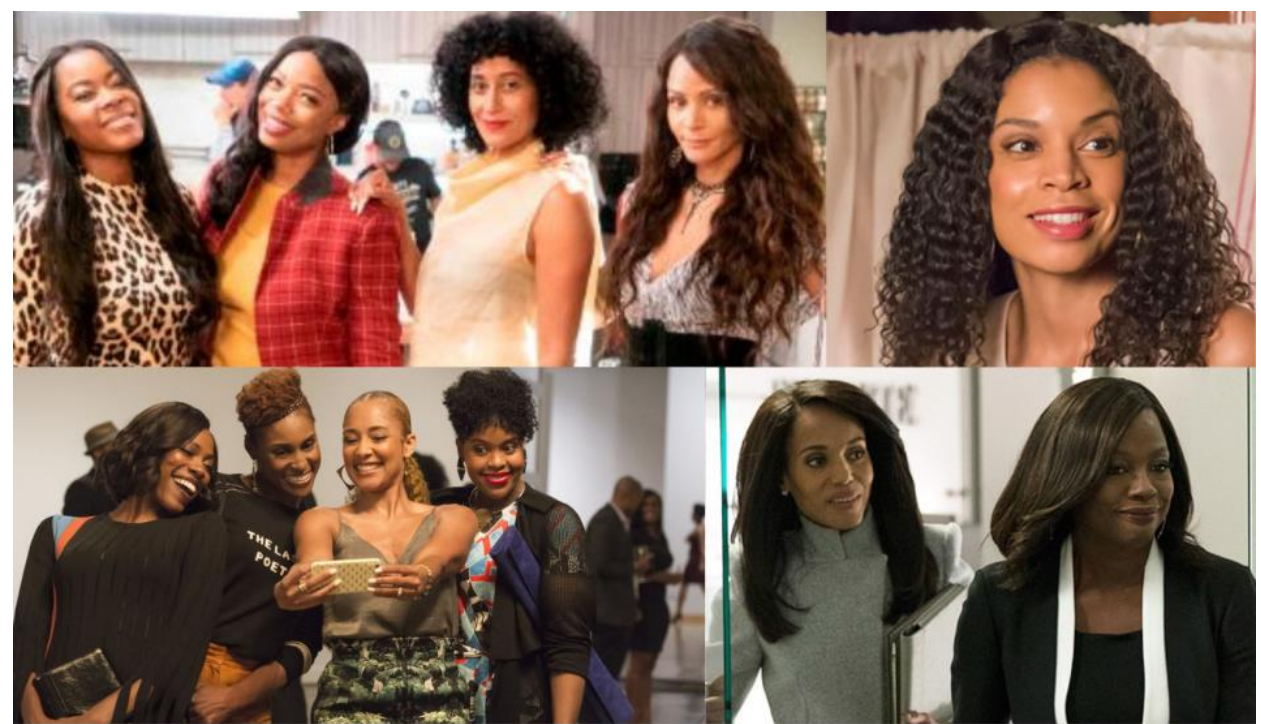

VOLUNTEERS NEEDED FOR A

\section{RESEARCH STUDY}

Chapman University College of Educational Studies

A research study is being conducted to

find out if media representations of Black women impact

Black women's college experiences.

\section{REQUIREMENTS}

-Identify as a Black woman

-Currently enrolled or a graduate

- Has access and is comfortable with a virtual, video interview

You will be asked to discuss your experiences during a single virtual interview.

\footnotetext{
Contact Kandace Branch at branclllemail.chapman.edu

Please include your name, college/university,

and best form of contact.
} 


\section{Appendix D}

Photos from each episode.

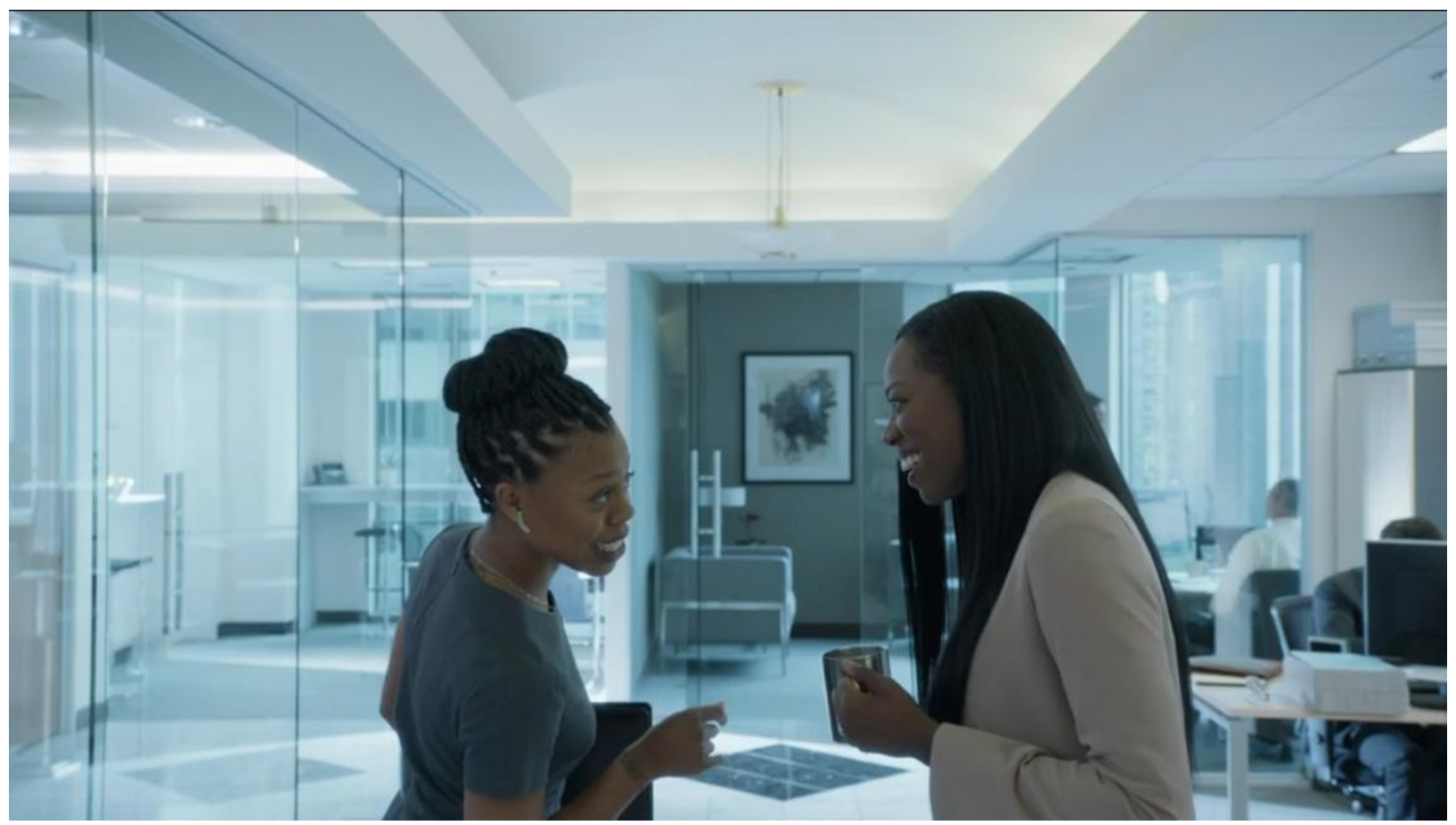

Insecure "Racist As Fuck".

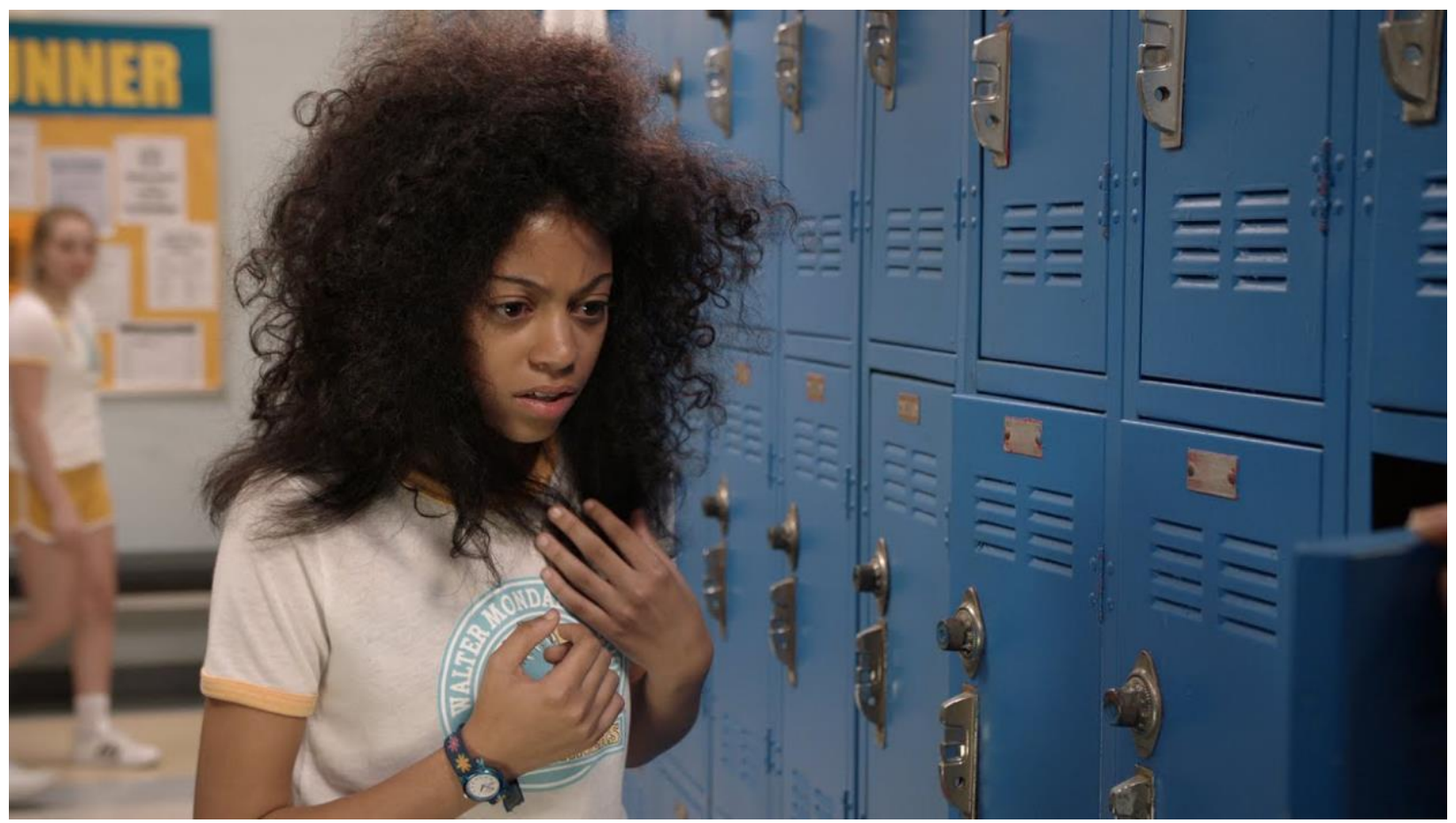

Mixedish "Let Your Hair Down". 


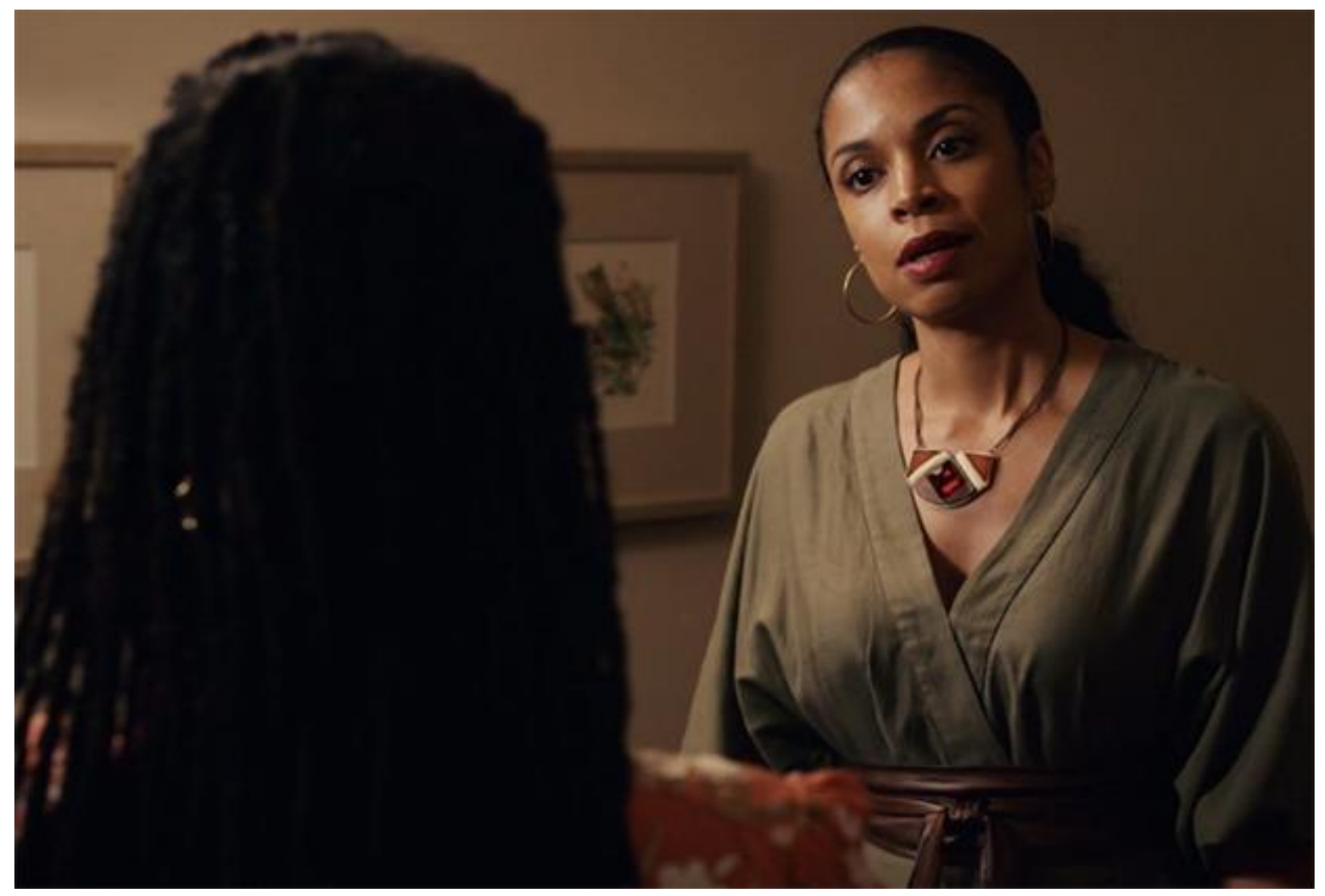

This Is Us. "Dinner and Date" 